\title{
An environmental assessment system for environmental technologies
}

\author{
Clavreul, Julie; Baumeister, Hubert; Christensen, Thomas Højlund; Damgaard, Anders
}

\section{Published in:}

Environmental Modelling \& Software

Link to article, DOI:

10.1016/j.envsoft.2014.06.007

Publication date:

2014

Document Version

Peer reviewed version

Link back to DTU Orbit

Citation (APA):

Clavreul, J., Baumeister, H., Christensen, T. H., \& Damgaard, A. (2014). An environmental assessment system for environmental technologies. Environmental Modelling \& Software, 60, 18-30.

https://doi.org/10.1016/j.envsoft.2014.06.007

\section{General rights}

Copyright and moral rights for the publications made accessible in the public portal are retained by the authors and/or other copyright owners and it is a condition of accessing publications that users recognise and abide by the legal requirements associated with these rights.

- Users may download and print one copy of any publication from the public portal for the purpose of private study or research.

- You may not further distribute the material or use it for any profit-making activity or commercial gain

- You may freely distribute the URL identifying the publication in the public portal

If you believe that this document breaches copyright please contact us providing details, and we will remove access to the work immediately and investigate your claim. 


\section{Supplementary information}

\section{EASETECH - an Environmental Assessment System for Environmental TECHnologies}

Julie Clavreul $^{1}$, Hubert Baumeister ${ }^{2}$, Thomas H Christensen ${ }^{1}$, Anders Damgaard* ${ }^{1}$

${ }^{1}$ Technical University of Denmark, Department of Environmental Engineering, Building 113, DK-2800 Kongens Lyngby, Denmark

${ }^{2}$ Technical University of Denmark, Department of Informatics and Mathematical Modelling, Building 303B, DK-2800 Kongens Lyngby, Denmark

* Corresponding author

Phone: +4545251612

Fax: +4545932850

E-mail: adam@env.dtu.dk

"NOTE: this is the author's version of a work that was accepted for publication in Environmental Modelling and Software journal. Changes resulting from the publishing process, such as peer review, editing, corrections, structural formatting, and other quality control mechanisms may not be reflected in this document. Minor changes may have been made to this manuscript since it was accepted for publication. A definitive version is published in Environmental Modelling and Software, vol 60, pp 18-30, doi: 10.1016/j.envsoft.2014.06.007" 


\section{TABLE OF CONTENTS}

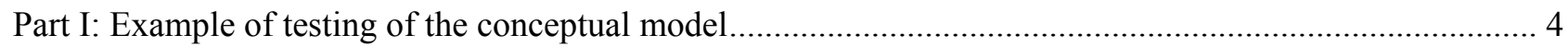

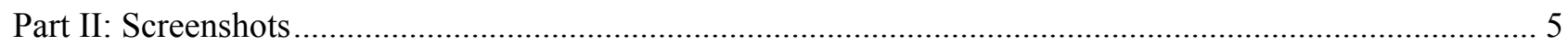

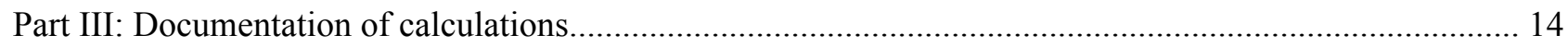

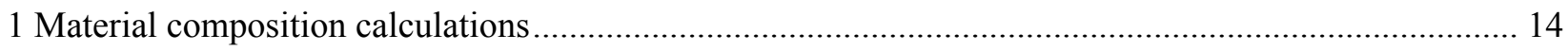

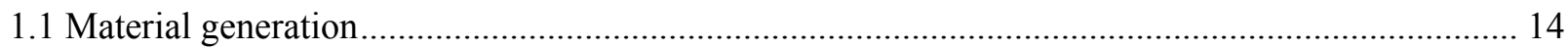

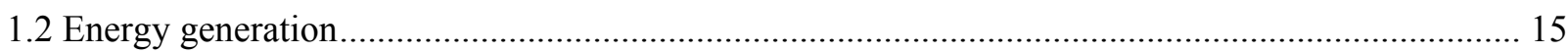

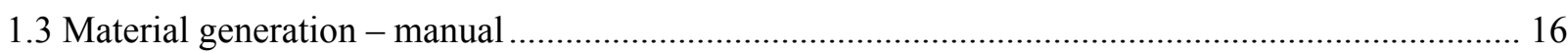

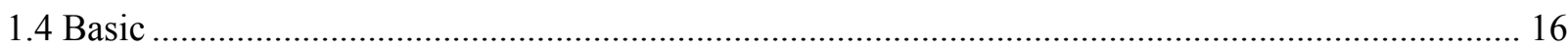

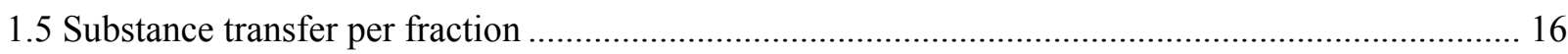

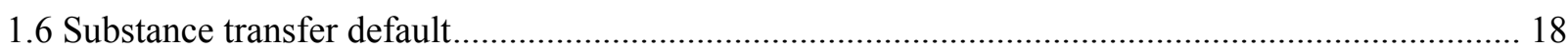

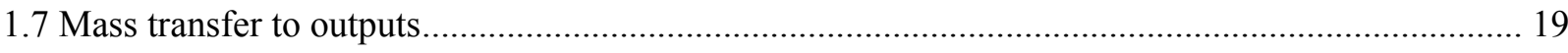

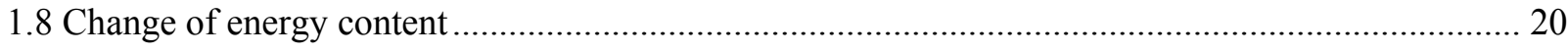

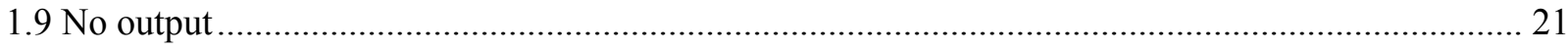

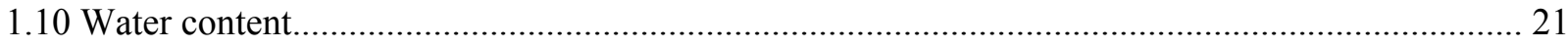

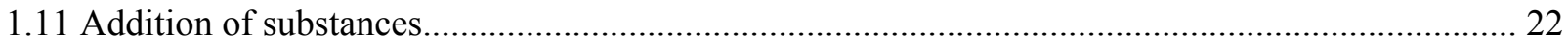

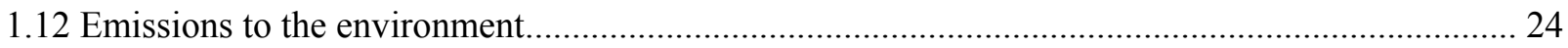

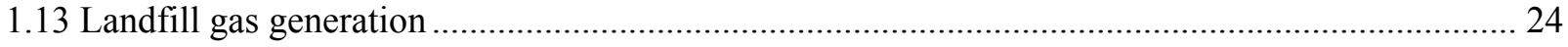

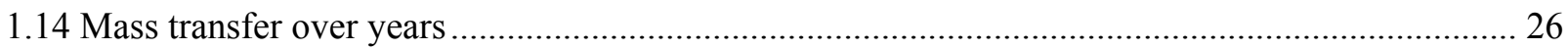

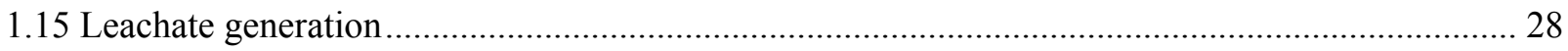

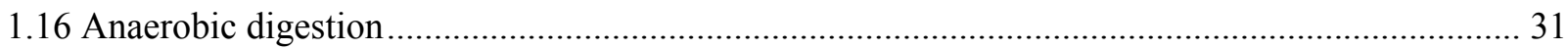

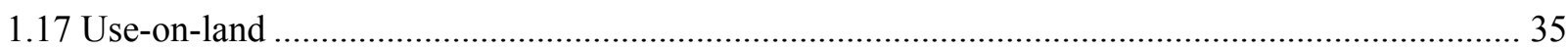

2 LCA calculations in all processes: process-specific emissions and external processes .......................... 36

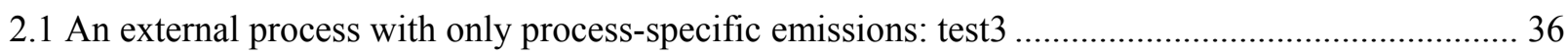

2.2 An external process with process-specific emissions and one external process: test 2 ..................... 38

2.3 An external process with process-specific emissions and an external process that uses another

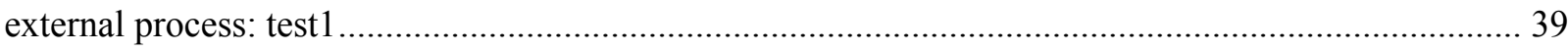

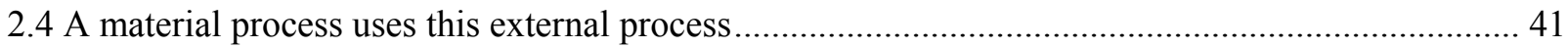

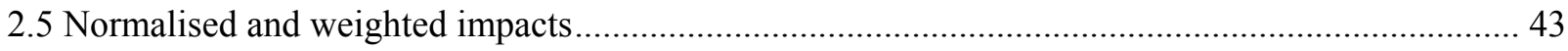

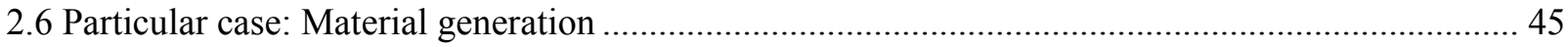

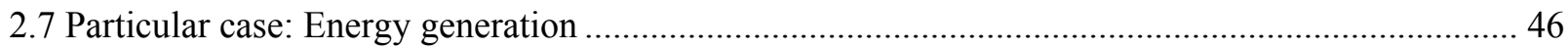

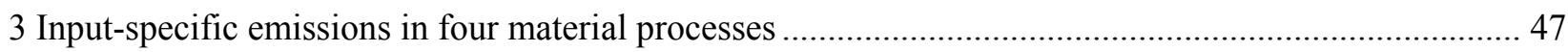

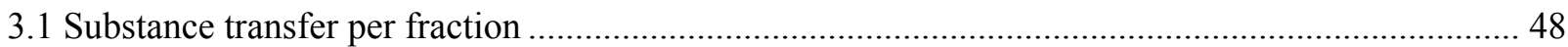

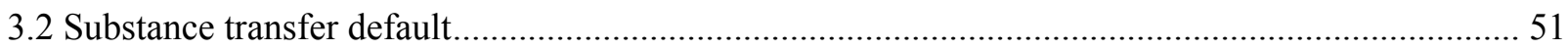

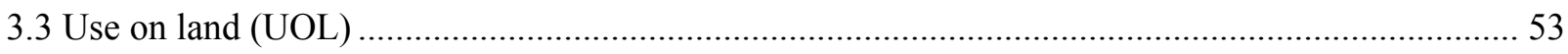




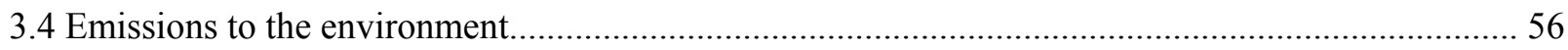

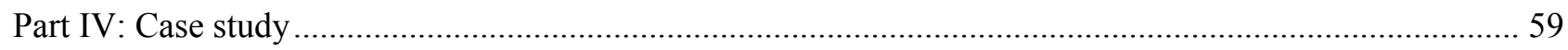

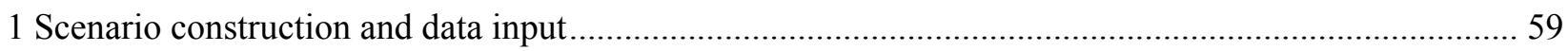

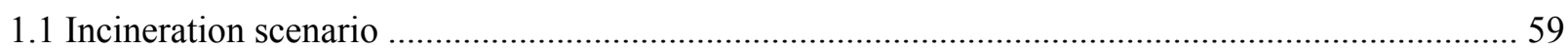

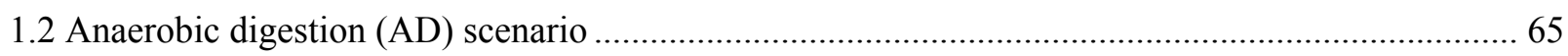

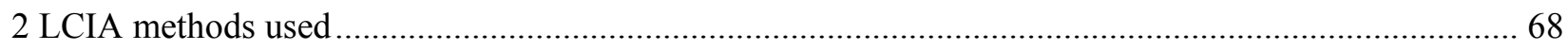

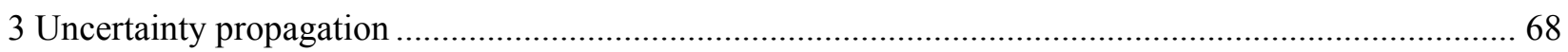

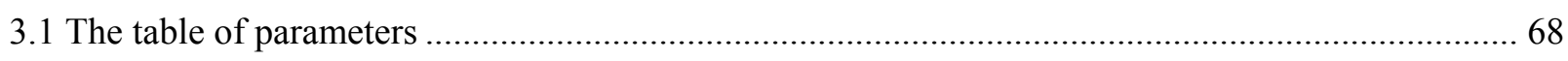

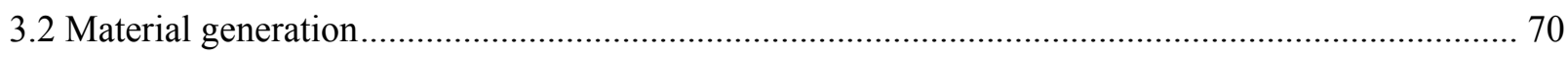

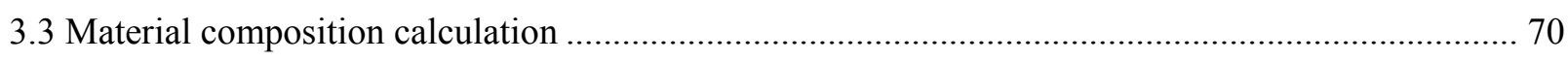

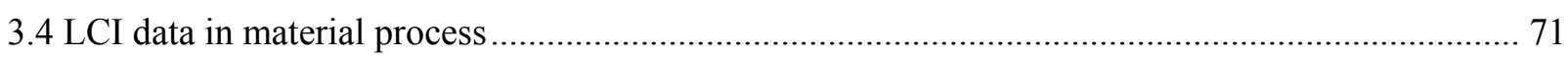

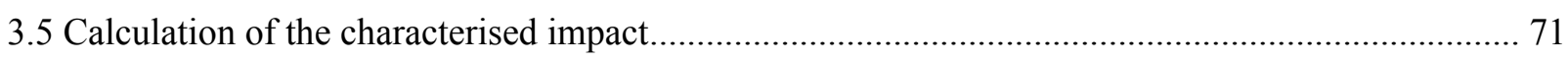

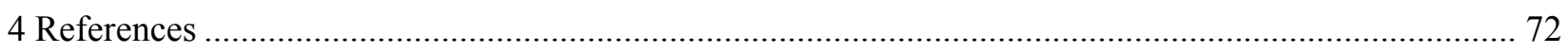




\section{PART I: EXAMPLE OF TESTING OF THE CONCEPTUAL MODEL}

The testing of the conceptual model was performed using the FitNesse Wiki, an automated testing tool which uses the Framework for Integrated Tests (Fit) to evaluate user stories in the context of the developed conceptual model. Figure S1 presents an example of such a Wiki page testing the correct computation of life cycle inventories (LCI).

This user story is one of the first ones that were implemented. It consists of 3 input tables and of one result table. The objective is to enter input values and check if the conceptual model gives the expected result in the last table. Note that the text outside of tables is only comments and is never evaluated.

In the $1^{\text {st }}$ table, a waste process is defined that uses $2 \mathrm{MJ} / \mathrm{kg}$ of electricity per $\mathrm{kg}$ of wet weight of the input waste. This electricity is supplied by an external process called "1 MJ Electricity production (DK)". The $2^{\text {nd }}$ table describes the elementary flows induced by the external process " 1 MJ Electricity production (DK)": producing $1 \mathrm{MJ}$ of electricity will emit $20 \mathrm{~kg} \mathrm{CO}_{2}$ into the air. The $3^{\text {rd }}$ table describes the waste input: here the waste has a wet weight of $2 \mathrm{~kg}$. Finally the last table computes the LCI of the process. The green color shows that the result is the one we expected: the emission of $80 \mathrm{~kg} \mathrm{of} \mathrm{CO}_{2}$ into the air.

This simple example illustrates how basic calculations can be tested in the FitNesse Wiki.

We want to incinerate 2 tons of waste without any remains, and we are using 2 units per ton of the process "1MJ Electricity production (DK)".

\begin{tabular}{|l|l|l|l|}
\hline \multicolumn{4}{|l|}{ WasteProcessFixture } \\
\hline Amount & ExternalProcess & WasteProperty & edit? \\
\hline$-2 \mathrm{MJ} / \mathrm{kg}$ & $1 \mathrm{MJ}$ Electricity production (DK) & Wet weight & true \\
\hline
\end{tabular}

\begin{tabular}{|c|c|c|c|}
\hline \multicolumn{4}{|l|}{ ExternalProcessFixture } \\
\hline Name & Flow produced & Amount & create? \\
\hline 1MJ Electricity production (DK) & "CO2, kg, to air" & $20 \mathrm{~kg} / \mathrm{MJ}$ & true \\
\hline
\end{tabular}

\begin{tabular}{|l|l|l|}
\hline \multicolumn{3}{|l|}{ WasteFixture } \\
\hline WasteProperty & Value & create? \\
\hline Wet weight & $2 \mathrm{~kg}$ & true \\
\hline
\end{tabular}

The result is a list of ElementaryFlow produced by the WasteProcess.

\begin{tabular}{|l|l|}
\hline \multicolumn{2}{|l|}{ LciFixture } \\
\hline ElementaryFlow & Amount \\
\hline "CO2, kg, to air" & $80 \mathrm{~kg}$ \\
\hline
\end{tabular}

Figure S1: Example of a FitNesse Wiki page testing the conceptual model 


\section{PART II: SCREENSHOTS}

All numbers refer to the general overview of the interface in Figure 5 of the article.

"Material transfer" tab (2a):

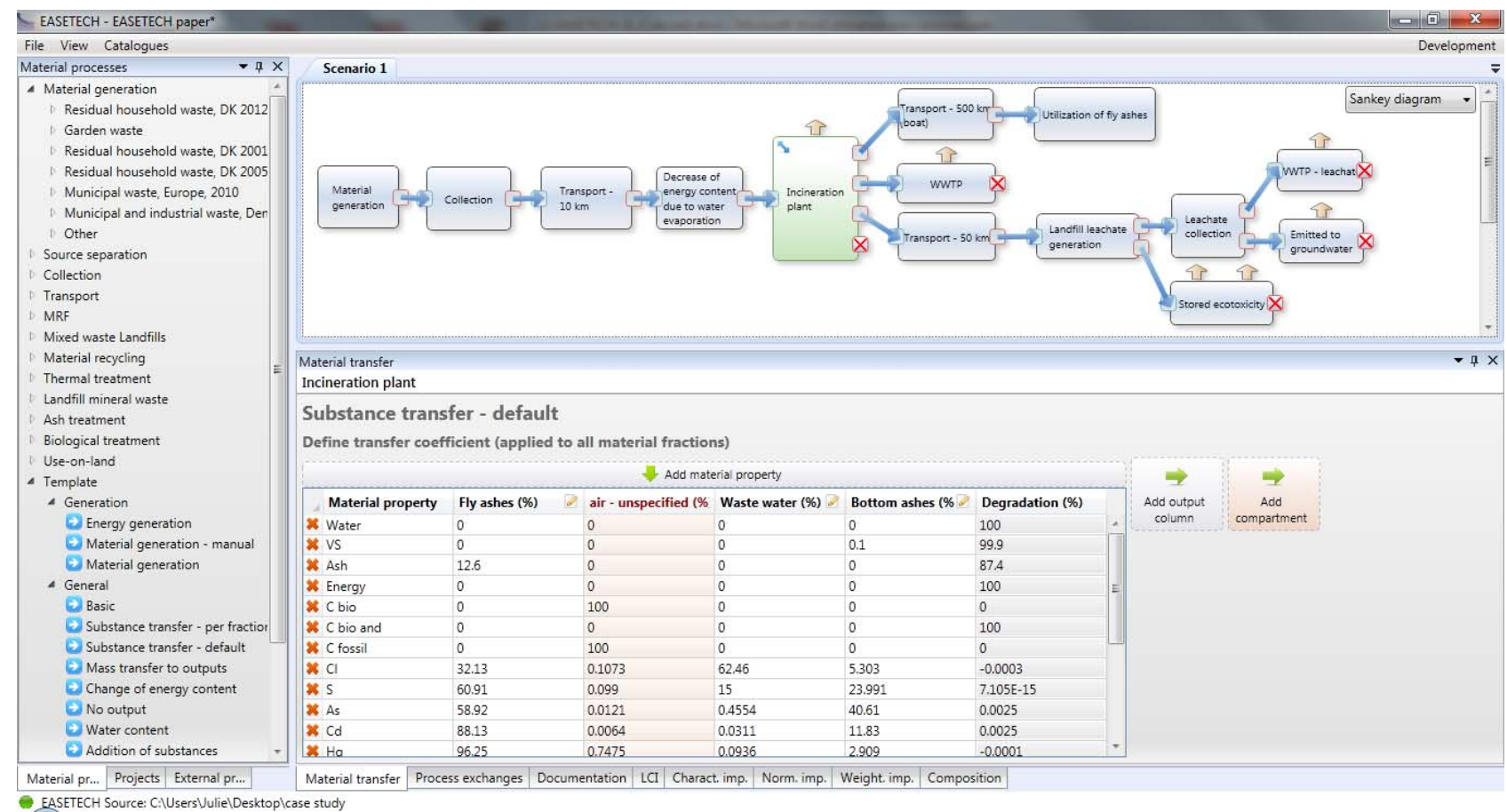

"Process exchanges" tab (2b):

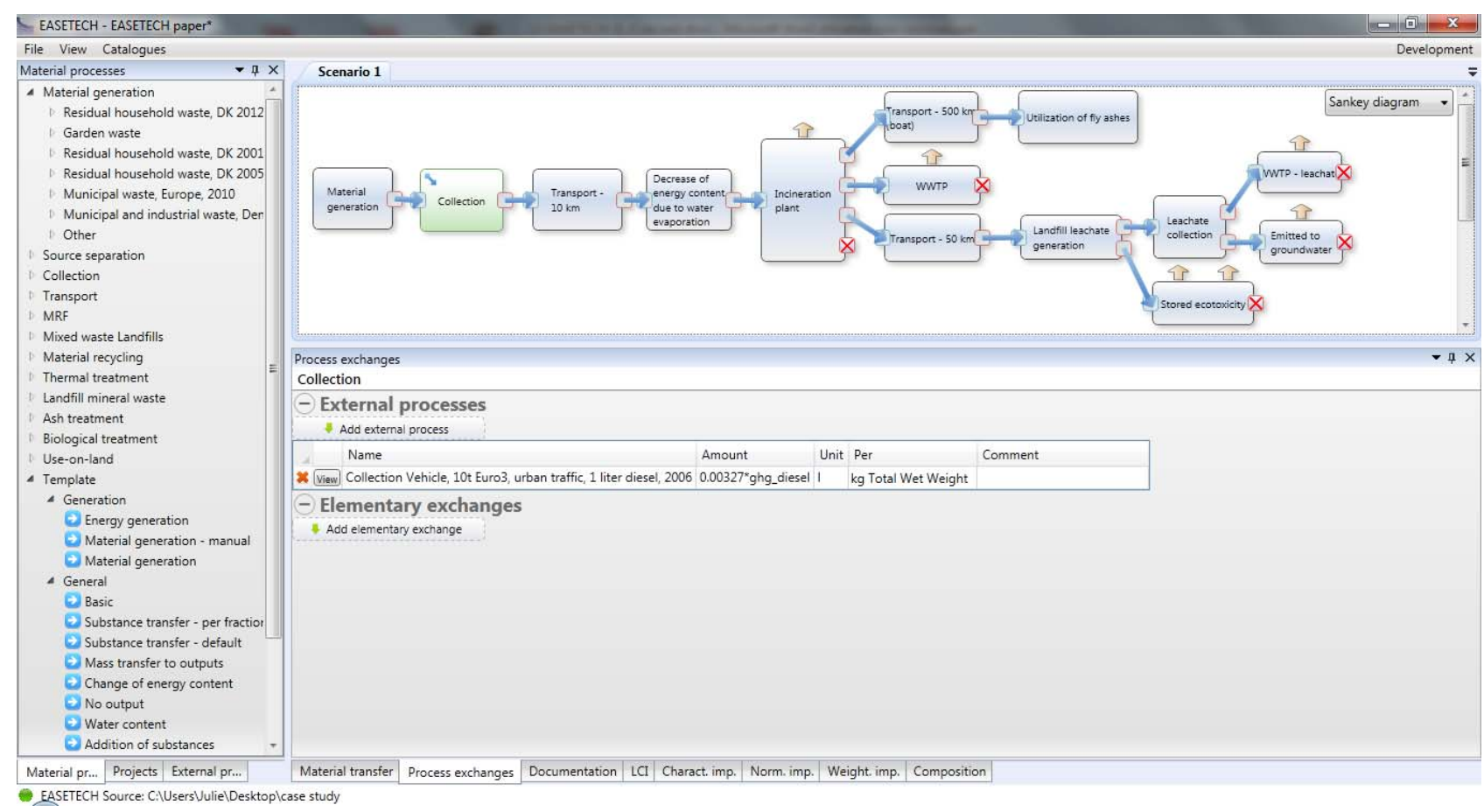


"Documentation" tab (2c):

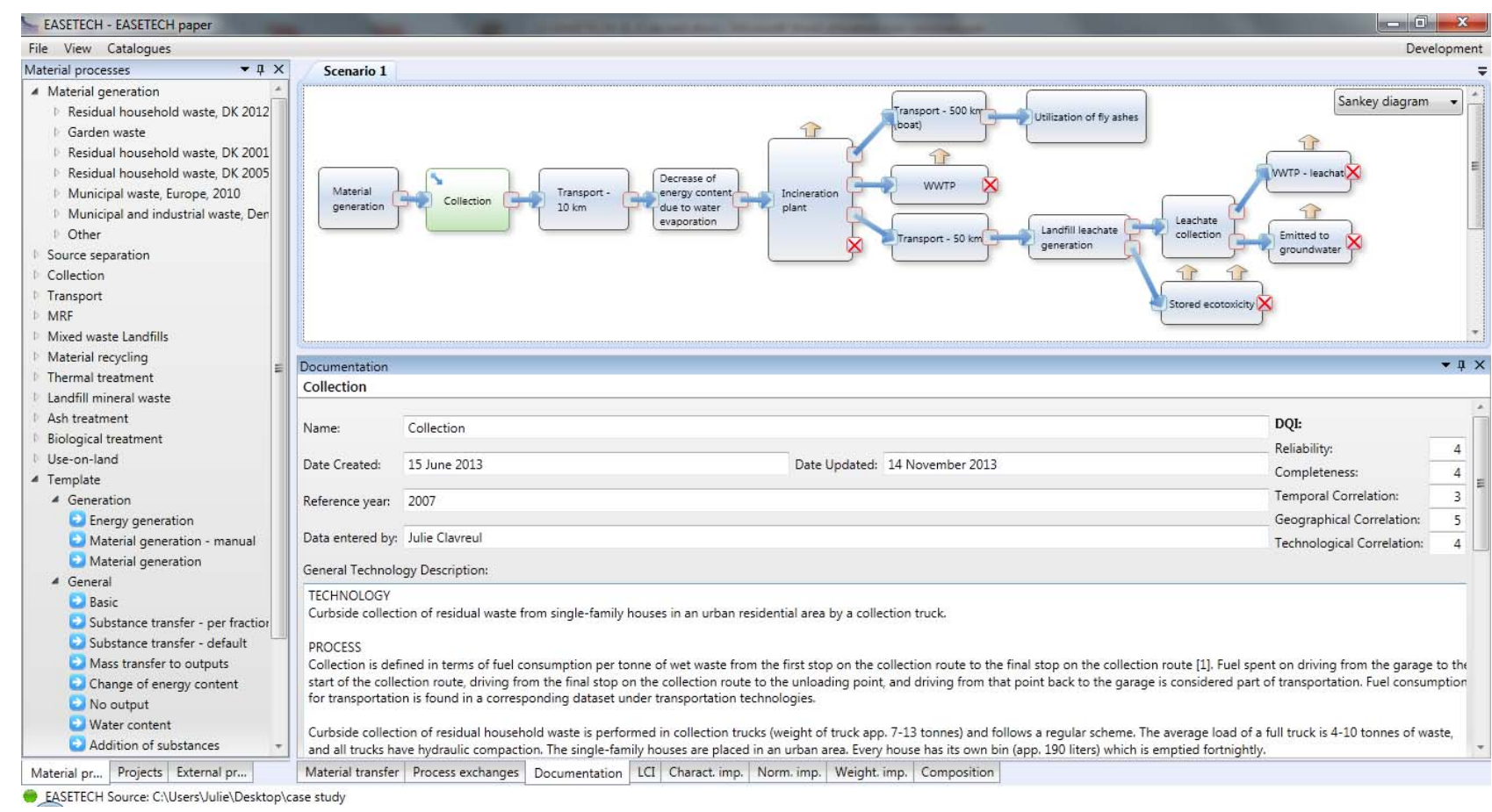

"LCI" tab (2d):

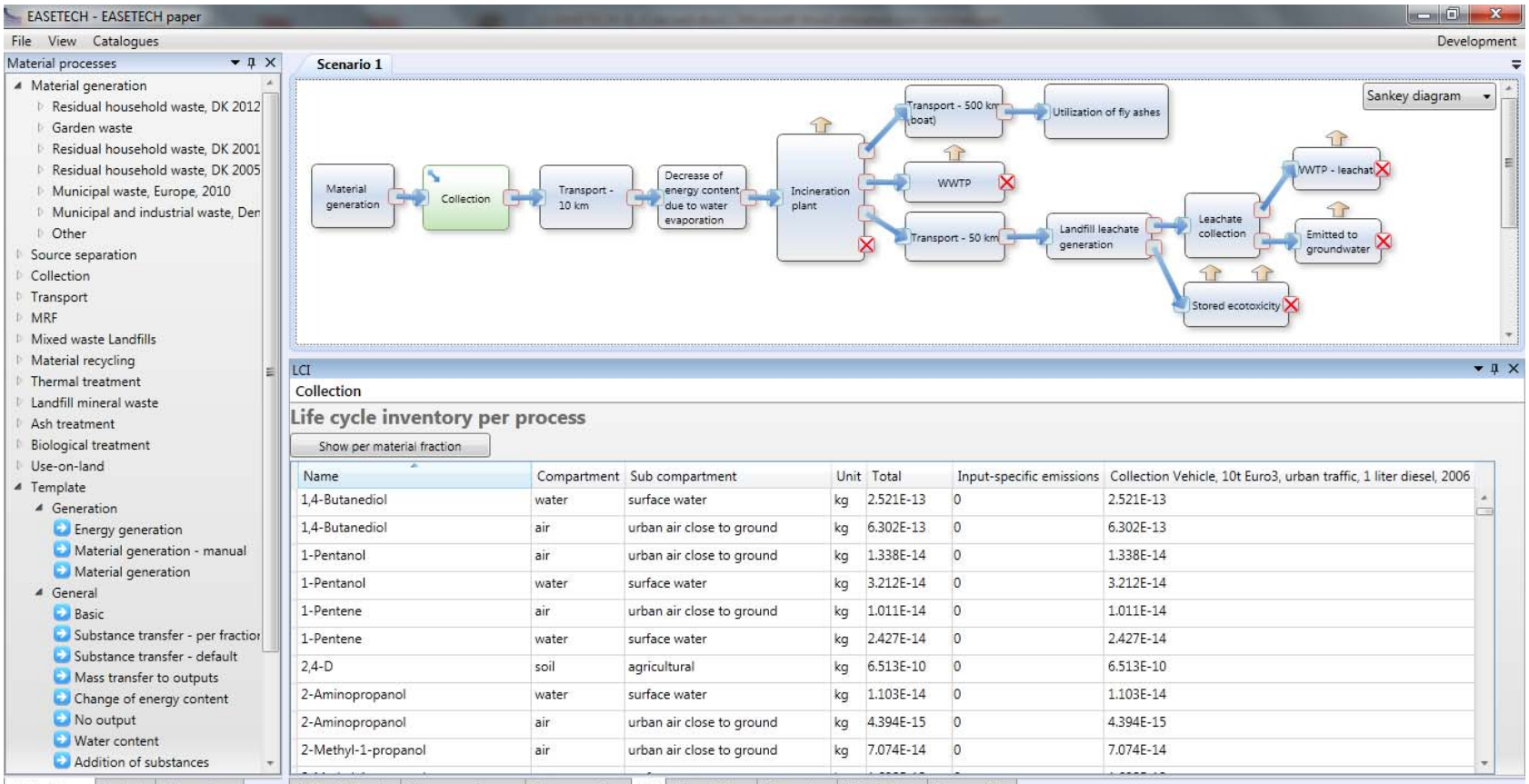

\begin{tabular}{l|l|l|l|l|l|l|l|l|l} 
Material pr... & Projects & External pr... & Material transfer & Process exchanges & Documentation & LCI & Charact. imp. Norm. imp. Weight. imp. Composition \\
\hline
\end{tabular}

- EASETECH Source: C: Users VulielDesktoplcase study 
"Characterised impacts" tab, "per substance" and "per process" views (2e):
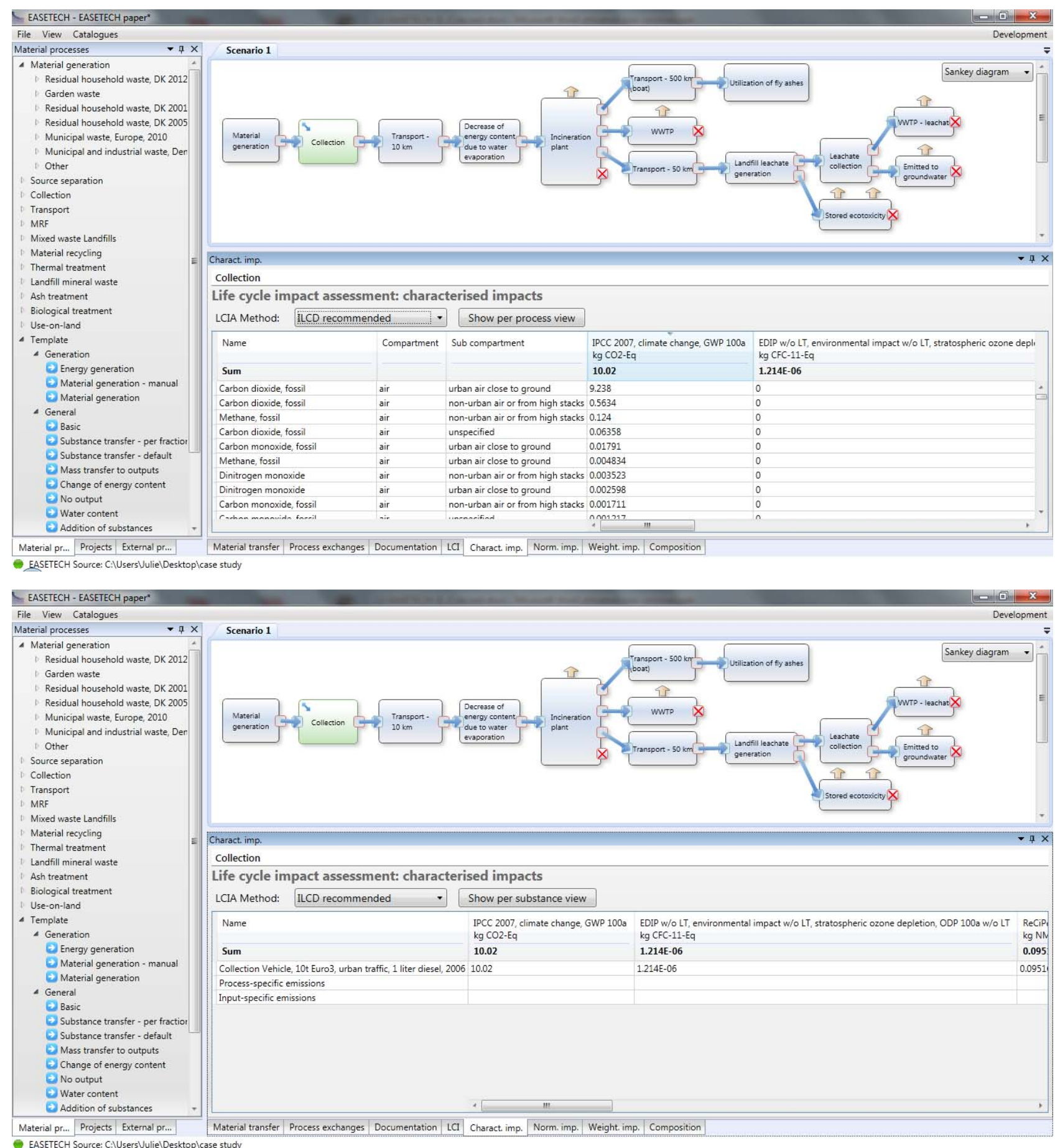

- EASETECH Source: C:UsersVulielDesktoplcase study 
"Normalised impacts" tab, "per substance" and "per process" views (2f):
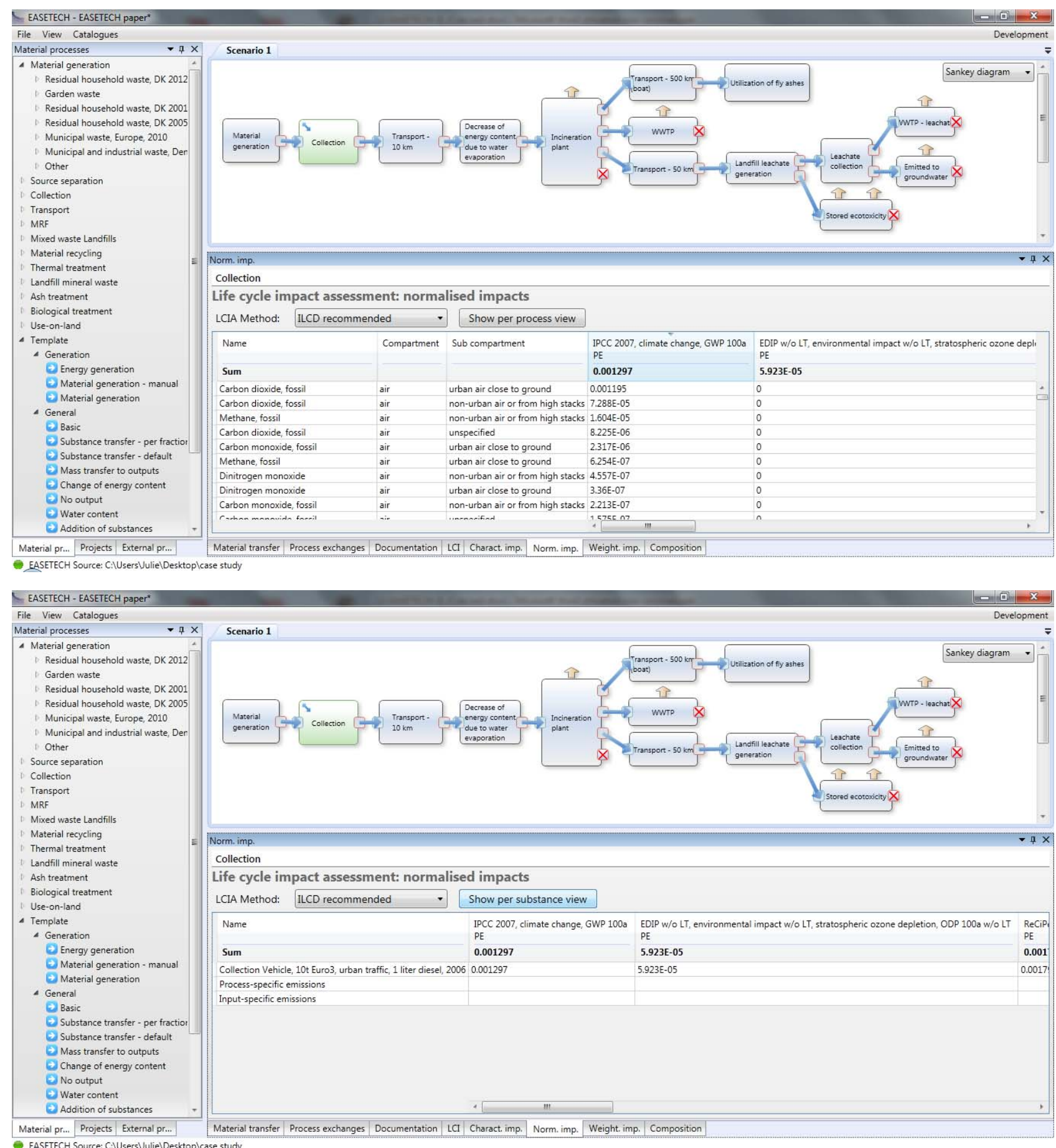

- EASETECH Source: C:IUsers Vulie|Desktoplcase study 
"Weighted impacts" tab, "per substance" and "per process" views (2g):
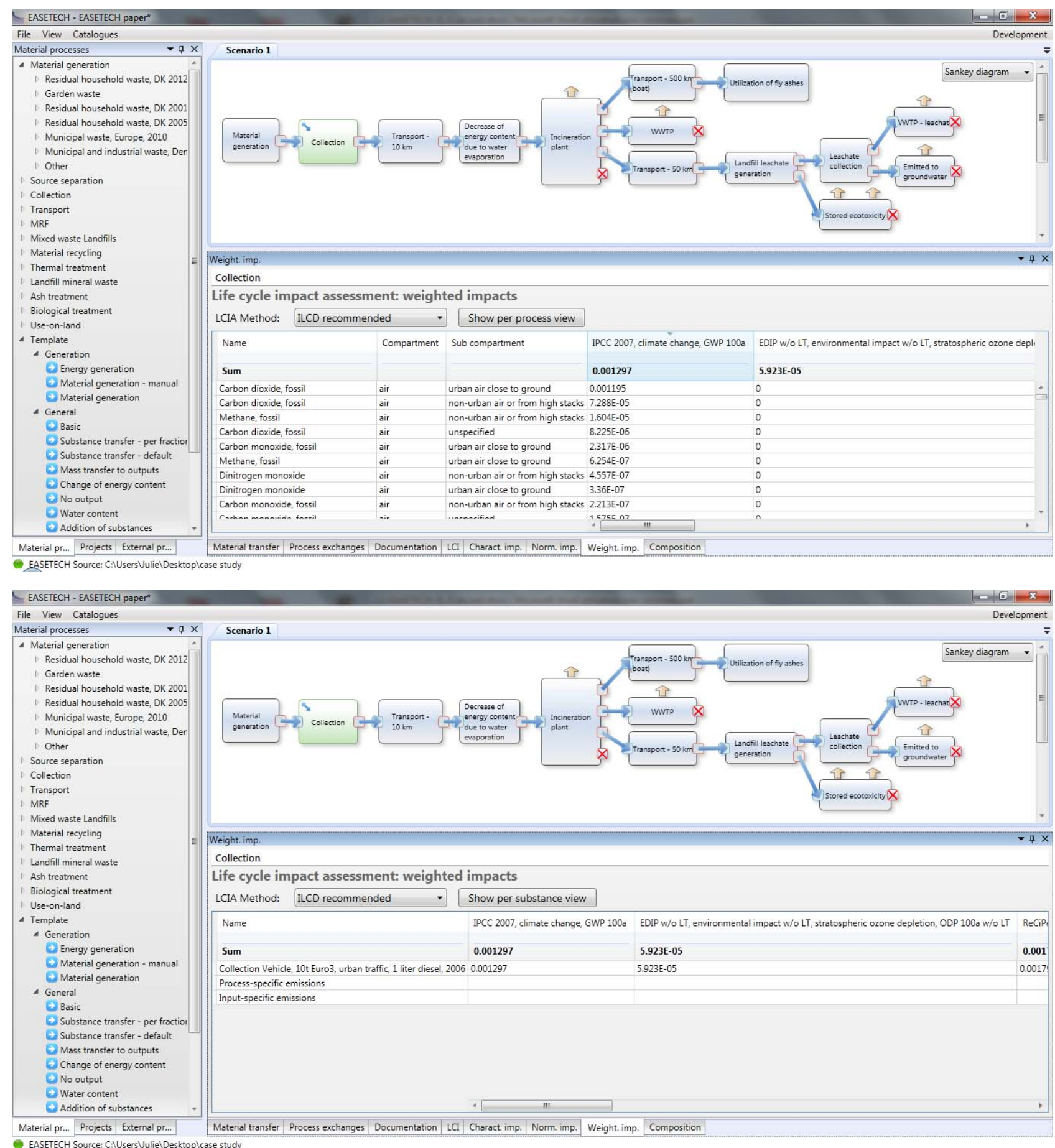

- EASETECH Source: C:IUsers Vulie|Desktoplcase study 
"Composition" tab (2h):

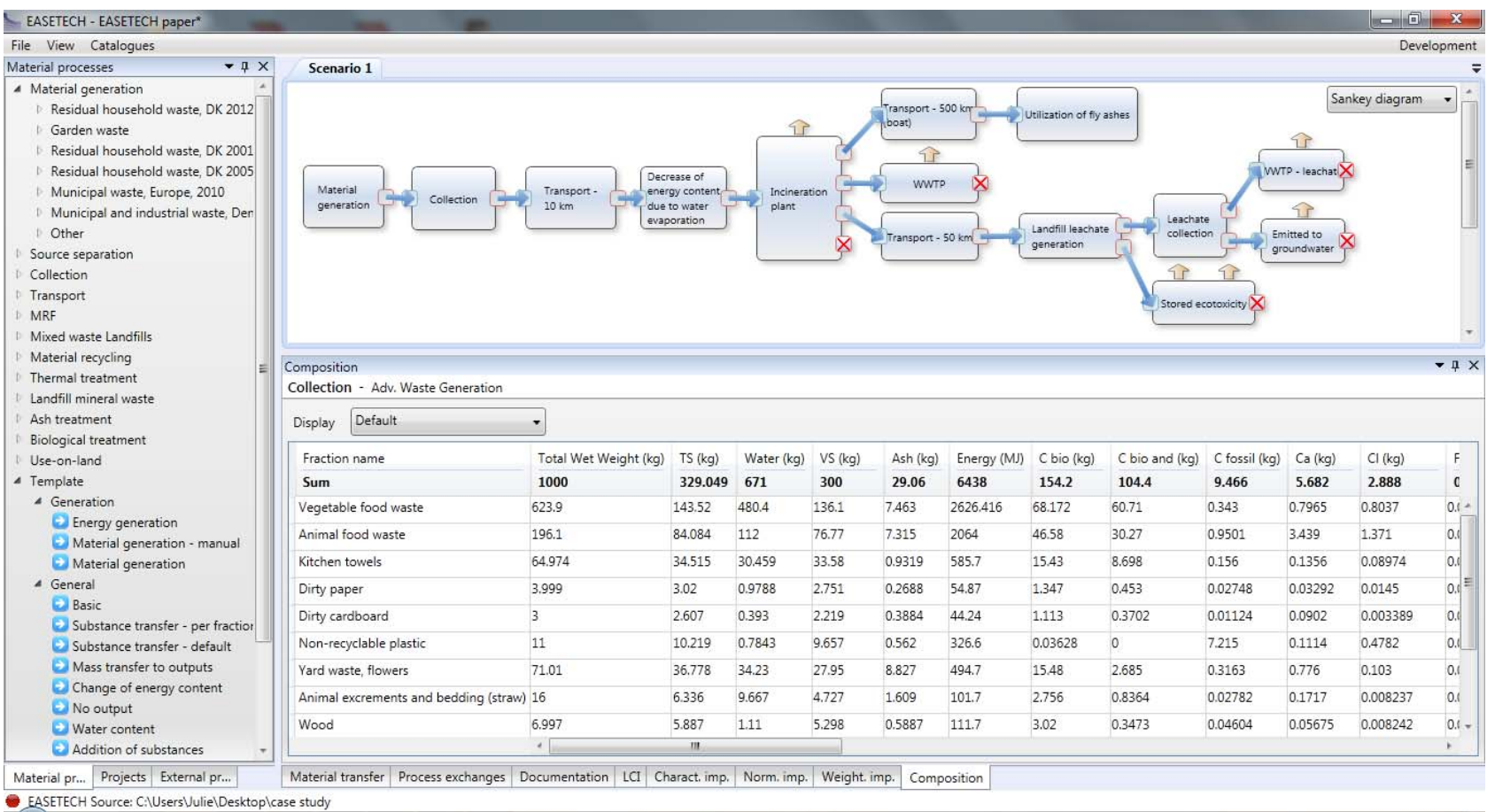

"Material fractions" catalogue (4a):

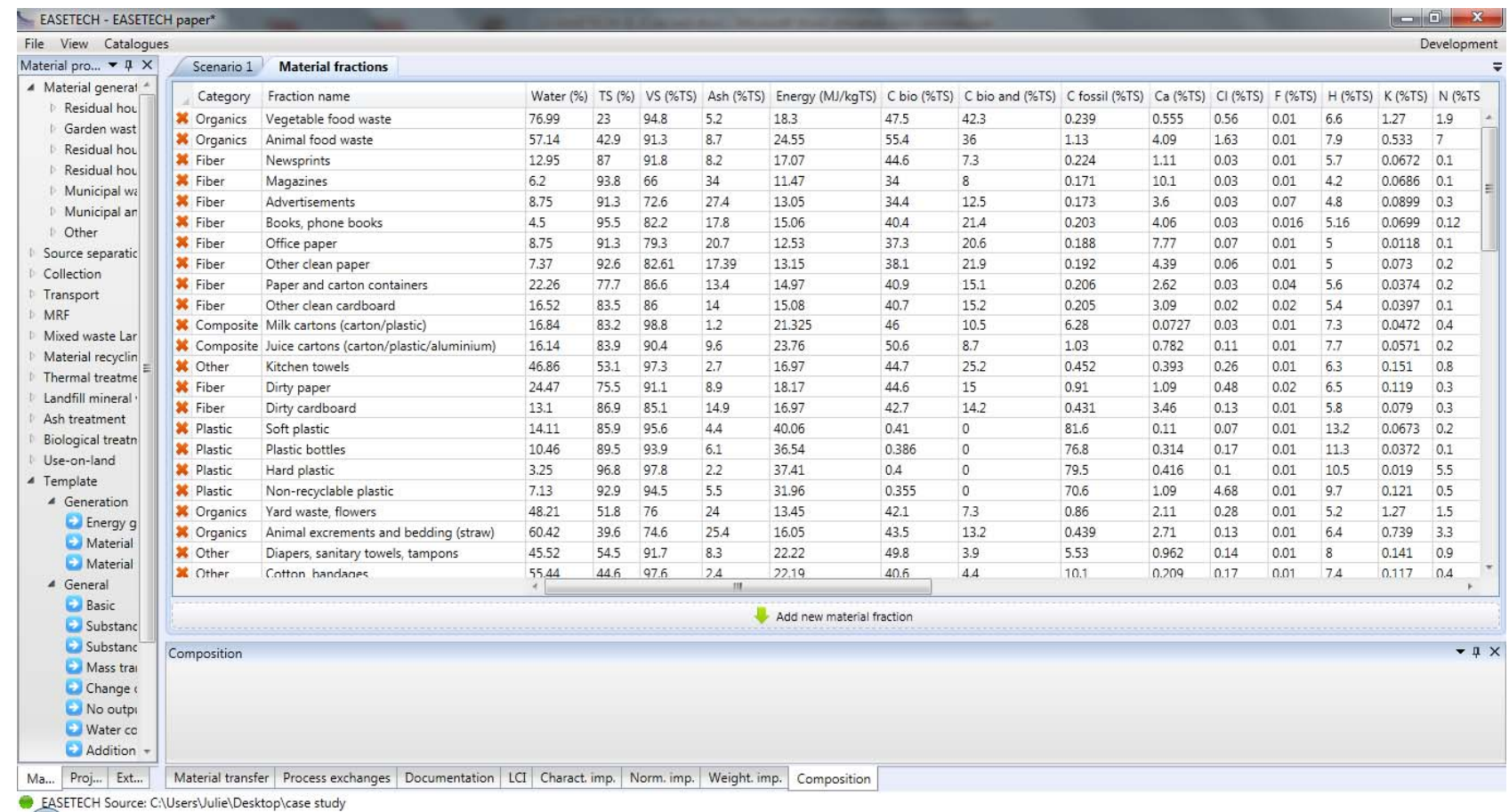


"Elementary exchanges" catalogue (4b):

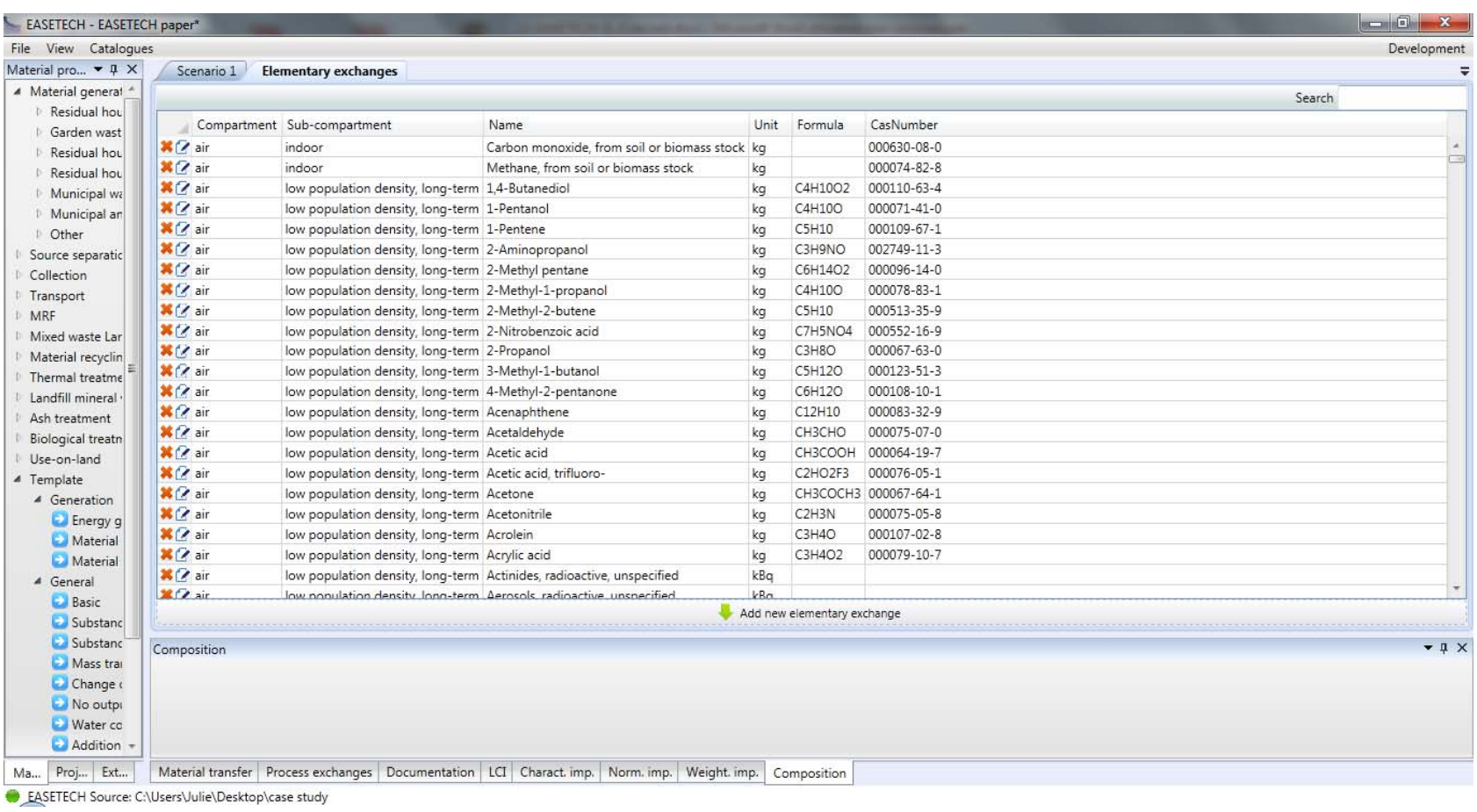

"Impact categories" catalogue (4c):

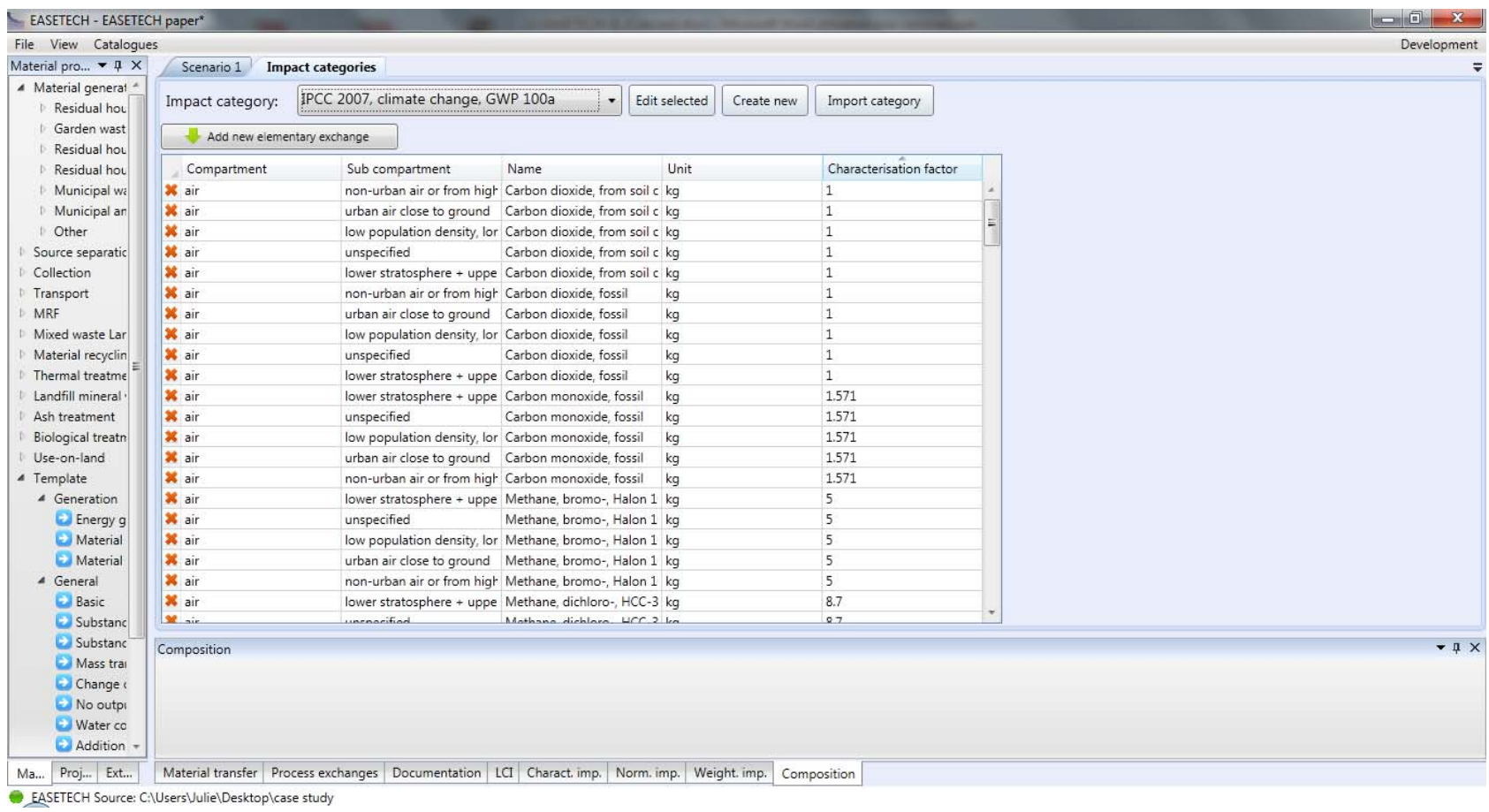


"Methods" catalogue (4d):

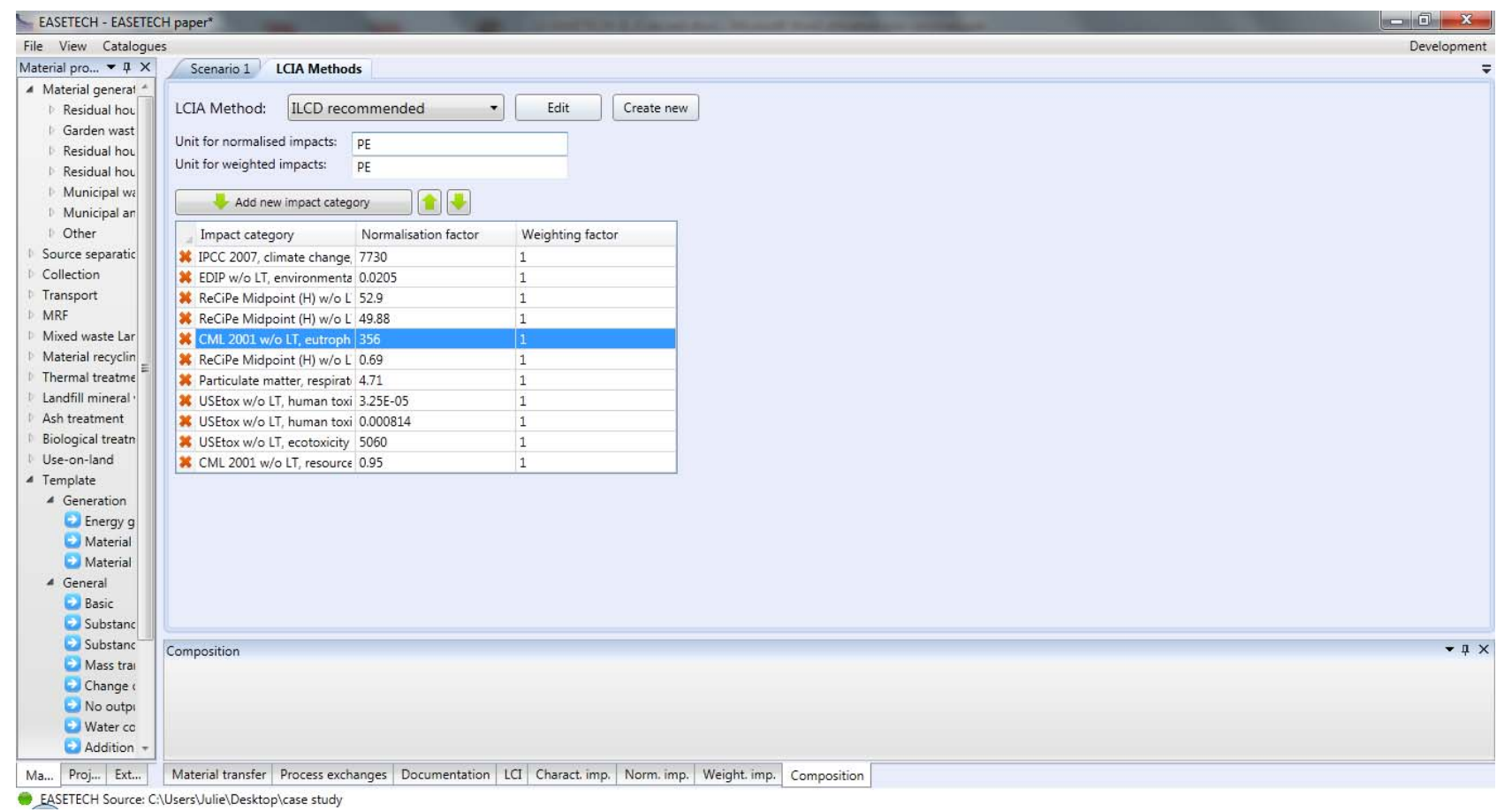

"Interfaces" catalogue (4e):

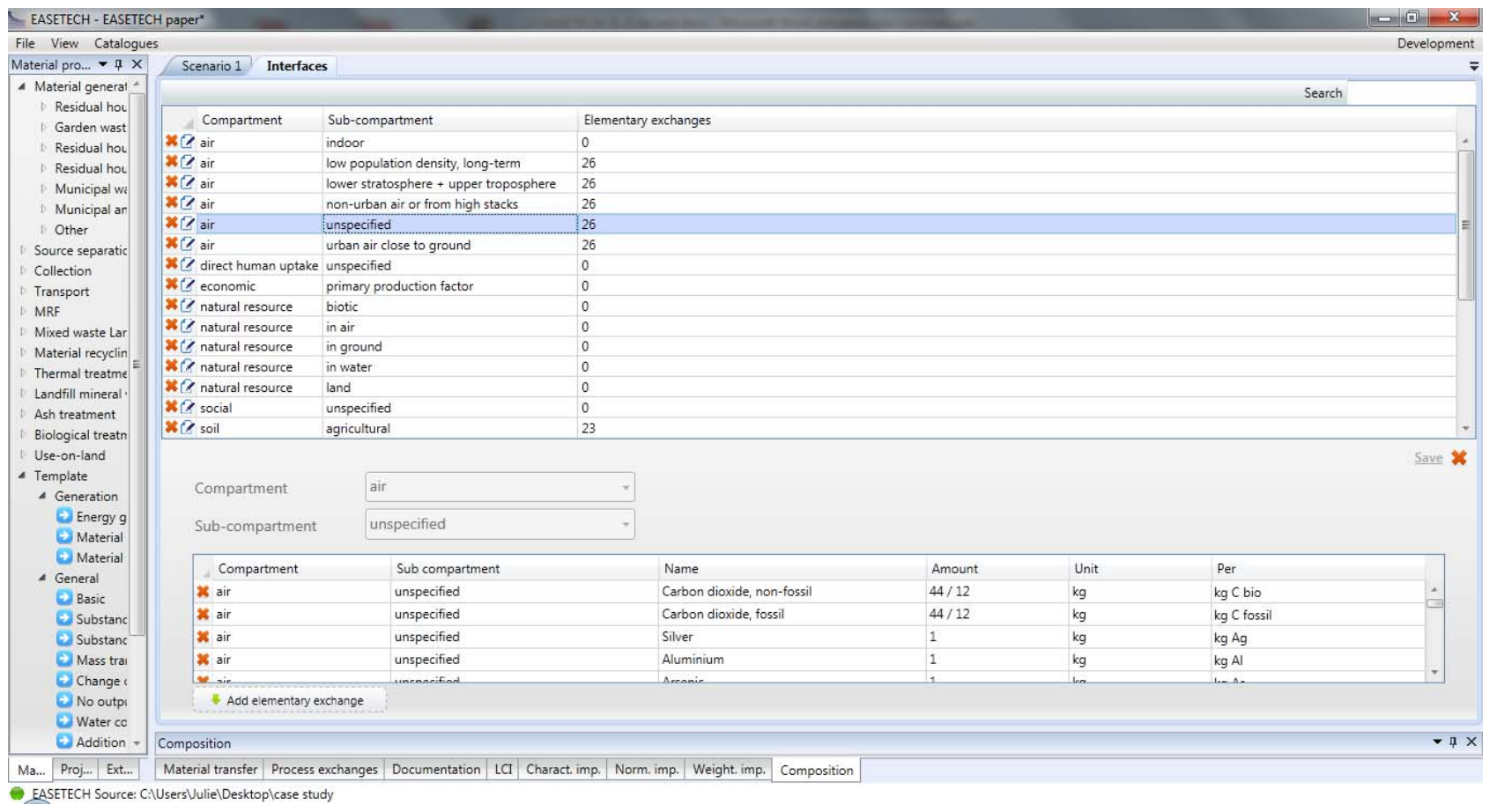


"Constants" catalogue (4f):

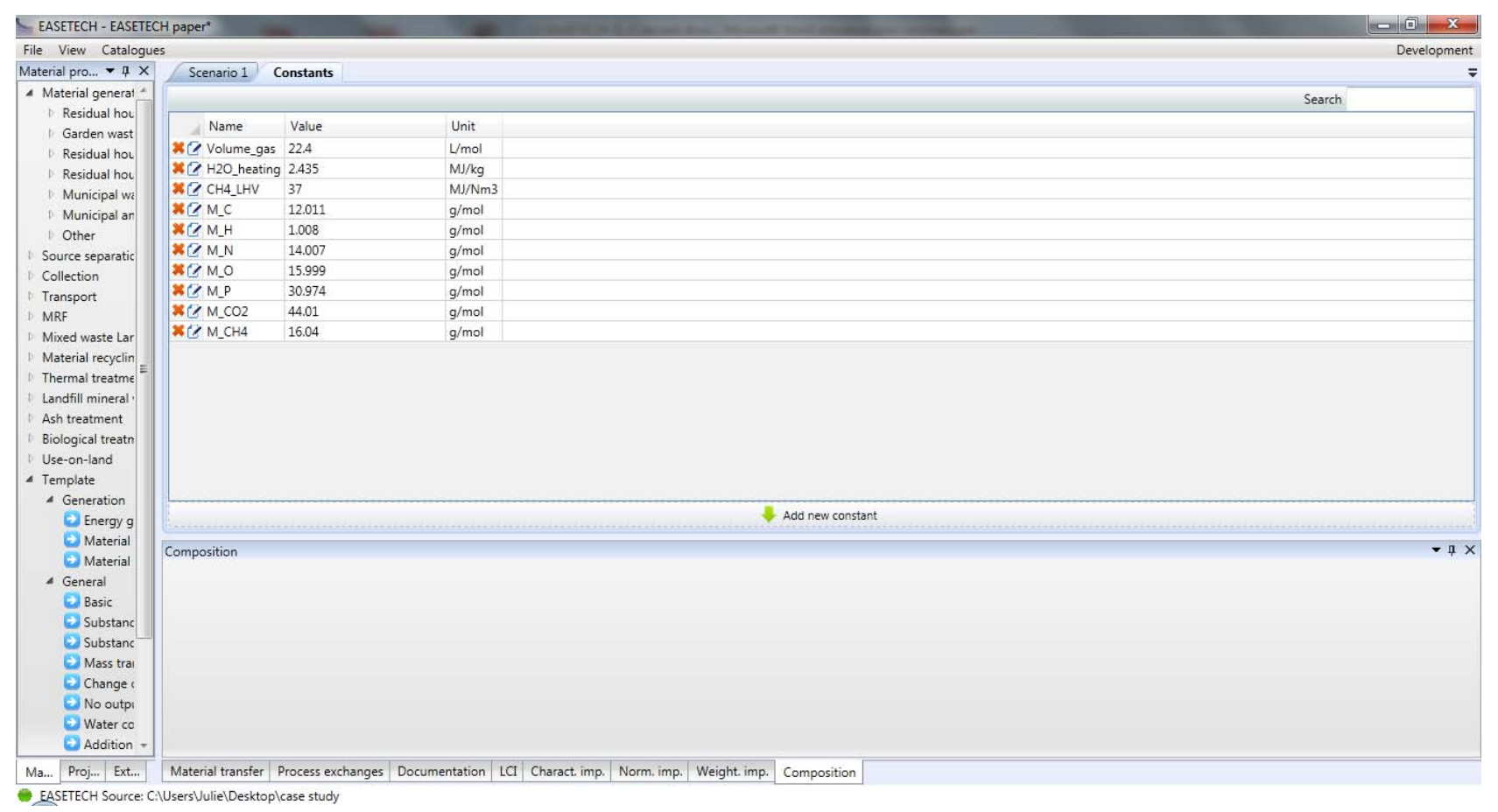

"Material properties" catalogue (4g):

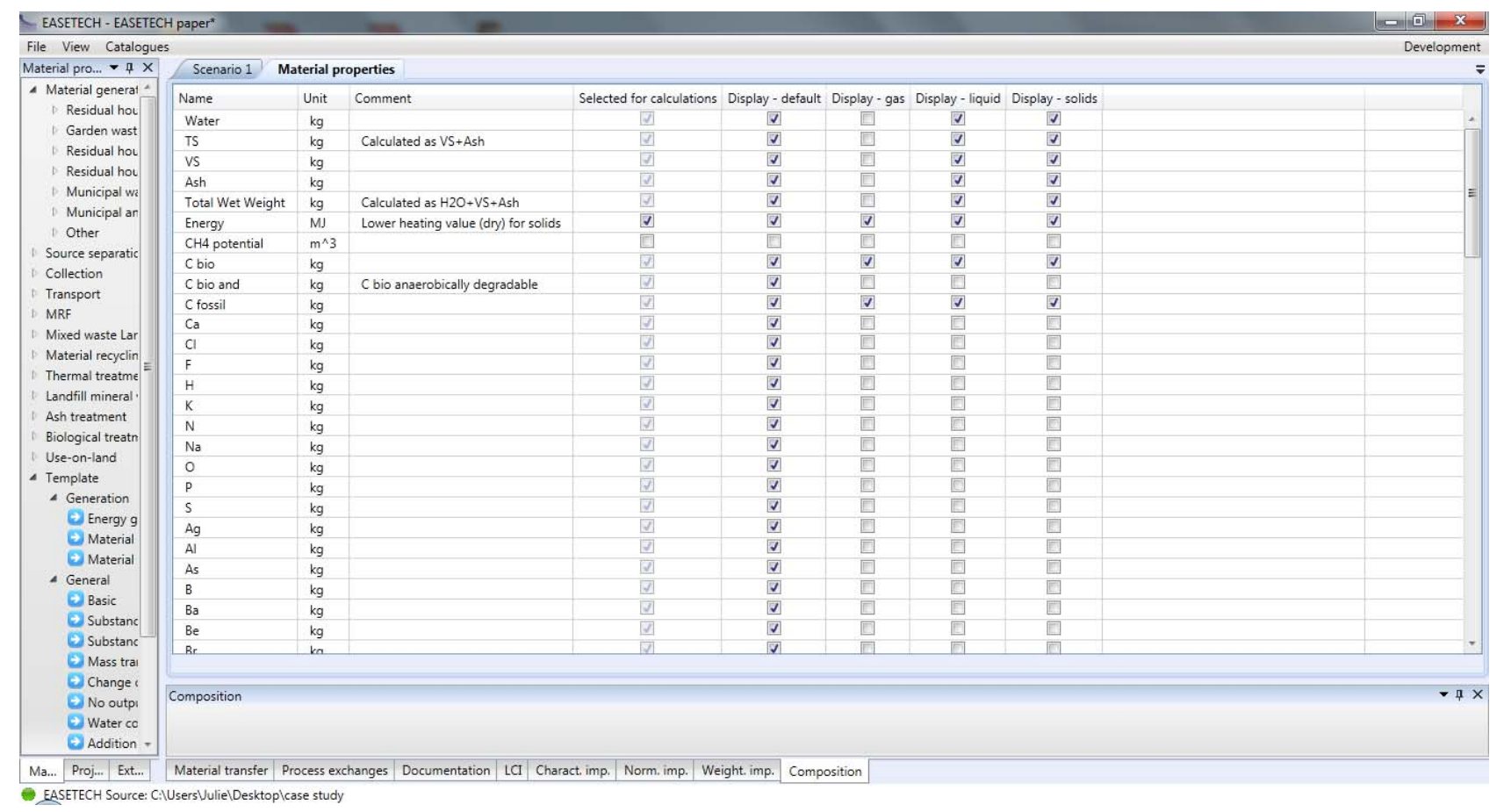




\section{PART III: DOCUMENTATION OF CALCULATIONS}

This document was used to communicate with the development team and explain how calculations should be implemented. It uses simple words and lots of examples to illustrate the calculations happening in each template process.

In a first section, the different calculations of output flow compositions are presented. The second section describes the general LCA calculations happening in all processes, related to data in the "Process exchanges" tab, i.e. external processes and process-specific emissions. The third section presents the inputspecific emissions calculated in 4 material processes whose "Material transfer" tab produces input-specific emissions.

\section{Material composition calculations}

\subsection{Material generation}

In this process, the user defines a TotalAmount and the composition in terms of fractions (called "percent" here). Data about each fraction are taken in the library of material fractions.

For each material fraction,

- $\quad$ water $(\mathrm{kg})=$ water\% $($ fraction $) / 100 *$ percent(fraction) $/ 100 *$ TotalAmount $(\mathrm{kg})$

- $\quad \operatorname{vs}(\mathrm{kg})=\mathrm{VS} \%($ fraction) $) / 100 * \operatorname{percent}($ fraction $)) / 100 *$ TotalAmount $(\mathrm{kg})$

- $\quad \operatorname{ash}(\mathrm{kg})=\operatorname{ash} \%($ fraction $)) / 100 * \operatorname{percent}($ fraction $)) / 100 *$ TotalAmount $(\mathrm{kg})$

- $\quad$ energy $(\mathrm{MJ})=\operatorname{energy} \%($ fraction $) * \mathrm{TS} \%($ fraction $) / 100 *$ percent(fraction) $) / 100$

*TotalAmount $(\mathrm{kg})$

- $\quad$ for all other material properties: materialproperty $(\mathrm{kg})=$ materialproperty $\%($ fraction $)) / 100 *$ $\mathrm{TS} \%$ (fraction) ) $/ 100 *$ percent(fraction) $) / 100 *$ TotalAmount $(\mathrm{kg})$

where e.g. "ash\%" is the ash content of the fraction in the library of material fractions.

Total wet weight and TS are calculated as usual, respectively as the sum of TS and water, and the sum of VS and ash. Figure $\mathrm{S} 2$ shows an example of material generation process.

\begin{tabular}{|c|c|c|c|c|c|c|c|c|c|c|c|c|c|c|c|c|c|c|}
\hline \multirow{2}{*}{$\begin{array}{l}\text { Scenario } 2 \\
\text { Category }\end{array}$} & \multicolumn{3}{|c|}{ Scenario 1} & \multicolumn{2}{|c|}{ LCIA Methods } & \multicolumn{13}{|c|}{ Material fractions } \\
\hline & \multicolumn{2}{|c|}{ Fraction name } & Water (\%) & TS (\%) & VS (\%TS) & Ash (\%TS) & Energy $(\mathrm{MJ} / \mathrm{kgTS})$ & C bio (\%TS) & $\mathrm{C}$ bio and $(\% \mathrm{TS})$ & C fossil (\%TS) & $\mathrm{Ca}(\% \mathrm{TS})$ & $\mathrm{Cl}(\% \mathrm{TS})$ & $F(\% T S)$ & $H(\% T S)$ & $K(\% T S)$ & $\mathrm{N}(\% \mathrm{TS})$ & $\mathrm{Na}(\% \mathrm{TS})$ & $O(\%)$ \\
\hline × Organics & \multicolumn{2}{|c|}{ Vegetable food waste } & 76.99 & 23 & 94.8 & 5.2 & 18.3 & 47.5 & 42.3 & 0.239 & 0.555 & 0.56 & 0.01 & 6.6 & 1.27 & 1.9 & 0.312 & 39.5 \\
\hline * Organics & \multicolumn{2}{|c|}{ Animal food waste } & 57.14 & 42.9 & 91.3 & 8.7 & 24.55 & 55.4 & 36 & 1.13 & 4.09 & 1.63 & 0.01 & 7.9 & 0.533 & 7 & 1.08 & 18.2 \\
\hline * Fiber & \multicolumn{2}{|c|}{ Newsprints } & 12.95 & 87 & 91.8 & 8.2 & 17.07 & 44.6 & 7.3 & 0.224 & 1.11 & 0.03 & 0.01 & 5.7 & 0.0672 & 0.1 & 0.0246 & 44.2 \\
\hline * Fiber & \multicolumn{2}{|c|}{ Magazines } & 6.2 & 93.8 & 66 & 34 & 11.47 & 34 & 8 & 0.171 & 10.1 & 0.03 & 0.01 & 4.2 & 0.0686 & 0.1 & 0.0898 & 27.5 \\
\hline * Fiber & \multicolumn{2}{|c|}{ Advertisements } & 8.75 & 91.3 & 72.6 & 27.4 & 13.05 & 34.4 & 12.5 & 0.173 & 3.6 & 0.03 & 0.07 & 4.8 & 0.0899 & 0.3 & 0.128 & 32.9 \\
\hline * Fiber & \multicolumn{2}{|c|}{ Books, phone books } & 4.5 & 95.5 & 82.2 & 17.8 & 15.06 & 40.4 & 21.4 & 0.203 & 4.06 & 0.03 & 0.016 & 5.16 & 0.0699 & 0.12 & 0.0545 & 38.1 \\
\hline $\boldsymbol{X}$ Fiber & \multicolumn{2}{|c|}{ Office paper } & 8.75 & 91.3 & 79.3 & 20.7 & 12.53 & 37.3 & 20.6 & 0.188 & 7.77 & 0.07 & 0.01 & 5 & 0.0118 & 0.1 & 0.0774 & 36.7 \\
\hline * Fiber & \multicolumn{2}{|c|}{ Other clean paper } & 7.37 & 92.6 & 82.61 & 17.39 & 13.15 & 38.1 & 21.9 & 0.192 & 4.39 & 0.06 & 0.01 & 5 & 0.073 & 0.2 & 0.0977 & 38.5 \\
\hline * Fiber & \multicolumn{2}{|c|}{ Paper and carton contain } & 22.26 & 77.7 & 86.6 & 13.4 & 14.97 & 40.9 & 15.1 & 0.206 & 2.62 & 0.03 & 0.04 & 5.6 & 0.0374 & 0.2 & 0.0476 & 39.6 \\
\hline Fiber & \multicolumn{2}{|c|}{ Other clean cardboard } & 16.52 & 83.5 & 86 & 14 & 15.08 & 40.7 & 15.2 & 0.205 & 3.09 & 0.02 & 0.02 & 5.4 & 0.0397 & 0.1 & 0.0416 & 39.5 \\
\hline X Composite & \multicolumn{2}{|c|}{ Milk cartons (carton/plast } & 16.84 & 83.2 & 98.8 & 1.2 & 21.325 & 46 & 10.5 & 6.28 & 0.0727 & 0.03 & 0.01 & 7.3 & 0.0472 & 0.4 & 0.15 & 38.8 \\
\hline * Composite & \multicolumn{2}{|c|}{ Juice cartons (carton/plas } & 16.14 & 83.9 & 90.4 & 9.6 & 23.76 & 50.6 & 8.7 & 1.03 & 0.782 & 0.11 & 0.01 & 7.7 & 0.0571 & 0.2 & 0.174 & 30.8 \\
\hline Other & \multicolumn{2}{|c|}{ Kitchen towels } & 46.86 & 53.1 & 97.3 & 2.7 & 16.97 & 44.7 & 25.2 & 0.452 & 0.393 & 0.26 & 0.01 & 6.3 & 0.151 & 0.8 & 0.206 & 44.8 \\
\hline \multirow[t]{2}{*}{ * Fiber } & \multicolumn{2}{|c|}{ Dirty paper } & 24.47 & 75.5 & 91.1 & 8.9 & 18.17 & 44.6 & 15 & 0.91 & 1.09 & 0.48 & 0.02 & 6.5 & 0.119 & 0.3 & 0.109 & 38.3 \\
\hline & & & $\cdot \square$ & & & III & & $\square$ & & & & & & & & & & \\
\hline \multicolumn{19}{|c|}{ Add new material fraction } \\
\hline \multirow{2}{*}{\multicolumn{19}{|c|}{$\begin{array}{l}\text { Uaterial transfer } \\
\text { Material generation }\end{array}$}} \\
\hline & & & & & & & & & & & & & & & & & & \\
\hline \multicolumn{19}{|c|}{ Material generation: amount and fractions } \\
\hline \multicolumn{19}{|c|}{ Total amount $(\mathrm{kg}) \quad 30$} \\
\hline \multicolumn{19}{|c|}{$\square$ Include upstream impacts } \\
\hline \multicolumn{19}{|c|}{ Add fraction Normalise composition to $100 \%$} \\
\hline Material frc & action & $\%$ & & & & & & & & & & & & & & & & \\
\hline * Vegetable f & food waste & te 70 & & & & & & & & & & & & & & & & \\
\hline $\boldsymbol{X}$ Office pape & & 30 & & & & & & & & & & & & & & & & \\
\hline
\end{tabular}

Figure S2: Material transfer of a "Material generation” process and catalogue of material fractions 
The output is (Figure S3):

- for fraction "vegetable food waste":

$$
\begin{aligned}
& \text { o water: } 76.99 / 100 * 70 / 100 * 30 \mathrm{~kg}=16.169 \mathrm{~kg} \\
& \text { o VS: } 94.8 / 100 * 23 / 100 * 70 / 100 * 30 \mathrm{~kg}=4.579 \mathrm{~kg} \\
& \text { o ash: } 5.2 / 100 * 23 / 100 * 70 / 100 * 30 \mathrm{~kg}=0.251 \mathrm{~kg} \\
& \text { o energy: } 18.3 * 23 / 100 * 70 / 100 * 30 \mathrm{~kg}=88.389 \mathrm{MJ} \\
& \text { o } \text { C bio: } 47.5 / 100 * 23 / 100 * 70 / 100 * 30 \mathrm{~kg}=2.294 \mathrm{~kg} \\
& \text { o } \ldots
\end{aligned}
$$

\begin{tabular}{|c|c|c|c|c|c|c|c|c|c|c|c|c|c|c|}
\hline \multirow{2}{*}{\multicolumn{15}{|c|}{$\begin{array}{l}\text { Composition } \\
\text { Material generation - Adv. Waste Generation }\end{array}$}} \\
\hline & & & & & & & & & & & & & & \\
\hline Display & Default & 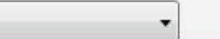 & & & & & & & & & & & & \\
\hline \multicolumn{2}{|c|}{ Fraction name } & Total Wet Weight $(\mathrm{kg})$ & TS $(\mathrm{kg})$ & Water $(\mathrm{kg})$ & VS (kg) & Ash $(\mathrm{kg})$ & Energy (MJ) & C bio $(\mathrm{kg})$ & $\mathrm{C}$ bio and $(\mathrm{kg})$ & C fossil (kg) & $\mathrm{Ca}(\mathrm{kg})$ & $\mathrm{Cl}(\mathrm{kg})$ & $F(k g)$ & Ho \\
\hline \multicolumn{2}{|l|}{ Sum } & 30 & 13.047 & 16.96 & 11.09 & 1.952 & 191.3 & 5.359 & 3.736 & 0.02699 & 0.6653 & 0.0328 & 0.001305 & 0.7 \\
\hline \multicolumn{2}{|c|}{ Vegetable food waste } & 21 & 4.83 & 16.17 & 4.579 & 0.2512 & 88.389 & 2.294 & 2.043 & 0.01154 & 0.02681 & 0.02705 & 0.000483 & 0.31 \\
\hline \multicolumn{2}{|c|}{ Office paper } & 9.005 & 8.217 & 0.7875 & 6.516 & 1.701 & 103 & 3.065 & 1.693 & 0.01545 & 0.6385 & 0.005752 & 0.0008217 & 0.41 \\
\hline
\end{tabular}

- for fraction "office paper":

$$
\begin{aligned}
& \text { o water: } 8.75 / 100 * 30 / 100 * 30 \mathrm{~kg}=0.7875 \mathrm{~kg} \\
& \text { o VS: } 79.3 / 100 * 91.3 / 100 * 30 / 100 * 30 \mathrm{~kg}=6.516 \mathrm{~kg} \\
& \text { o } \text { ash: } 20.7 / 100 * 91.3 / 100 * 30 / 100 * 30 \mathrm{~kg}=1.701 \mathrm{~kg} \\
& \text { o } \text { energy: } 12.53 * 91.3 / 100 * 30 / 100 * 30 \mathrm{~kg}=102.96 \mathrm{MJ} \\
& \text { o } \\
& \text { C bio: } 37.3 / 100 * 91.3 / 100 * 30 / 100 * 30 \mathrm{~kg}=3.065 \mathrm{~kg}
\end{aligned}
$$

Figure S3: Material composition of the output of the "Material generation” process

\subsection{Energy generation}

The user defines a TotalAmount and the composition in terms of fractions (called "percent" here). Data about each fraction is taken in the library of material fractions.

For each material fraction,

\begin{tabular}{|c|c|c|c|c|c|}
\hline \multicolumn{6}{|c|}{ Energy generation } \\
\hline \multicolumn{6}{|c|}{ Energy generation: amount and fractions } \\
\hline \multicolumn{5}{|c|}{ Total amount (MJ) 30} & \\
\hline \multicolumn{6}{|c|}{$\square$ Include upstream impacts } \\
\hline \multicolumn{3}{|c|}{ Add fraction } & \multicolumn{3}{|c|}{ Normalise composition to $100 \%$} \\
\hline & Mass & Material $\mathrm{f}$ & ction & $\%$ & \\
\hline & $\nabla$ & Vegetable & ood waste & 70 & \\
\hline $\boldsymbol{x}$ & $\square$ & Office pap & & 30 & \\
\hline
\end{tabular}

- $\quad$ energy $(\mathrm{MJ})=\operatorname{percent}($ fraction $) / 100 *$ TotalAmount(MJ)

- $\quad \operatorname{vs}(\mathrm{kg})=\mathrm{VS} \%($ fraction $)) / 100 * \operatorname{percent}($ fraction $)) / 100 *$ TotalAmount $(\mathrm{MJ}) /$ energy $\%(\mathrm{MJ} / \mathrm{kg})$

- $\quad \operatorname{ash}(\mathrm{kg})=\operatorname{ash} \%($ fraction $) / 100 * \operatorname{percent}($ fraction $)) / 100 *$ TotalAmount(MJ) /energy\%(MJ/kg)

- $\quad$ water $(\mathrm{kg})=$ water $\%($ fraction $) / \mathrm{TS} \%($ fraction $) *$ percent $($ fraction $) / 100 *$ TotalAmount $(\mathrm{MJ})$ $/$ energy $\%(\mathrm{MJ} / \mathrm{kg})$

- for all other material properties: materialproperty $(\mathrm{kg})=$ materialproperty $\%($ fraction $)) / 100 *$ percent(fraction) $) / 100 *$ TotalAmount(MJ) / energy $\%(\mathrm{MJ} / \mathrm{kg})$

where e.g. "ash\%" is the ash content of the fraction in the library of material fractions.

Total wet weight and TS are calculated as usual, respectively as the sum of TS and water, and the sum of VS and ash.

Figure S4: Material transfer of a "Material generation” process and catalogue of material fractions 
Vegetable food waste is:

$$
\begin{array}{ll}
\text { - } & \text { Energy }=70 / 100 * 30 \mathrm{MJ}=21 \mathrm{MJ} \\
\text { - } & \mathrm{TS}=(70 / 100 * 30 \mathrm{MJ}) / 18.3 \mathrm{MJ} / \mathrm{kg}=1.148 \mathrm{~kg} \\
\text { - } & \mathrm{VS}=(70 / 100 * 30 \mathrm{MJ}) / 18.3 \mathrm{MJ} / \mathrm{kg} * 94.8 / 100=1.088 \mathrm{~kg} \\
\text { - } & \text { Ash }=(70 / 100 * 30 \mathrm{MJ}) / 18.3 \mathrm{MJ} / \mathrm{kg} * 5.2 / 100=0.0597 \mathrm{~kg} \\
\text { - } & \text { Water }=76.99 / 23.01 * 70 / 100 * 30 \mathrm{MJ} / 18.3 \mathrm{MJ} / \mathrm{kg}=3.841 \mathrm{~kg}
\end{array}
$$

Because the tickbox "Mass" is unticked for "Office paper", this fraction has only:

- $\quad$ Energy $=30 / 100 * 30 \mathrm{MJ}=9 \mathrm{MJ}$

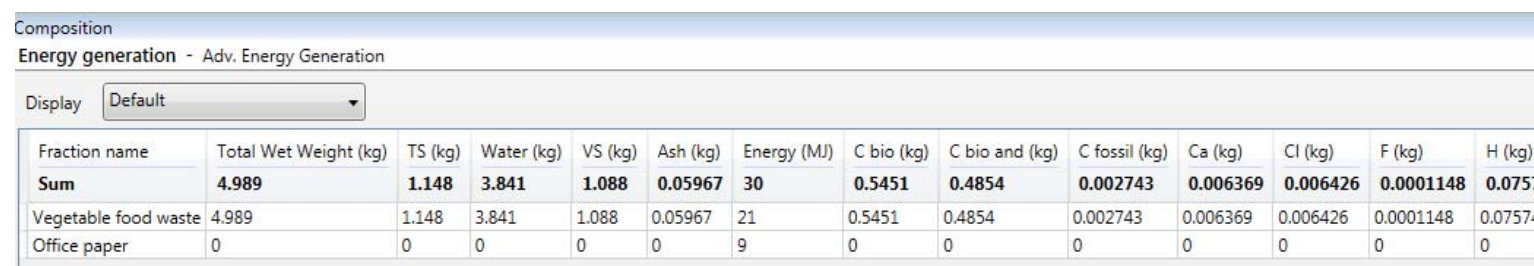

Figure S5: Material composition of the output of the "Material generation" process

\subsection{Material generation - manual}

In this process, the user defines the number of fractions and the amounts of material properties directly. So the only thing to calculate is "Total solids (TS)" equal to VS+ash, and "Total wet weight (TWW)" equal to TS+waterContent.

\subsection{Basic}

Output $=$ input.

\subsection{Substance transfer per fraction}

The number of outputs is determined by the user. The user can define the name of the output by right clicking on the column header in the table "Material transfer". Each output has the same material fractions as the input (in terms of numbers and names).

For each output, for each fraction, for each material property,

\section{outputNumber.fraction.property = input.fraction.property*TC(property, fraction, outputNumber)/100}

where TC is a transfer coefficient input by the user in the table of "Material transfer" in an output column, in a material fraction line.

- If the fraction doesn't exist in the table, the calculation uses the "default" line".

- Also, by default, all TC are equal to zero in newly-created output columns.

- For each fraction line, the TC to the last output (called "Residues") is defined as 100 minus the TC of the other columns, so when the other TC are not defined, $100 \%$ of the material property go to the output "Residues".

- If a "degradation" output is added, a column "Degradation" is added which works like any other column, but a special cross-output is displayed and this output cannot be connected to any process. Note that only one degradation output can be created. 
Example: For an input of $30 \mathrm{~kg}$ of $70 \%$ vegetable food waste and $30 \%$ office paper, we have the input flow specified in Table S1.

Table S1: Material composition of the input flow

\begin{tabular}{|c|c|c|c|c|c|c|c|c|c|c|c|c|c|c|c|c|c|c|c|c|c|c|}
\hline $\begin{array}{l}\text { Fracti } \\
\text { on } \\
\text { name }\end{array}$ & $\begin{array}{l}\text { Total } \\
\text { Wet } \\
\text { Weight } \\
\text { (kg) }\end{array}$ & $\begin{array}{l}\text { TS } \\
\text { (kg } \\
\text { ) }\end{array}$ & $\begin{array}{l}\text { Wa } \\
\text { ter } \\
(\mathrm{kg} \\
)\end{array}$ & $\begin{array}{l}\text { VS } \\
\text { (kg } \\
\text { ) }\end{array}$ & $\begin{array}{l}\text { Ash } \\
\text { (kg } \\
\text { ) }\end{array}$ & $\begin{array}{l}\text { Ener } \\
\text { gy } \\
(\mathbf{M J})\end{array}$ & $\begin{array}{l}\text { C } \\
\text { bio } \\
\text { (kg } \\
)\end{array}$ & $\begin{array}{l}\text { C bio } \\
\text { and } \\
(\mathrm{kg})\end{array}$ & $\begin{array}{l}\text { C } \\
\text { fossil } \\
(\mathbf{k g})\end{array}$ & $\begin{array}{l}\text { Ca } \\
\text { (kg } \\
\text { ) }\end{array}$ & $\begin{array}{l}\mathrm{Cl} \\
(\mathrm{kg} \\
)\end{array}$ & $\begin{array}{l}\text { F } \\
\text { (kg } \\
\text { ) }\end{array}$ & $\begin{array}{l}\mathrm{H} \\
(\mathrm{kg} \\
)\end{array}$ & $\begin{array}{l}\mathrm{K} \\
(\mathrm{kg} \\
)\end{array}$ & $\begin{array}{l}\mathrm{N} \\
(\mathrm{kg} \\
)\end{array}$ & $\begin{array}{l}\mathrm{Na} \\
\text { (kg } \\
\text { ) }\end{array}$ & $\begin{array}{l}\text { O } \\
(\mathrm{kg} \\
)\end{array}$ & $\begin{array}{l}\mathbf{P} \\
(\mathrm{kg} \\
)\end{array}$ & $\begin{array}{l}\text { S } \\
(\mathbf{k g} \\
)\end{array}$ & $\begin{array}{l}\text { Ag } \\
\text { (kg } \\
\text { ) }\end{array}$ & $\begin{array}{l}\begin{array}{l}\text { Al } \\
(\mathrm{kg}\end{array} \\
\text { ) }\end{array}$ & $\begin{array}{l}\begin{array}{l}\text { As } \\
\text { (kg }\end{array} \\
\text { ) }\end{array}$ \\
\hline $\begin{array}{l}\text { Veget } \\
\text { able } \\
\text { food } \\
\text { waste }\end{array}$ & 21 & $\begin{array}{l}4.8 \\
3\end{array}$ & $\begin{array}{l}16 . \\
17\end{array}$ & $\begin{array}{l}4.5 \\
79\end{array}$ & $\begin{array}{l}0.2 \\
512\end{array}$ & $\begin{array}{l}88.38 \\
9\end{array}$ & $\begin{array}{l}2.2 \\
94\end{array}$ & 2.043 & $\begin{array}{l}0.01 \\
154\end{array}$ & $\begin{array}{l}0.0 \\
268 \\
1\end{array}$ & $\begin{array}{l}0.0 \\
270 \\
5\end{array}$ & $\begin{array}{l}0.0 \\
004 \\
83\end{array}$ & $\begin{array}{l}0.3 \\
188\end{array}$ & $\begin{array}{l}0.0 \\
613 \\
4\end{array}$ & $\begin{array}{l}0.0 \\
917 \\
7\end{array}$ & $\begin{array}{l}0.0 \\
150 \\
7\end{array}$ & $\begin{array}{l}1.9 \\
08\end{array}$ & $\begin{array}{l}0.0 \\
111 \\
6\end{array}$ & $\begin{array}{l}0.0 \\
088 \\
87\end{array}$ & 0 & $\begin{array}{l}0.0 \\
049 \\
75\end{array}$ & $\begin{array}{l}1.2 \\
65 \mathrm{E} \\
-06\end{array}$ \\
\hline $\begin{array}{l}\text { Office } \\
\text { paper }\end{array}$ & 9.005 & $\begin{array}{l}8.2 \\
17\end{array}$ & $\begin{array}{l}0.7 \\
875\end{array}$ & $\begin{array}{l}6.5 \\
16\end{array}$ & $\begin{array}{l}1.7 \\
01\end{array}$ & 103 & $\begin{array}{l}3.0 \\
65\end{array}$ & 1.693 & $\begin{array}{l}0.01 \\
545\end{array}$ & $\begin{array}{l}0.6 \\
385\end{array}$ & $\begin{array}{l}0.0 \\
057 \\
52\end{array}$ & $\begin{array}{l}0.0 \\
008 \\
217\end{array}$ & $\begin{array}{l}0.4 \\
109\end{array}$ & $\begin{array}{l}0.0 \\
009 \\
696\end{array}$ & $\begin{array}{l}0.0 \\
082 \\
17\end{array}$ & $\begin{array}{l}0.0 \\
063 \\
6\end{array}$ & $\begin{array}{l}3.0 \\
16\end{array}$ & $\begin{array}{l}0.0 \\
003 \\
139\end{array}$ & $\begin{array}{l}0.0 \\
052 \\
84\end{array}$ & 0 & $\begin{array}{l}0.0 \\
107 \\
6\end{array}$ & $\begin{array}{l}1.7 \\
5 \mathrm{E}- \\
06\end{array}$ \\
\hline
\end{tabular}

We bring this to a "substance transfer per fraction" process with transfer coefficients specified only for VS and $\mathrm{Hg}$ :

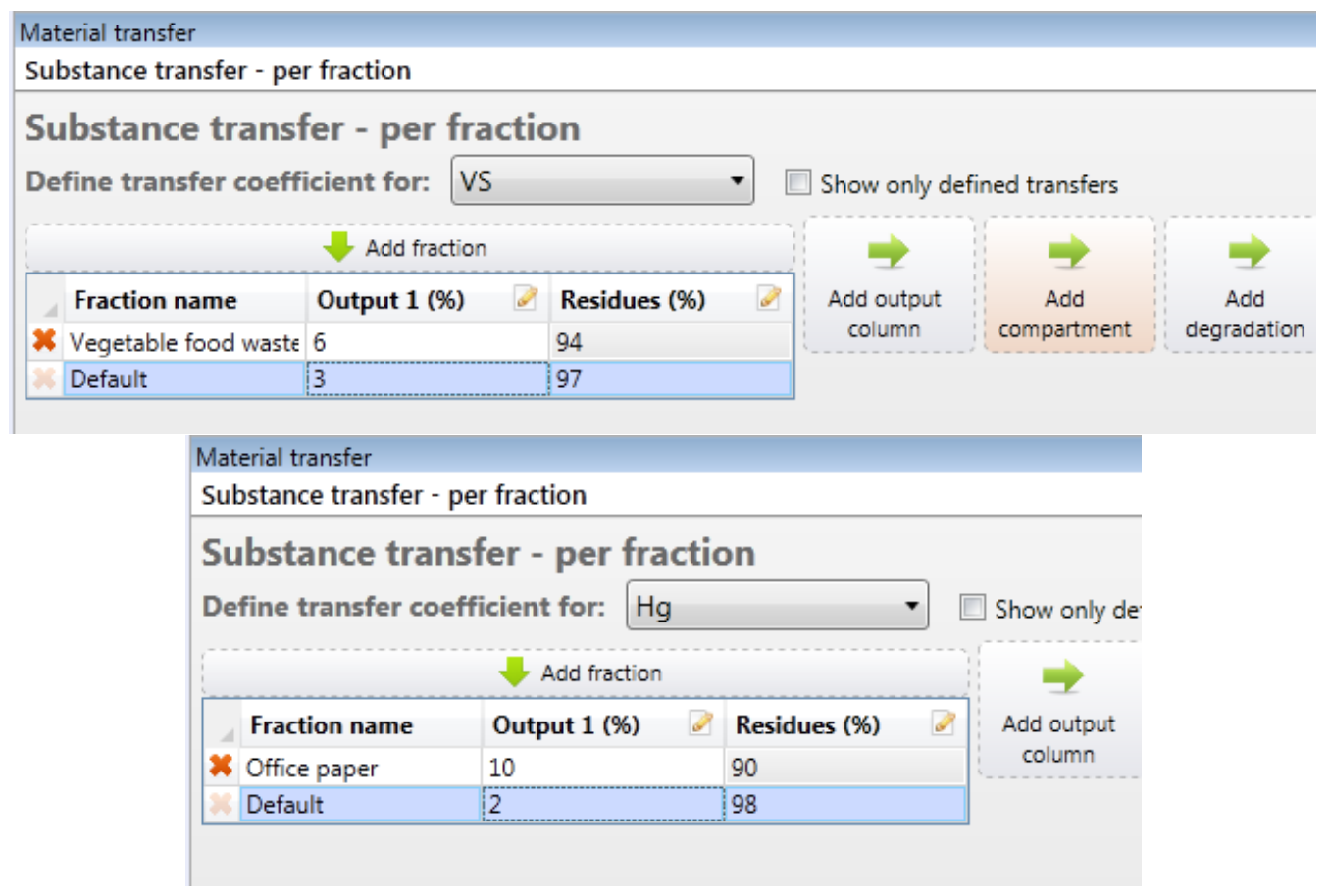

Figure S6: Material transfer for the "substance transfer per fraction” process

Output1 has:

- for fraction "vegetable food waste":

o VS: $4.579 \mathrm{~kg} * 6 / 100=0.275 \mathrm{~kg}$

o Hg: $9.66 \mathrm{E}-8 \mathrm{~kg} * 2 / 100=1.932 \mathrm{E}-9 \mathrm{~kg}$

o all others: 0

- for fraction "office paper":

o VS: $6.516 \mathrm{~kg} * 3 / 100=0.195 \mathrm{~kg}$

o Hg: $2.925 \mathrm{E}-7 \mathrm{~kg} * 10 / 100=2.925 \mathrm{E}-8 \mathrm{~kg}$

o all others: 0

Output "residues" has:

- for fraction "vegetable food waste":

o VS: $4.579 \mathrm{~kg} * 94 / 100=4.304 \mathrm{~kg}$ 
o $\quad \mathrm{Hg}: 9.66 \mathrm{E}-8 \mathrm{~kg} * 98 / 100=9.47 \mathrm{E}-8 \mathrm{~kg}$

0 all others equal to the fraction "vegetable food waste" in the input

- for fraction "office paper":

o VS: $6.516 \mathrm{~kg} * 97 / 100=6.321 \mathrm{~kg}$

o $\mathrm{Hg}: 2.925 \mathrm{E}-7 \mathrm{~kg} * 90 / 100=2.632 \mathrm{E}-7 \mathrm{~kg}$

0 all others equal to the fraction "office paper" in the input

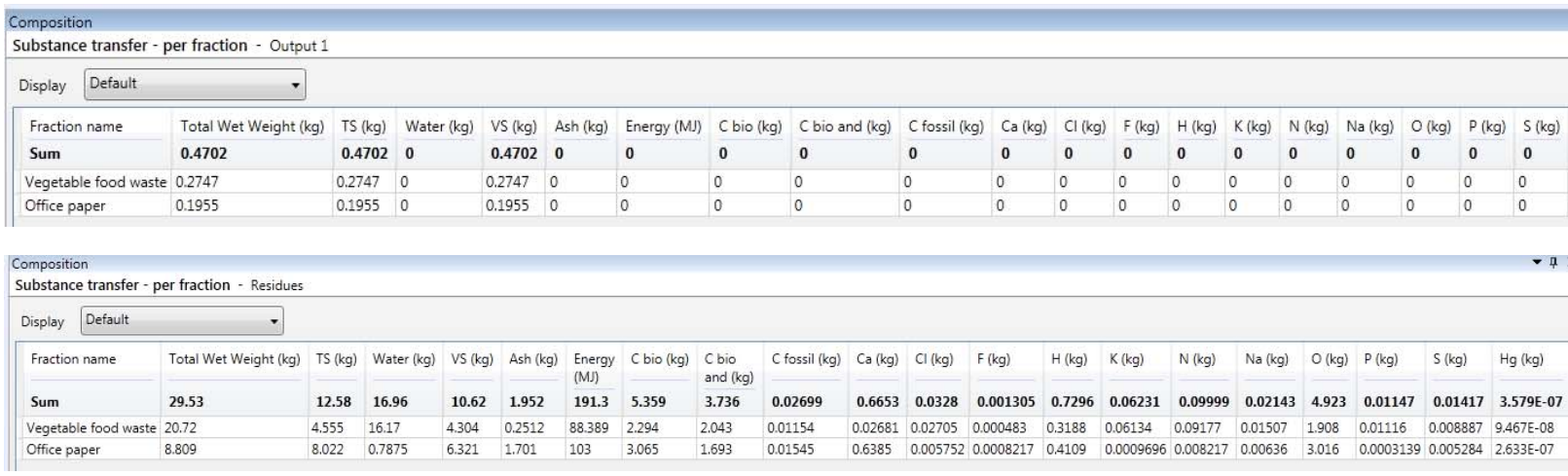

Figure S7: Material composition of output1 and residues

\subsection{Substance transfer default}

This process is very similar to "substance transfer per fraction" except that it doesn't allow the user to specify different TC for different material fractions. The number of outputs is determined by the user. The user can define the name of the output by right clicking on the column header in the table "Material transfer". Each output has the same material fractions as the input (in terms of numbers and names).

For each output, for each fraction, for each material property,

\section{outputNumber.fraction.property = input.fraction.property*TC $($ property, outputNumber $) / 100$}

where TC is a transfer coefficient input by the user in the table of "Material transfer" in an output column.

- It is the same transfer coefficients for all fractions.

- Also, by default, all TC are equal to zero in newly-created output columns.

- The default output is the "Degradation" output which cannot be removed and which cannot be connected to any process.

- The TC to the last output (called "Degradation") is defined as 100 minus the TC of the other columns, so when the other TC are not defined, $100 \%$ of the material property go to the output "Degradation".

The input composition is specified in Table $\mathrm{S} 1$ and this input is brought this to the "substance transfer default" process specified in Figure S8. 


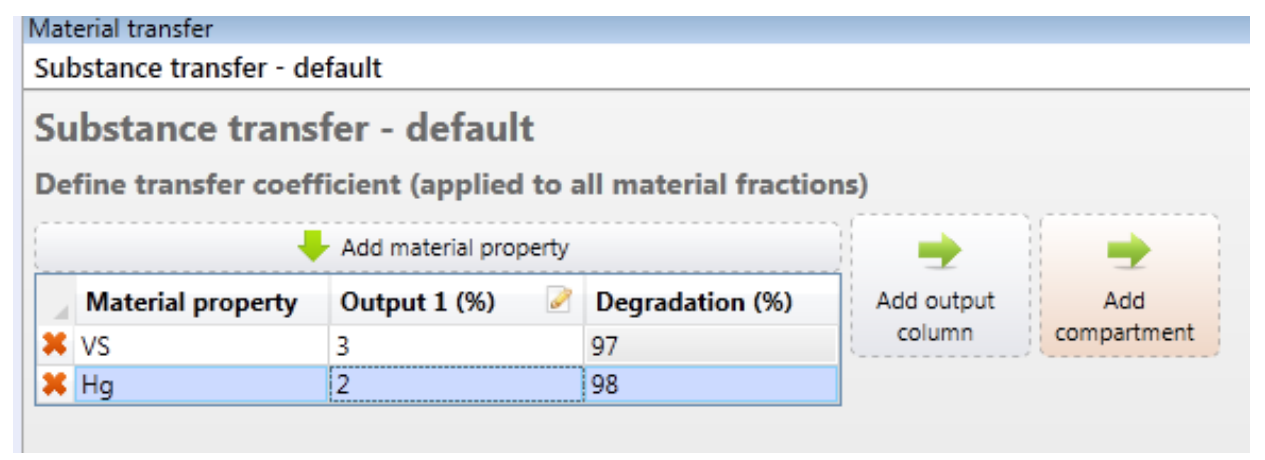

Figure S8: Material transfer for the "substance transfer default” process

Output1 has:

- for fraction "vegetable food waste":

$$
\begin{array}{ll}
\text { o } & \text { VS: } 4.579 \mathrm{~kg}^{*} 3 / 100=0.137 \mathrm{~kg} \\
\text { o } & \mathrm{Hg}: 9.66 \mathrm{E}-8 \mathrm{~kg} * 2 / 100=1.932 \mathrm{E}-9 \mathrm{~kg} \\
\text { o } & \text { all others: } 0
\end{array}
$$

- for fraction "office paper":

\begin{tabular}{|c|c|c|c|c|c|c|c|c|c|c|c|c|c|c|c|c|c|c|c|c|c|}
\hline \multicolumn{22}{|c|}{$\begin{array}{l}\text { Composition } \\
\text { Substance transfer - default - Output } 1\end{array}$} \\
\hline Display & Default & $\checkmark$ & & & & & & & & & & & & & & & & & & & \\
\hline \multicolumn{2}{|c|}{ Fraction name } & Total Wet Weight $(\mathrm{kg})$ & TS $(\mathrm{kg})$ & Water (kg) & VS $(\mathrm{kg})$ & Ash (kg) & Energy (MJ) & C bio $(\mathrm{kg})$ & C bio and $(\mathrm{kg})$ & C fossil (kg) & $\mathrm{Ca}(\mathrm{kg})$ & $\mathrm{Cl}(\mathrm{kg})$ & $F(\mathrm{~kg})$ & $H(\mathrm{~kg})$ & $\mathrm{K}(\mathrm{kg})$ & $\mathrm{N}(\mathrm{kg})$ & $\mathrm{Na}(\mathrm{kg})$ & $O(\mathrm{~kg})$ & $P(\mathrm{~kg})$ & $\mathrm{S}(\mathrm{kg})$ & $\mathrm{Hg}(\mathrm{kg})$ \\
\hline \multicolumn{2}{|c|}{ Sum } & 0.3328 & 0.3328 & 0 & 0.3328 & 0 & 0 & 0 & 0 & 0 & 0 & 0 & 0 & 0 & 0 & 0 & 0 & 0 & 0 & 0 & $7.783 \mathrm{E}-09$ \\
\hline \multicolumn{2}{|c|}{ Vegetable food waste } & 0.1374 & 0.1374 & 0 & 0.1374 & 0 & 0 & 0 & 0 & 0 & 0 & 0 & 0 & 0 & 0 & 0 & 0 & 0 & 0 & 0 & $1.932 E-09$ \\
\hline \multicolumn{2}{|c|}{ Office paper } & 0.1955 & 0.1955 & 0 & 0.1955 & 0 & 0 & 0 & 0 & 0 & 0 & 0 & 0 & 0 & 0 & 0 & 0 & 0 & 0 & 0 & $5.851 \mathrm{E}-09$ \\
\hline
\end{tabular}

$$
\begin{array}{ll}
\text { o } & \text { VS: } 6.516 \mathrm{~kg} * 3 / 100=0.195 \mathrm{~kg} \\
\text { o } & \text { Hg: } 2.925 \mathrm{E}-7 \mathrm{~kg} * 2 / 100=5.85 \mathrm{E}-9 \mathrm{~kg} \\
\text { o } & \text { all others: } 0
\end{array}
$$

And the output "Degradation" cannot be viewed.

Figure S9: Material composition of output1

\subsection{Mass transfer to outputs}

This process is similar to "substance transfer per fraction" but each output gets a transfer coefficient for the total mass, not specifically for each material property. The number of outputs is determined by the user. The user can define the name of the output by right clicking on the column header in the table "Material transfer". Each output has the same material fractions as the input (in terms of numbers and names).

For each output, for each fraction, for each material property,

outputNumber.fraction.property = input.fraction.property*TC(fraction, outputNumber)/100

where TC is a transfer coefficient input by the user in the table of "Material transfer" in an output column, in a material fraction line.

- If the fraction doesn't exist in the table, the calculation uses the "default" line".

- Also, by default, all TC are equal to zero in newly-created output columnss.

- For each fraction line, the TC to the last output (called "Residues") is defined as 100 minus the TC of the other columns, so when the other TC are not defined, $100 \%$ of the material property go to the output "Residues".

The input composition is specified in Table $\mathrm{S} 1$ and this input is brought this to a "mass transfer" process with transfer coefficients specified in Figure S10. 


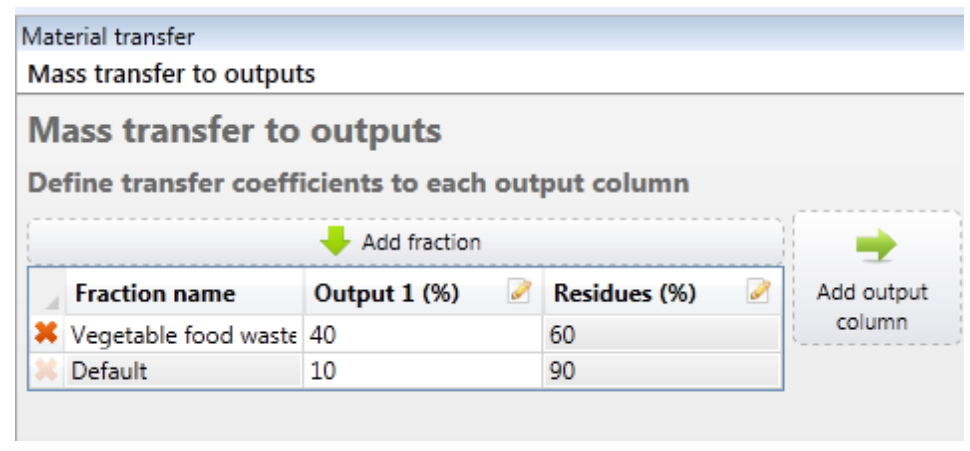

Figure S10: Material transfer for the "substance transfer default” process

Output1 has:

- for fraction "vegetable food waste": $40 \%$ of input of "vegetable food waste"

- for fraction "office paper": $10 \%$ of input of "office paper".

Output "residues" has:

- for fraction "vegetable food waste": $60 \%$ of input of "vegetable food waste"

- for fraction "office paper": $90 \%$ of input of "office paper".

\begin{tabular}{|c|c|c|c|c|c|c|c|c|c|c|c|c|c|c|c|}
\hline \multirow{2}{*}{\multicolumn{16}{|c|}{$\begin{array}{l}\text { Composition } \\
\text { Mass transfer to outputs - Output } 1\end{array}$}} \\
\hline & & & & & & & & & & & & & & & \\
\hline Display & \multicolumn{15}{|c|}{ Default } \\
\hline \multicolumn{2}{|c|}{ Fraction name } & Total Wet Weight (kg) & TS (kg) & Water (kg) & VS (kg) & Ash (kg) & Energy (MJ) & C bio (kg) & $\mathrm{C}$ bio and $(\mathrm{kg})$ & C fossil $(\mathrm{kg})$ & $\mathrm{Ca}(\mathrm{kg})$ & $\mathrm{Cl}(\mathrm{kg})$ & $F(\mathrm{~kg})$ & $H(k g)$ & $\mathrm{K}(\mathrm{kg})$ \\
\hline \multicolumn{2}{|c|}{ Sum } & 9.3 & 2.754 & 6.546 & 2.483 & 0.2706 & 45.65 & 1.224 & 0.9865 & 0.006162 & 0.07457 & 0.01139 & 0.0002754 & 0.1686 & $\begin{array}{ll}86 & 0.024\end{array}$ \\
\hline \multicolumn{2}{|c|}{ Vegetable food waste } & 8.399 & 1.932 & 6.467 & 1.832 & 0.1005 & 35.36 & 0.9177 & 0.8172 & 0.004617 & 0.01072 & 0.01082 & 0.0001932 & 0.1275 & $5 \quad 0.0245$ \\
\hline \multicolumn{2}{|c|}{ Office paper } & 0.9005 & 0.8217 & 0.07875 & 0.6516 & 0.1701 & 10.3 & 0.3065 & 0.1693 & 0.001545 & 0.06385 & 0.0005752 & $28.217 \mathrm{E}-05$ & 0.04109 & $.099 .696 \mathrm{E}$ \\
\hline \multirow{2}{*}{\multicolumn{16}{|c|}{$\begin{array}{l}\text { Composition } \\
\text { Mass transfer to outputs - Residues }\end{array}$}} \\
\hline & & & & & & & & & & & & & & & \\
\hline Display & \multicolumn{15}{|c|}{ Default } \\
\hline \multicolumn{2}{|c|}{ Fraction name } & Total Wet Weight (kg) & TS $(\mathrm{kg})$ & Water $(\mathrm{kg})$ & VS (kg) & Ash (kg) & Energy (MJ) & $\mathrm{C}$ bio $(\mathrm{kg})$ & $\mathrm{C}$ bio and $(\mathrm{kg})$ & C fossil $(\mathrm{kg})$ & $\mathrm{Ca}(\mathrm{kg})$ & $\mathrm{Cl}(\mathrm{kg})$ & $\mathrm{F}(\mathrm{kg})$ & $H(\mathrm{~kg})$ & $\mathrm{K}(\mathrm{kg})$ \\
\hline \multicolumn{2}{|c|}{ Sum } & 20.7 & 10.29 & 10.41 & 8.612 & 1.682 & 145.7 & 4.135 & 2.749 & 0.02083 & 0.5907 & 0.02141 & 0.001029 & 0.561 & 0.03768 \\
\hline \multicolumn{2}{|c|}{ Vegetable food waste } & 12.6 & 2.898 & 9.701 & 2.747 & 0.1507 & 53.03 & 1.377 & 1.226 & 0.006926 & 0.01608 & 0.01623 & 0.0002898 & 0.1913 & 0.0368 \\
\hline \multicolumn{2}{|c|}{ Office paper } & 8.104 & 7.395 & 0.7088 & 5.864 & 1.531 & 92.66 & 2.758 & 1.523 & 0.0139 & 0.5746 & 0.005177 & 0.0007395 & 0.3698 & 0.0008726 \\
\hline
\end{tabular}

Figure S11: Material composition of output1 and residues

\subsection{Change of energy content}

There is one output with all material properties equal to the input, except for the output's energy content which is recalculated based on the following formula.

The principle is that the "energy content" is equal to the energy content of the input added to amounts depending on selected material properties. For example, the energy content is decreased of $2 \mathrm{MJ}$ per $\mathrm{kg}$ of water content and decreased of $0.1 \mathrm{MJ}$ per $\mathrm{kg}$ of Ash.

For each material fraction,

\section{output.fraction.energycontent (MJ) = input.fraction.energycontent(MJ) + sumForAllProperties [ value(fraction, slectedProperty)* input.fraction.selectedProperty ]}

where percent is the value given by the user between 0 and 100, which can be specified for each material fraction.

The input composition is specified in Table $\mathrm{S} 1$ and this input is brought this to a "change of energy content" process where the energy content is decreased of $3 \mathrm{MJ}$ per $\mathrm{kg}$ of water content for all fraction except for "vegetable food waste" for which it is 2, and it is also decreased of $0.1 \mathrm{MJ}$ per kg of Ash for all fractions. 

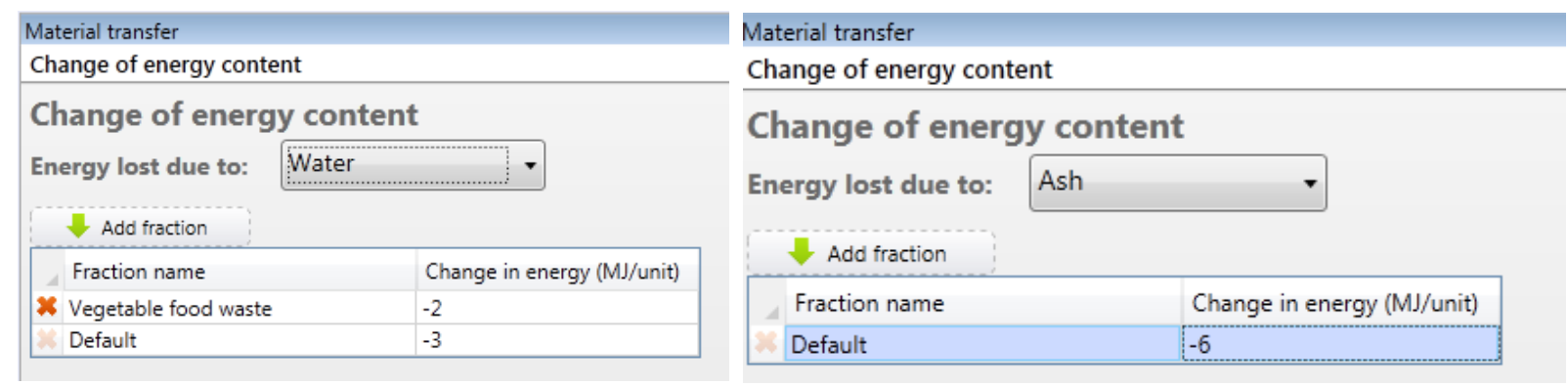

Figure S12: Material transfer of "Change of energy content"

So the calculation of the energy content is:

- for vegetable food waste, energycontent $(\mathrm{kg})=$ energycontent $(\mathrm{kg})+(-2)^{*} \mathrm{water}(\mathrm{kg})+(-0.1)$ $* \operatorname{ash}(\mathrm{kg})=88.389+(-2)^{*} 16.17+(-6) * 0.2512=54.54 \mathrm{MJ}$

- for office paper, energycontent $(\mathrm{kg})=$ energycontent $(\mathrm{kg})+(-3) * \mathrm{water}(\mathrm{kg})+(-0.1) * \operatorname{ash}(\mathrm{kg})=$ $103+(-3) * 0.7875+(-6) * 1.701=90.43 \mathrm{MJ}$

\begin{tabular}{|c|c|c|c|c|c|c|c|c|c|c|c|c|c|c|c|}
\hline \multirow{2}{*}{\multicolumn{16}{|c|}{$\begin{array}{l}\text { Composition } \\
\text { Change of energy content - Rejects }\end{array}$}} \\
\hline & & & & & & & & & & & & & & & \\
\hline Display & \multicolumn{15}{|c|}{ Default $\quad-$} \\
\hline \multicolumn{2}{|c|}{ Fraction name } & Total Wet Weight $(\mathrm{kg})$ & TS $(\mathrm{kg})$ & Water $(\mathrm{kg})$ & VS (kg) & Ash $(\mathrm{kg})$ & Energy (MJ) & C bio $(\mathrm{kg})$ & $\mathrm{C}$ bio and $(\mathrm{kg})$ & C fossil $(\mathrm{kg})$ & $\mathrm{Ca}(\mathrm{kg})$ & $\mathrm{Cl}(\mathrm{kg})$ & $\mathrm{F}(\mathrm{kg})$ & $H(\mathrm{~kg})$ & $K(\mathrm{~kg})$ \\
\hline \multicolumn{2}{|c|}{ Sum } & 30 & 13.047 & 16.96 & 11.09 & 1.952 & 144.9 & 5.359 & 3.736 & 0.02699 & 0.6653 & 0.0328 & 0.001305 & 0.7296 & 0.06231 \\
\hline \multicolumn{2}{|c|}{ Vegetable food waste } & 21 & 4.83 & 16.17 & 4.579 & 0.2512 & 54.55 & 2.294 & 2.043 & 0.01154 & 0.02681 & 0.02705 & 0.000483 & 0.3188 & 0.06134 \\
\hline \multicolumn{2}{|c|}{ Office paper } & 9.005 & 8.217 & 0.7875 & 6.516 & 1.701 & 90.39 & 3.065 & 1.693 & 0.01545 & 0.6385 & 0.005752 & 0.0008217 & 0.4109 & 0.0009696 \\
\hline
\end{tabular}

Figure S13: Material composition of the output

\subsection{No output}

No output.

\subsection{Water content}

There is one output with all material properties equal to the input, except for the output's water content which is recalculated based on the following formula.

For each material fraction,

output.fraction.water $(\mathbf{k g})=$ input.fraction.TS $(\mathrm{kg}) *($ percent(fraction) / (100-percent(fraction)) )

where percent is the value given by the user between 0 and 100 , which can be specified for each material fraction.

Of course the Total Wet Weight is changed, as it calculated as the sum of water and TS.

The input composition is specified in Table $\mathrm{S} 1$ and this input is brought this to a "water content" process and say that the water content should be $50 \%$ for vegetable food waste and $10 \%$ by default. 


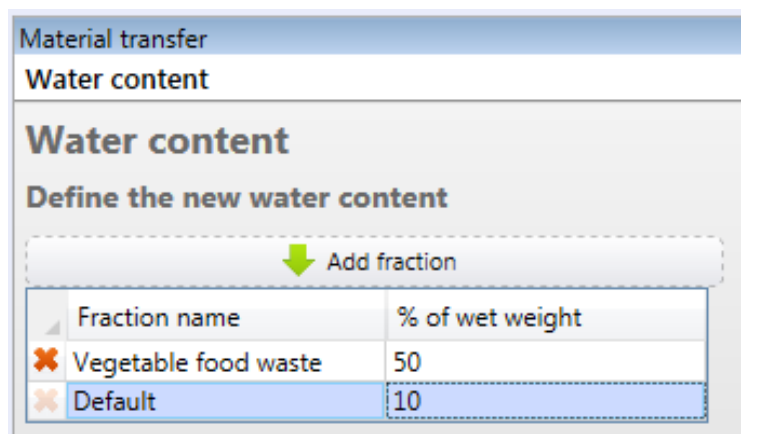

Figure S14: Material transfer of "Water content"

So the calculation of the water content is:

- $\quad$ for vegetable food waste, water $(\mathrm{kg})=\mathrm{TS}(\mathrm{kg}) *(50 /(100-50))=4.83 \mathrm{~kg} *(50 /(100-50))=4.83$ $\mathrm{kg}$

- $\quad$ for office paper, water $(\mathrm{kg})=\mathrm{TS}(\mathrm{kg}) *(10 /(100-10))=8.217 \mathrm{~kg} *(10 /(100-10))=0.913 \mathrm{~kg}$

\begin{tabular}{|c|c|c|c|c|c|c|c|c|c|c|c|c|c|c|c|c|c|}
\hline \multirow{2}{*}{\multicolumn{18}{|c|}{$\begin{array}{l}\text { Composition } \\
\text { Water content - Output }\end{array}$}} \\
\hline & & & & & & & & & & & & & & & & & \\
\hline Display & \multicolumn{17}{|c|}{ Default } \\
\hline \multicolumn{2}{|c|}{ Fraction name } & Total Wet Weight $(\mathrm{kg})$ & TS $(\mathrm{kg})$ & Water $(\mathrm{kg})$ & VS (kg) & Ash $(\mathrm{kg})$ & Energy (MJ) & C bio $(\mathrm{kg})$ & $\mathrm{C}$ bio and $(\mathrm{kg})$ & C fossil (kg) & $\mathrm{Ca}_{a}(\mathrm{~kg})$ & $\mathrm{Cl}(\mathrm{kg})$ & $\mathrm{F}(\mathrm{kg})$ & $H(\mathrm{~kg})$ & $\mathrm{K}(\mathrm{kg})$ & $\mathrm{N}(\mathrm{kg})$ & $\mathrm{Na}(\mathrm{k}$ \\
\hline \multicolumn{2}{|l|}{ Sum } & 18.79 & 13.047 & 5.743 & 11.09 & 1.952 & 191.3 & 5.359 & 3.736 & 0.02699 & 0.6653 & 0.0328 & 0.001305 & 0.7296 & 0.06231 & 0.09999 & 0.02 \\
\hline \multicolumn{2}{|c|}{ Vegetable food waste } & 9.66 & 4.83 & 4.83 & 4.579 & 0.2512 & 88.389 & 2.294 & 2.043 & 0.01154 & 0.02681 & 0.02705 & 0.000483 & 0.3188 & 0.06134 & 0.09177 & 0.015 \\
\hline \multicolumn{2}{|c|}{ Office paper } & 9.13 & 8.217 & 0.913 & 6.516 & 1.701 & 103 & 3.065 & 1.693 & 0.01545 & 0.6385 & 0.005752 & 0.0008217 & 0.4109 & 0.0009696 & 0.008217 & 0.006 \\
\hline
\end{tabular}

Figure S15: Material composition of the output

\subsection{Addition of substances}

There is one output with all material properties equal to the input, except for the material properties selected in the table of Material transfer. The calculations depend on which radio button has been selected by the user.

For each material property in the table, for each material fraction,

- if "solid material":

output.fraction.selectedMaterialProperty = input.fraction.selectedMaterialProperty + amount(selectedMaterialProperty)*input.fraction.TotalWetWeight $/ 10^{\wedge} 6$

- if "gas":

output.fraction.selectedMaterialProperty $=$ input.fraction.selectedMaterialProperty + amount(selectedMaterialProperty)* (input.fraction.ch $4+$ input.fraction.co2) $/ 10 \wedge 3$

- if "liquid":

output.fraction.selectedMaterialProperty $=$ input.fraction.selectedMaterialProperty + amount(selectedMaterialProperty)*input.fraction.WaterContent $/ 10 \wedge 6$

- if "energy":

output.fraction.selectedMaterialProperty = input.fraction.selectedMaterialProperty + amount(selectedMaterialProperty)*input.fraction.EnergyContent $/ 10^{\wedge} 3$

where "amount" is the value given by the user in the table, for the specific material property.

The input composition is specified in Table S1 and this input is brought this to a "addition of substances" process with in the table "Hg; 2 ". 


\section{If we select "solid":}

\begin{tabular}{|c|c|c|}
\hline \multicolumn{3}{|c|}{ Material transfer } \\
\hline \multicolumn{3}{|c|}{ Addition of substances } \\
\hline \multicolumn{3}{|c|}{ Addition of substances } \\
\hline \multicolumn{3}{|c|}{ Define substances added to flow } \\
\hline \multicolumn{2}{|c|}{ Add substance } & Add substance based on: \\
\hline Substance name & Amount & solld materlal ( $\mathrm{g} / \mathrm{ton}$, based on total wet weignt) \\
\hline \multirow[t]{2}{*}{$\mathbf{N H g}$} & 0.02 & liquid (mg/L, based on water content) \\
\hline & & energy ( $g / \mathrm{MJ}$, based on energy content) \\
\hline
\end{tabular}

Figure S16: Material transfer of "Addition of substance" in the case of "solid" selection

The output is the same as the input except for $\mathrm{Hg}$, which is:

- for vegetable food waste: $9.66 \mathrm{E}-8 \mathrm{~kg}+0.02 \mathrm{~g} / 10^{\wedge} 6 \mathrm{~g} * 21 \mathrm{~kg}=0.966 \mathrm{E}-7 \mathrm{~kg}+4.2 \mathrm{E}-7 \mathrm{~kg}=5.16 \mathrm{E}-7 \mathrm{~kg}$.

- for office paper: $2.925 \mathrm{E}-7 \mathrm{~kg}+0.02 \mathrm{~g} / 10^{\wedge} 6 \mathrm{~g} * 9.005 \mathrm{~kg}=2.925 \mathrm{E}-7 \mathrm{~kg}+1.801 \mathrm{E}-7 \mathrm{~kg}=4.726 \mathrm{E}-7 \mathrm{~kg}$.

$>$ If we select "gas":

The output is the same as the input including for $\mathrm{Hg}$ as $\mathrm{CO} 2$ and $\mathrm{CH} 4$ are zero. To see the calculation, we add an anaerobic digestion process with yield of $10 \%$ for all fractions (Figure S17).

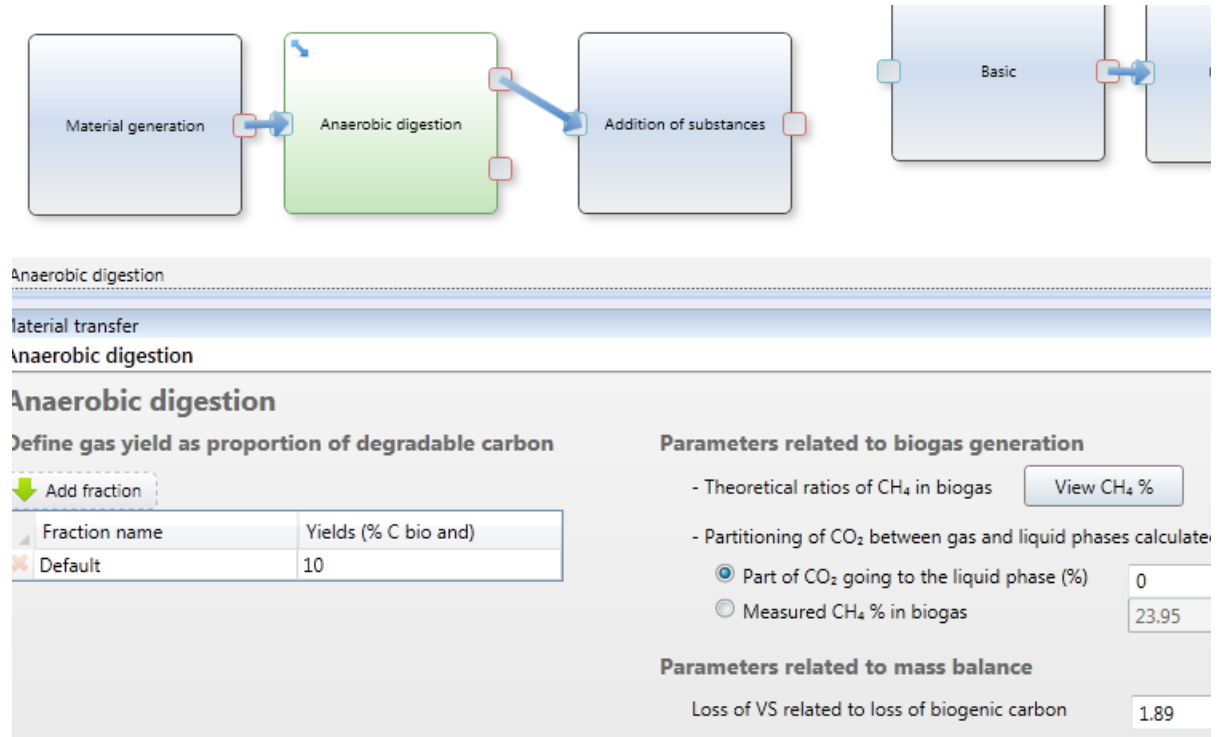

Figure S17: Material transfer of “Anaerobic digestion” process needed in the case of "gas" selection As explained in subsection 16, the output of this AD process is as shown in Figure S18.

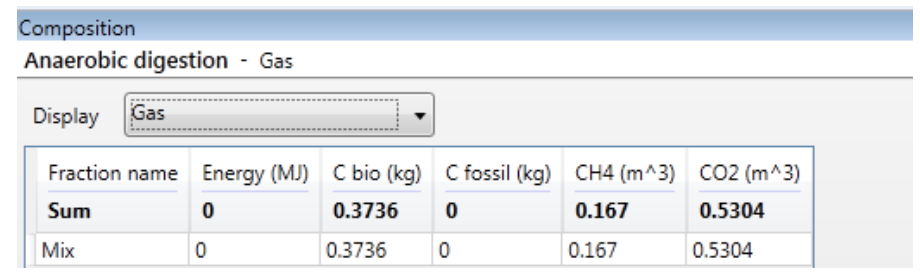

Figure S18: Material composition of the output of the AD process (input of "addition of substance")

So when we $0.02 \mathrm{~g} / \mathrm{m} 3$ of biogas, the amount of $\mathrm{Hg}$ in the fraction mix is:

$0.02 \mathrm{~g} *(0.167 \mathrm{m3}+0.5304 \mathrm{~m} 3) / 10^{\wedge} 3 \mathrm{~g}=1.395 \mathrm{E}-5 \mathrm{~kg}$. 


\section{If we select "liquid":}

The output is the same as the input except for $\mathrm{Hg}$, which is:

- for vegetable food waste: $9.66 \mathrm{E}-8 \mathrm{~kg}+0.02 \mathrm{mg} / 10^{\wedge} 6 \mathrm{~g} * 16.17 \mathrm{~kg}=0.966 \mathrm{E}-7 \mathrm{~kg}+3.234 \mathrm{E}-7 \mathrm{~kg}=4.2 \mathrm{E}-7$ $\mathrm{kg}$.

- for office paper: $2.925 \mathrm{E}-7 \mathrm{~kg}+0.02 \mathrm{mg} / 10^{\wedge} 6 \mathrm{~g} * 0.7875 \mathrm{l}=2.925 \mathrm{E}-7 \mathrm{~kg}+0.1575 \mathrm{E}-7 \mathrm{~kg}=3.0825 \mathrm{E}-7 \mathrm{~kg}$.

\section{$>$ If we select "energy":}

The output is the same as the input except for $\mathrm{Hg}$, which is:

- for vegetable food waste: $9.66 \mathrm{E}-8 \mathrm{~kg}+0.02 \mathrm{~g} / 10^{\wedge} 3 \mathrm{~g} * 88.389 \mathrm{MJ}=0.966 \mathrm{E}-7 \mathrm{~kg}+1.77 \mathrm{E}-3 \mathrm{~kg}=1.77 \mathrm{E}-3$ $\mathrm{kg}$.

- for office paper: $2.925 \mathrm{E}-7 \mathrm{~kg}+0.02 \mathrm{~g} / 10^{\wedge} 3 \mathrm{~g} * 103 \mathrm{MJ}=2.925 \mathrm{E}-7 \mathrm{~kg}+2.06 \mathrm{E}-3 \mathrm{~kg}=2.06 \mathrm{E}-3 \mathrm{~kg}$.

\subsection{Emissions to the environment}

No output.

\subsection{Landfill gas generation}

The user needs to specify in the "Material transfer" window of the anaerobic digestion process:

- $\quad \mathbf{k}$ rates $\left(\right.$ in $\mathrm{yr}^{-1}$ ) for each material fraction. They are the speed of decay of the $\mathrm{C}$ bio and.

- A factor that the user can change (named number_of_years in the rest of the text. The default value is 100 .

- A factor that the user can change (named vs_cbio in the rest of the text). The default value is 1.89 .

Principle is that we degrade $\mathbf{C}$ bio and with a first order decay. In consequence $\mathbf{C}$ bio is degraded. $\mathbf{C O} 2$ and CH4 are produced as a function of $\mathbf{C}$ bio and using the CH4_in_biogas property. Finally the gas produced has a lot of fractions named "year 1", "year 2", "year 3" etc, and C bio, CH4 and CO2 are calculated for each year and put in the corresponding fractions of the gas output.

\section{$>$ Calculation of $\mathrm{CH} 4$ in_biogas property}

This is exactly the same calculation as in the anaerobic digestion module.

In the calculations of the outputs, we need to calculate for each material fraction a new material property called ch4_biogas, which is in percentage the part of $\mathrm{C}$ bio that is transformed into $\mathrm{CH} 4$ (the rest being transformed into $\mathrm{CO} 2$ ). This is calculated based on 4 other material properties named " $\mathrm{C}$ bio and", " $\mathrm{H}$ ", O" and "N" with this formula:

Ch4_biogas $=\frac{1}{2}+\frac{168 * H-21 * O-36 * N}{112 * \text { Cbioand }}($ the value obtained is between 0 and 1$)$

\section{Calculations of the gas output}

The gas output has the number of fractions defined by the user by "number_of_years". Each fraction is named "Year 1", "Year 2", etc. For year n $(1 \leq \mathrm{n} \leq$ number_of_years] these are the properties [NB: C_bio_and, $\mathrm{k}$ and ch4_biogas are specific for each fraction] :

- C bio [kg] is: Sum_for_all_material_fractions_of [ C_bio_and * exp $(-\mathrm{k} *(\mathrm{n}-1)) *(1-\exp (-\mathrm{k}))$ ]

- $\quad$ CH4 [m3] is: Sum_for_all_material_fractions_of [ C_bio_and * exp $(-\mathrm{k} *(\mathrm{n}-1)) *(1-\exp (-\mathrm{k})) *$ CH4_biogas] $* 22.4 / 12$ 
- $\mathrm{CO} 2[\mathrm{~m} 3]$ is: Sum_for_all_material_fractions_of [C_bio_and * $\exp (-\mathrm{k} *(\mathrm{n}-1)) *(1-\exp (-\mathrm{k})) *(1-$ CH4_biogas) ] *22.4/12

- All other properties are zero, including water, VS and ash.

\section{$>$ Calculation of the Residues output}

The residues output has the same number of material fractions as the input. It is basically defined as equal to the input minus the carbon going to gas. For each material fraction, here are the properties [NB: $\mathrm{k}$ is specific to the fraction!]:

- $\quad \mathrm{C}$ bio $[\mathrm{kg}]$ is: $\quad$ input.c_bio - input.c_bio_and $*(1-\exp (-$ number_of_years $* \mathrm{k}))$

- C bio and is: input.c_bio_and *exp(-number_or_years*k)

- VS is: input.vs - vs_cbio *input.c_bio_and * (1-exp( - number_or_years*k))

- LHV dry [MJ]: input.lhvdry /input.vs *(input.vs - vs_cbio*input.c_bio_and * exp( number_or_years*k))

- All other properties are equal to the input.

\section{Example:}

\begin{tabular}{|c|c|c|c|}
\hline $\begin{array}{l}\text { Material transfer } \\
\text { Landfill gas generation }\end{array}$ & & & \\
\hline Landfill gas gene & tion & & \\
\hline Define 1st order decay & ate for mer & tion & \\
\hline Add & action & Time horizon of the inventory (in years) & 100 \\
\hline Fraction name & $\mathrm{k}$ rate $(1 / \mathrm{yr})$ & Loss of VS related to loss of $\mathrm{C}$ bio (\%) & 1.89 \\
\hline * Vegetable food waste & 0.3 & & \\
\hline Default & 0.1 & & \\
\hline
\end{tabular}

Figure S19: Material transfer of the "Landfill gas generation" process

Gas output, at year n:

- $\quad$ C bio [kg] is: $2.043 * \exp (-0.3 *(\mathrm{n}-1)) *(1-\exp (-0.3))+1.693 * \exp (-0.1 *(\mathrm{n}-1)) *(1-\exp (-0.1))$ so for $\mathrm{n}=1,0.6906$, and for $\mathrm{n}=2,0.5380$, and sum $=3.736 \mathrm{~kg}$.

- $\quad \mathrm{CH} 4$ [m3] is: $\quad(2.043 * \exp (-0.3 *(\mathrm{n}-1)) *(1-\exp (-0.3)) * 0.5445+1.693 * \exp (-0.1 *(\mathrm{n}-1)) *(1-$ $\exp (-0.1)) * 0.5285) * 22.4 / 12$ so for $\mathrm{n}=1: 0.6971 \mathrm{~m}^{3}$ and for $\mathrm{n}=2: 0.5425 \mathrm{~m}^{3}$, and $\mathrm{sum}=3.746$

- $\quad \mathrm{CO} 2[\mathrm{~m} 3]$ is: $\quad(2.043 * \exp (-0.3 *(\mathrm{n}-1)) *(1-\exp (-0.3)) *(1-0.5445)+1.693 * \exp (-0.1 *(\mathrm{n}-1))$ $*(1-\exp (-0.1)) *(1-0.5285)) * 22.4 / 12$ so for $\mathrm{n}=1: 0.5920 \mathrm{~m}^{3}$ and for $\mathrm{n}=2: 0.4618 \mathrm{~m}^{3}$ and sum=3.227

- All other properties are zero, including water, VS and ash. 


\begin{tabular}{|c|c|c|c|c|c|c|}
\hline \multicolumn{7}{|c|}{ Composition } \\
\hline \multicolumn{7}{|c|}{ Landfill gas generation - Gas } \\
\hline Display & & -7 & & & & \\
\hline Fraction name & Energy (MJ) & C bio $(\mathrm{kg})$ & C fossil $(\mathrm{kg})$ & $\mathrm{CH} 4\left(m^{\wedge} 3\right)$ & $\mathrm{CO} 2\left(m^{\wedge} 3\right)$ & \\
\hline Sum & 0 & 3.736 & 0 & 3.746 & 3.227 & \\
\hline Year 1 & 0 & 0.6906 & 0 & 0.6971 & 0.592 & . \\
\hline Year 2 & 0 & 0.538 & 0 & 0.5425 & 0.4618 & \\
\hline Year 3 & 0 & 0.4225 & 0 & 0.4255 & 0.3632 & $\equiv$ \\
\hline Year 4 & 0 & 0.3346 & 0 & 0.3365 & 0.2881 & \\
\hline Year 5 & 0 & 0.2675 & 0 & 0.2686 & 0.2306 & \\
\hline Year 6 & 0 & 0.2159 & 0 & 0.2165 & 0.1865 & \\
\hline Year 7 & 0 & 0.1759 & 0 & 0.1762 & 0.1522 & \\
\hline Year 8 & 0 & 0.1448 & 0 & 0.1448 & 0.1255 & \\
\hline Year 9 & 0 & 0.1204 & 0 & 0.1202 & 0.1045 & \\
\hline Year 10 & 0 & 0.1011 & 0 & 0.1008 & 0.0879 & \\
\hline Year 11 & 0 & 0.08562 & 0 & 0.08526 & 0.07457 & \\
\hline Year 12 & 0 & 0.07315 & 0 & 0.07275 & 0.0638 & \\
\hline Year 13 & 0 & 0.06299 & 0 & 0.06257 & 0.05501 & \\
\hline Year 14 & 0 & 0.05462 & 0 & 0.0542 & 0.04775 & \\
\hline Year 15 & 0 & 0.04766 & 0 & 0.04726 & 0.04171 & \\
\hline
\end{tabular}

Figure S20: Composition of the gas output from "Landfill gas generation” process

Residues output:

- $\quad$ C bio $(\mathrm{vfw})=2.294+2.043 *(\exp (-100 * 0.3)-1)=0.251 \mathrm{~kg}$

$($ ofp $)=3.065+1.693 *(\exp (-100 * 0.1)-1)=1.372 \mathrm{~kg}$

- $\quad C$ bio and $(\mathrm{vfw})=2.043 * \exp (-100 * 0.3))=1.91 \mathrm{E}-13 \mathrm{~kg}$

(ofp) $=1.693 * \exp (-100 * 0.1)=7.68 \mathrm{E}-5 \mathrm{~kg}$

- $\quad \mathrm{VS}(\mathrm{vfw})=4.579-1.89 * 2.043 *(1-\exp (-100 * 0.3))=0.718 \mathrm{~kg}$

$($ ofp $)=6.516-1.89 * 1.693 *(1-\exp (-100 * 0.1))=3.316 \mathrm{~kg}$

- $\quad$ LHV dry $(\mathrm{vfw})=88.39 / 4.579 *(4.579-1.89 * 2.043 *(1-\exp (-100 * 0.3)))=13.85 \mathrm{MJ}$

$($ ofp $)=103 / 6.156 *(6.516-1.89 * 1.693 *(1-\exp (-100 * 0.1)))=55.49 \mathrm{MJ}$

- All other properties are equal to the input.

\begin{tabular}{|c|c|c|c|c|c|c|c|c|c|c|c|c|c|c|}
\hline Default & $\cdot$ & & & & & & & & & & & & & \\
\hline Fraction name & Total Wet Weight (kg) & TS $(\mathrm{kg})$ & Water $(\mathrm{kg})$ & VS (kg) & Ash $(\mathrm{kg})$ & Energy (MJ) & C bio $(\mathrm{kg})$ & $\mathrm{C}$ bio and $(\mathrm{kg})$ & C fossil (kg) & $\mathrm{Ca}(\mathrm{kg})$ & $\mathrm{Cl}(\mathrm{kg})$ & $\mathrm{F}(\mathrm{kg})$ & $H(\mathrm{~kg})$ & $\mathrm{K}(\mathrm{kg})$ \\
\hline Sum & 22.94 & 5.986 & 16.96 & 4.034 & 1.952 & 66.26 & 1.623 & $7.685 \mathrm{E}-05$ & 0.02699 & 0.6653 & 0.0328 & 0.001305 & 0.7296 & 0.06231 \\
\hline Vegetable food waste & 17.14 & 0.9686 & 16.17 & 0.7174 & 0.2512 & 13.85 & 0.2512 & $1.912 \mathrm{E}-13$ & 0.01154 & 0.02681 & 0.02705 & 0.000483 & 0.3188 & 0.06134 \\
\hline Office paper & 5.805 & 5.018 & 0.7875 & 3.317 & 1.701 & 52.41 & 1.372 & $7.685 \mathrm{E}-05$ & 0.01545 & 0.6385 & 0.005752 & 0.0008217 & 0.4109 & 0.0009696 \\
\hline
\end{tabular}

Figure S21: Composition of the residues output from "Landfill gas generation” process

\subsection{Mass transfer over years}

The user specifies for different time periods the routing to different outputs. Each output has as many year fractions as the input.

For each output $\mathrm{O}$, for each year $\mathrm{Y}$,

- $\quad$ Find the period $\mathrm{P}$ where $\mathrm{Y}$ is located

- $\quad$ all material properties are calculated as: Input.fraction.year.materialProperty *TC(P, O)/100

where TC is the transfer coefficient specified by the user in the table, for the period $\mathrm{P}$ and the output $\mathrm{O}$.

In this example we connect this process to a landfill gas generation (Figure S22). 


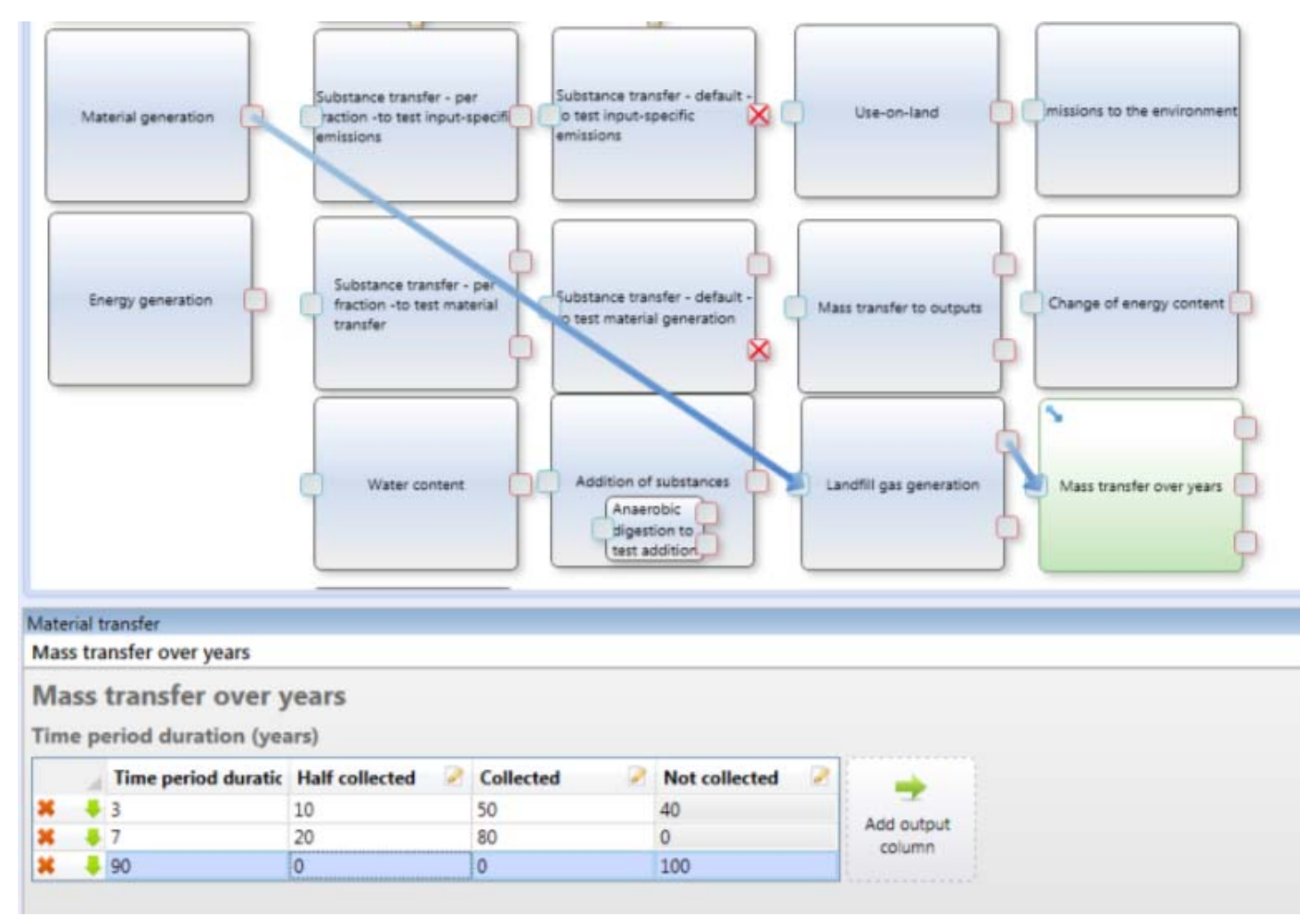

Figure S22: Material transfer of the "Mass transfer over years" process

The input from the landfill gas generation was:

\begin{tabular}{|c|c|c|c|c|c|c|}
\hline \multicolumn{7}{|l|}{ Composition } \\
\hline \multicolumn{7}{|c|}{ Landfill gas generation - Gas } \\
\hline Display & & $\bullet$ & & & & \\
\hline Fraction name & Energy (MJ) & $\mathrm{C}$ bio $(\mathrm{kg})$ & $\mathrm{C}$ fossil $(\mathrm{kg})$ & $\mathrm{CH} 4\left(m^{\wedge} 3\right)$ & $\mathrm{CO} 2\left(\mathrm{~m}^{\wedge} 3\right)$ & \\
\hline Sum & 0 & 3.736 & 0 & 3.746 & 3.227 & \\
\hline Year 1 & 0 & 0.6906 & 0 & 0.6971 & 0.592 & 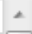 \\
\hline Year 2 & 0 & 0.538 & 0 & 0.5425 & 0.4618 & \\
\hline Year 3 & 0 & 0.4225 & 0 & 0.4255 & 0.3632 & $\equiv$ \\
\hline Year 4 & 0 & 0.3346 & 0 & 0.3365 & 0.2881 & \\
\hline Year 5 & 0 & 0.2675 & 0 & 0.2686 & 0.2306 & \\
\hline Year 6 & 0 & 0.2159 & 0 & 0.2165 & 0.1865 & \\
\hline Year 7 & 0 & 0.1759 & 0 & 0.1762 & 0.1522 & \\
\hline Year 8 & 0 & 0.1448 & 0 & 0.1448 & 0.1255 & \\
\hline Year 9 & 0 & 0.1204 & 0 & 0.1202 & 0.1045 & \\
\hline Year 10 & 0 & 0.1011 & 0 & 0.1008 & 0.0879 & \\
\hline Year 11 & 0 & 0.08562 & 0 & 0.08526 & 0.07457 & \\
\hline Year 12 & 0 & 0.07315 & 0 & 0.07275 & 0.0638 & \\
\hline Year 13 & 0 & 0.06299 & 0 & 0.06257 & 0.05501 & \\
\hline Year 14 & 0 & 0.05462 & 0 & 0.0542 & 0.04775 & \\
\hline Year 15 & 0 & 0.04766 & 0 & 0.04726 & 0.04171 & \\
\hline Year 16 & 0 & 0.04182 & 0 & 0.04144 & 0.03664 & \\
\hline Year 17 & 0 & 0.03688 & 0 & 0.03651 & 0.03233 & \\
\hline Year 18 & 0 & 0.03266 & 0 & 0.03231 & 0.02865 & \\
\hline Year 19 & 0 & 0.02902 & 0 & 0.0287 & 0.02547 & \\
\hline Year 20 & 0 & 0.02586 & 0 & 0.02557 & 0.02271 & \\
\hline Vane 21 & $n$ & ח & $n$ & ח חoven & $\ln \cap 302$ & \\
\hline
\end{tabular}

Figure S23: Material composition of the input to the "Mass transfer over years" process

So the calculations for $\mathrm{CH} 4$ are:

- For "Half collected" output,

o Year $1($ period=1): $0.6971 * 10 / 100=0.06971$

o Year 2 (period $=1): 0.5425 * 10 / 100=0.05425$ 
o Year 3 (period=1): $0.4255 * 10 / 100=0.04255$

o Year 4 (period $=2)$ : $0.3365 * 20 / 100=0.0673$

o $\ldots$

o Year 10 (period=2): $0.1008 * 20 / 100=0.02016$

o Year 11 (period $=3): 0.08526 * 0 / 100=0$

o $\ldots$

- For "Collected" output,

o Year 1 (period=1): $0.6971 * 50 / 100=0.3485$

o Year 2 (period $=1): 0.5425 * 50 / 100=0.2712$

o Year $3($ period $=1): 0.4255 * 50 / 100=0.2127$

o Year 4 (period $=2): 0.3365 * 80 / 100=0.2692$

o $\ldots$

o Year 10 (period=2): $0.1008 * 80 / 100=0.0806$

o Year $11($ period $=3): 0.08526 * 0 / 100=0$

o $\ldots$

- For "Not collected" output,

o Year $1($ period $=1): 0.6971 * 40 / 100=0.2788$

o Year 2 (period=1): $0.5425 * 40 / 100=0.217$

o Year 3 (period $=1$ ): $0.4255 * 40 / 100=0.1702$

o Year 4 (period=2): $0.3365 * 0 / 100=0$

o $\ldots$

o Year $10($ period $=2): 0.1008 * 0 / 100=0$

o Year $11($ period $=3): 0.08526 * 100 / 100=0.08526$

$0 \quad \ldots$

Concerning C bio, the C bio in year 8 of output "Half collected" is: 0.02896 .

\subsection{Leachate generation}

There are always two outputs: leachate and residues.

Leachate has year fractions. The number of year fractions is determined by the user in the field "Time horizon of the inventory (years)". For each year Y:

- The leachate has water $(\mathrm{kg})$ determined thanks to the left table. We need first to find the time period $\mathrm{P}$ containing the year $\mathrm{Y}$ :

leachate.year.water $=$ input.totalWetWeight $*$ netInflitration $(P) /($ density $*$ height $* 10 \wedge 3)$

where density is the user-defined value given in "Bulk density" field and height is the user-defined value given in the "Height of layer" field

- Substances $(\mathrm{kg})$ determined thanks to the right table: for each substance determined in the table on the right, we need to find the time period $\mathrm{P}$ ' that contains the year $\mathrm{Y}$ and then the amount of substance in that year $\mathrm{Y}$ is:

leachate.year.substance $=$ leachate.year.water ${ }^{*}$ concentrate(substance, $\left.P^{\prime}\right) * 10^{\wedge}-6$ or if easier:

leachate.year.substance $=$ input.totalWetWeight $*$ netInflitration $(P) /($ density $*$ height $* 10 \wedge 3)$

*concentrate(substance, $\left.P^{\prime}\right) * 10 \wedge-6$ 
where density is the user-defined value given in "Bulk density" field

and height is the user-defined value given in the "Height of layer" field

Residues is equal to the input minus the substances that go in the leachate. For all substances of input, for each material fraction, the amount in "residues" is:

If input.substance(of_all_fractions $=0$, then it is zero, else:

Input.fraction.substance - sum_for_all_years [leachate.year.water *concentrate(substance, $\left.\left.P^{\prime}\right){ }^{*} 10^{\wedge}-6\right]$ *input.fraction.substance/input.substance(of_all_fractions))

When connecting the process described in Figure

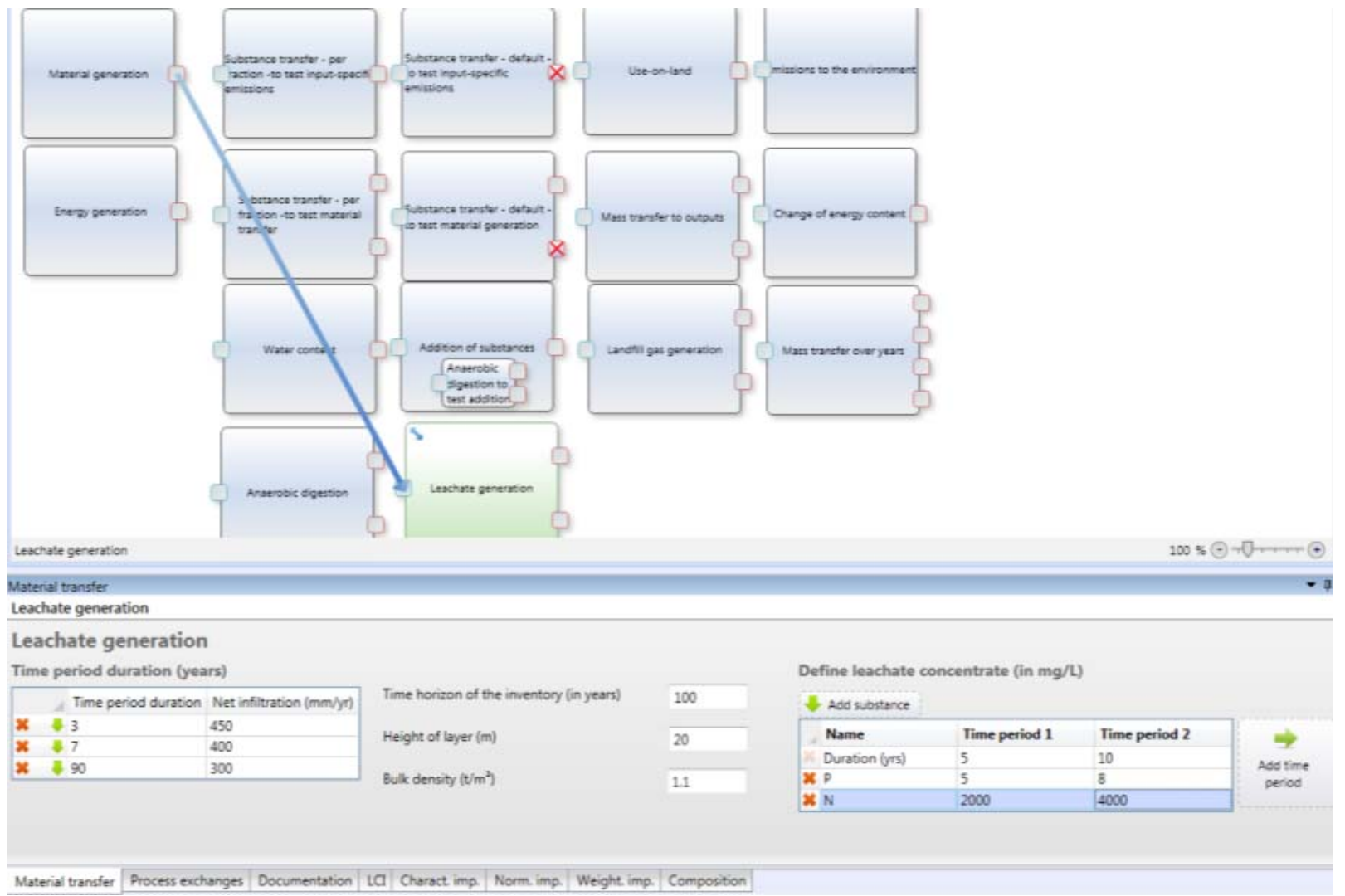

Figure S24: Material transfer of the "Leachate generation” process

So the calculations for water and $\mathrm{N}$ are:

- For "Leachate" output, the water is:

o Year 1 (period $=1): 30 * 450 /\left(1.1 * 20 * 10^{\wedge} 6\right)=0.614 \mathrm{~kg}$

o Year 2 (period $=1): 30 * 450 /\left(1.1 * 20 * 10^{\wedge} 6\right)=0.614 \mathrm{~kg}$

o Year $3($ period $=1): 30 * 450 /\left(1.1 * 20 * 10^{\wedge} 6\right)=0.614 \mathrm{~kg}$

o Year $4($ period $=2): 30 * 400 /\left(1.1 * 20 * 10^{\wedge} 6\right)=0.545 \mathrm{~kg}$

$0 \quad \ldots$

o Year $10($ period $=2): 30 * 400 /\left(1.1 * 20 * 10^{\wedge} 6\right)=0.545 \mathrm{~kg}$

o Year $11($ period $=3): 30 * 300 /\left(1.1 * 20 * 10^{\wedge} 6\right)=0.409 \mathrm{~kg}$

$0 \quad \ldots$

- For "leachate" output, $\mathrm{N}$ is:

o Year $1\left(\right.$ period $\left.=1, \mathrm{P}^{\prime}=1\right): 30 * 450 /\left(1.1 * 20 * 10^{\wedge} 3\right) * 2000 \mathrm{E}-6=1.227 \mathrm{E}-3 \mathrm{~kg}$ 
o Year $2\left(\right.$ period $\left.=1, \mathrm{P}^{\prime}=1\right): 30 * 450 /\left(1.1 * 20 * 10^{\wedge} 3\right) * 2000 \mathrm{E}-6=1.227 \mathrm{E}-3 \mathrm{~kg}$

o Year 3 (period $\left.=1, \mathrm{P}^{\prime}=1\right)$ ): $30 * 450 /\left(1.1 * 20 * 10^{\wedge} 3\right) * 2000 \mathrm{E}-6=1.227 \mathrm{E}-3 \mathrm{~kg}$

o Year $4\left(\right.$ period $\left.=2, \mathrm{P}^{\prime}=1\right): 30 * 400 /\left(1.1 * 20 * 10^{\wedge} 3\right) * 2000 \mathrm{E}-6=1.091 \mathrm{E}-3 \mathrm{~kg}$

o Year $5\left(\right.$ period $\left.=2, \mathrm{P}^{\prime}=1\right): 30 * 400 /\left(1.1 * 20 * 10^{\wedge} 3\right) * 2000 \mathrm{E}-6=1.091 \mathrm{E}-3 \mathrm{~kg}$

o Year $6\left(\right.$ period $\left.=2, \mathrm{P}^{\prime}=2\right): 30 * 400 /\left(1.1 * 20 * 10^{\wedge} 3\right) * 4000 \mathrm{E}-6=2.182 \mathrm{E}-3 \mathrm{~kg}$

$0 \quad \ldots$

o Year $10\left(\right.$ period=2, $\left.\mathrm{P}^{\prime}=2\right): 30 * 400 /\left(1.1 * 20 * 10^{\wedge} 3\right) * 4000 \mathrm{E}-6=2.182 \mathrm{E}-3 \mathrm{~kg}$

o Year $11\left(\right.$ period=3, $\left.\mathrm{P}^{\prime}=2\right): 30 * 300 /\left(1.1 * 20 * 10^{\wedge} 3\right) * 4000 \mathrm{E}-6=1.636 \mathrm{E}-3 \mathrm{~kg}$

$0 \quad \ldots$

o Year $16\left(\right.$ period=3, $\left.\mathrm{P}^{\prime}=3\right): 30 * 300 /\left(1.1 * 20 * 10^{\wedge} 3\right) * 0=0 \mathrm{~kg}$

- For "Residues" output, all properties are the same as the input except from $\mathrm{N}$ and $\mathrm{P}$, lets' check for $\mathrm{N}$ :

o Vegetable food waste: 0.09175 - sum_for_all_years[leachate.year.water *concentrate(N, $\left.\left.\left.\mathrm{P}^{\prime}\right)^{*} 10^{\wedge}-6\right] * 0.09175 / 0.09996\right)$

$=0.09175-[3 * 1.227 \mathrm{E}-3+2 * 1.091 \mathrm{E}-3+5 * 2.182 \mathrm{E}-3+5 * 1.636 \mathrm{E}-3] * 0.09175 / 0.09996$ $=0.0688 \mathrm{~kg}$

o Office paper: 0.008217 - sum_for_all_years[leachate.year.water *concentrate(N, P’)*10^_ 6] *0.008217/0.09996)

$=0.008217-[3 * 1.227 \mathrm{E}-3+2 * 1.091 \mathrm{E}-3+5 * 2.182 \mathrm{E}-3+5 * 1.636 \mathrm{E}-3] * 0.008217 / 0.09996$ $=0.006166 \mathrm{~kg}$

\begin{tabular}{|c|c|c|c|c|c|c|c|c|c|c|c|c|c|c|c|c|c|}
\hline \multicolumn{18}{|c|}{ Composition } \\
\hline \multicolumn{17}{|c|}{ Leachate generation - Leachate } & \\
\hline Display & & - & & & & & & & & & & & & & & & \\
\hline Fraction name & Total Wet Weight (kg) & TS (kg) & Water $(\mathrm{kg})$ & VS (kg) & Ash (kg) & Energy (MJ) & C bio $(\mathrm{kg})$ & $\mathrm{C}$ bio and $(\mathrm{kg})$ & C fossil $(\mathrm{kg})$ & $\mathrm{Ca}(\mathrm{kg})$ & $\mathrm{Cl}(\mathrm{kg})$ & $\mathrm{F}(\mathrm{kg})$ & $\mathrm{H}(\mathrm{kg})$ & $\mathrm{K}(\mathrm{kg})$ & $\mathrm{N}(\mathrm{kg})$ & $\mathrm{Na}(\mathrm{kg})$ & \\
\hline Sum & 42.48 & 0 & 42.48 & 0 & 0 & 0 & 0 & 0 & 0 & 0 & 0 & 0 & 0 & 0 & 0.02496 & 0 & \\
\hline Year 1 & 0.6137 & 0 & 0.6137 & 0 & 0 & 0 & 0 & 0 & 0 & 0 & 0 & 0 & 0 & 0 & 0.001227 & 0 & I \\
\hline Year 2 & 0.6137 & 0 & 0.6137 & 0 & 0 & 0 & 0 & 0 & 0 & 0 & 0 & 0 & 0 & 0 & 0.001227 & 0 & i \\
\hline Year 3 & 0.6137 & 0 & 0.6137 & 0 & 0 & 0 & 0 & 0 & 0 & 0 & 0 & 0 & 0 & 0 & 0.001227 & 0 & I \\
\hline Year 4 & 0.5455 & 0 & 0.5455 & 0 & 0 & 0 & 0 & 0 & 0 & 0 & 0 & 0 & 0 & 0 & 0.001091 & 0 & I \\
\hline Year 5 & 0.5455 & 0 & 0.5455 & 0 & 0 & 0 & 0 & 0 & 0 & 0 & 0 & 0 & 0 & 0 & 0.001091 & 0 & 1 \\
\hline Year 6 & 0.5455 & 0 & 0.5455 & 0 & 0 & 0 & 0 & 0 & 0 & 0 & 0 & 0 & 0 & 0 & 0.002182 & 0 & ! \\
\hline Year 7 & 0.5455 & 0 & 0.5455 & 0 & 0 & 0 & 0 & 0 & 0 & 0 & 0 & 0 & 0 & 0 & 0.002182 & 0 & 1 \\
\hline Year 8 & 0.5455 & 0 & 0.5455 & 0 & 0 & 0 & 0 & 0 & 0 & 0 & 0 & 0 & 0 & 0 & 0.002182 & 0 & 1 \\
\hline Year 9 & 0.5455 & 0 & 0.5455 & 0 & 0 & 0 & 0 & 0 & 0 & 0 & 0 & 0 & 0 & 0 & 0.002182 & 0 & I \\
\hline Year 10 & 0.5455 & 0 & 0.5455 & 0 & 0 & 0 & 0 & 0 & 0 & 0 & 0 & 0 & 0 & 0 & 0.002182 & 0 & I \\
\hline Year 11 & 0.4091 & 0 & 0.4091 & 0 & 0 & 0 & 0 & 0 & 0 & 0 & 0 & 0 & 0 & 0 & 0.001636 & 0 & 1 \\
\hline Year 12 & 0.4091 & 0 & 0.4091 & 0 & 0 & 0 & 0 & 0 & 0 & 0 & 0 & 0 & 0 & 0 & 0.001636 & 0 & 1 \\
\hline Year 13 & 0.4091 & 0 & 0.4091 & 0 & 0 & 0 & 0 & 0 & 0 & 0 & 0 & 0 & 0 & 0 & 0.001636 & 0 & ! \\
\hline Year 14 & 0.4091 & 0 & 0.4091 & 0 & 0 & 0 & 0 & 0 & 0 & 0 & 0 & 0 & 0 & 0 & 0.001636 & 0 & ' \\
\hline Year 15 & 0.4091 & 0 & 0.4091 & 0 & 0 & 0 & 0 & 0 & 0 & 0 & 0 & 0 & 0 & 0 & 0.001636 & 0 & ! \\
\hline Year 16 & 0.4091 & 0 & 0.4091 & 0 & 0 & 0 & 0 & 0 & 0 & 0 & 0 & 0 & 0 & 0 & 0 & 0 & I \\
\hline Year 17 & 0.4091 & 0 & 0.4091 & 0 & 0 & 0 & 0 & 0 & 0 & 0 & 0 & 0 & 0 & 0 & 0 & 0 & 1 \\
\hline Year 18 & 0.4091 & 0 & 0.4091 & 0 & 0 & 0 & 0 & 0 & 0 & 0 & 0 & 0 & 0 & 0 & 0 & 0 & I \\
\hline Year 19 & 0.4091 & 0 & 0.4091 & 0 & 0 & 0 & 0 & 0 & 0 & 0 & 0 & 0 & 0 & 0 & 0 & 0 & I \\
\hline \multirow[t]{2}{*}{ Year 20} & 0.4091 & 0 & 0.4091 & 0 & 0 & 0 & 0 & 0 & 0 & 0 & 0 & 0 & 0 & 0 & 0 & 0 & \\
\hline & \multicolumn{16}{|l|}{$\cdot$} & \\
\hline
\end{tabular}

Leachate generation - Residues

\begin{tabular}{|c|c|c|c|c|c|c|c|c|c|c|c|c|c|c|}
\hline Display & \multicolumn{14}{|l|}{ Default } \\
\hline \multicolumn{2}{|c|}{ Fraction name } & bio and $(\mathrm{kg})$ & C fossil $(\mathrm{kg})$ & $\mathrm{Ca}(\mathrm{kg})$ & $\mathrm{Cl}(\mathrm{kg})$ & $F(\mathrm{~kg})$ & $H(k g)$ & $\mathrm{K}(\mathrm{kg})$ & $\mathrm{N}(\mathrm{kg})$ & $\mathrm{Na}(\mathrm{kg})$ & $O(\mathrm{~kg})$ & $P(k g)$ & $\mathrm{S}(\mathrm{kg})$ & $\mathrm{Hg}(\mathrm{kg})$ \\
\hline \multicolumn{2}{|l|}{ Sum } & .736 & 0.02699 & 0.6653 & 0.0328 & 0.001305 & 0.7296 & 0.06231 & 0.07503 & 0.02143 & 4.923 & 0.01142 & 0.01417 & $3.891 E-07$ \\
\hline \multicolumn{2}{|c|}{ Vegetable food waste } & 043 & 0.01154 & 0.02681 & 0.02705 & 0.000483 & 0.3188 & 0.06134 & 0.06886 & 0.01507 & 1.908 & 0.01111 & 0.008887 & $9.66 \mathrm{E}-08$ \\
\hline \multicolumn{2}{|c|}{ Office paper } & 693 & 0.01545 & 0.6385 & 0.005752 & 0.0008217 & 0.4109 & 0.0009696 & 0.006166 & 0.00636 & 3.016 & 0.0003124 & 0.005284 & $2.925 \mathrm{E}-07$ \\
\hline
\end{tabular}

Figure S25: Composition of the two outputs of the "leachate generation" process 


\subsection{Anaerobic digestion}

This process has two outputs called "gas" and "digestate". The user needs to specify in the "Material transfer" window of the anaerobic digestion process:

- Yields (in \%) for each material fraction. They describe how much of the "C bio and" is actually degraded in the digester. Like in the other tables, there is always a "default" fraction, and the user can add and delete lines (i.e. fractions).

- A factor called "Loss of VS related to loss of C bio" (named vs_cbio in the rest of the text). Default value: 1.89 .

- A factor called "Part of $\mathrm{CO} 2$ going to the liquid phase (\%)" (named co2_liq in the rest of this text). The default value is zero.

- A list of pollutants and their transfer coefficients (TC) from the input to the gas and digestate outputs, given by the user in $\mathbf{k g} / \mathbf{N m} \mathbf{3}$ biogas. The user selects the material property and writes a transfer coefficient in the column "Gas" for the default fraction line (and possibly to specific fractions), the value in the column "digestate" is automatically calculated as "100-TCgas". By default everything goes to digestate. NB: VS, Cbio, Cbioand and energy cannot be changed in this table because they are calculated based on the other parameters.

\section{Calculation of $\mathrm{CH} 4$ for each material fractions (shown when clicking on button "View CH4\%”)}

In the calculations of the outputs, we need to calculate for each material fraction a material property called ch4_biogas, which is in percentage the part of $\mathrm{C}$ bio that is transformed into $\mathrm{CH} 4$ (the rest being transformed into CO2). This is calculated based on 4 other material properties named " $\mathrm{C}$ bio and", " $\mathrm{H}$ ", $\mathrm{O}$ " and "N" with this formula:

Ch4_biogas $=\frac{1}{2}+\frac{168 * H-21 * O-36 * N}{112 * \text { Cbioand }}($ the value obtained is between 0 and 1$)$

\section{Calculation of "Part of CO2 liquid" and "Measured CH4" depending on radio buttons}

- When the first radiobutton is selected: the user edits co2_liq and measuredCH4\% is calculated MeasuredCH4\% is $\mathrm{CH} 4$ divided by biogas:

100*Sum_for_all_material_fractions_of (yield/100*C_bio_and *ch4_biogas/100) /

[Sum_for_all_material_fractions_of (yield/100*C_bio_and * ch4_biogas/100) +

Sum_for_all_material_fractions_of (yield/100*C_bio_and $*(1-$ ch4_biogas/100) $) *(1-$ co2_liq/100) ]

- When the second radiobutton is selected: the user edits measuredCH4\% and co2liq is calculated

Co2liq is calculated like this:

$100-(100-$ measured_ch $4 \%) /$ measured_ch $4 \% *$ Sum_for_all_material_fractions_of (yield/100* C_bio_and $*$ ch4_biogas/100) / Sum_for_all_material_fractions_of (yield/100* C_bio_and * (1ch4_biogas/100))

\section{$>$ Calculation of the GAS output}

The gas output has one fraction called "Mix" with these properties:

- C bio [kg] is: Sum_for_all_material_fractions_of (yield/100*C_bio_and * $(1-$ co2_liq/100*(1ch4_biogas/100)) ) 
- $\quad \mathrm{CH} 4$ [m3] is: Sum_for_all_material_fractions_of (yield/100 * C_bio_and * ch4_biogas $/ 100) * 22.4 / 12$

- $\mathrm{CO} 2[\mathrm{~m} 3]$ is:

Sum_for_all_material_fractions_of : (yield/100*C_bio_and * (1-ch4_biogas/100) $*(1-$ co2_liq/100) $* 22.4 / 12$

- Pollutants [kg]: Sum_for_all_material_fractions_of (pollutant_kg(fraction)*TC_of_pollutants_to_gas/100)

- All other properties are zero, including water, VS, ash, Energy, C bio and.

\section{Calculation of the DIGESTATE output}

The digestate output has the same number of material fractions as the input, and their names. It is defined as equal to the input minus what goes to the gas (I write "input." to designate properties of the input material). For each material fraction, here are the properties:

- C bio [kg] is: input.c_bio - input.C_bio_and *yield/100*(1- co2_liq/100*(1-ch4_biogas/100)

- C bio and is: input.c_bio_and*(1 -yield/100)

- VS is: $\quad$ input.vs - vs_cbio $*$ C_bio_and $*$ yield $/ 100$

- $\quad$ LHV dry $[\mathrm{MJ}]$ is: $\quad$ input.lhvdry /input.vs * (input.vs - vs_cbio *C_bio_and *yield/100)

- For pollutants with defined transfer coefficients: pollutant $[\mathrm{kg}]=$ input.pollutant*TC_to_digestate/100

- All other properties are equal to the input, including water and ash.

\section{Example:}

We use the example of $30 \mathrm{~kg}$ of $70 \%$ vegetable food waste and $30 \%$ office paper (Table S1). The theoretical $\mathrm{CH} 4$ ratios are: $54.45 \%$ for vegetable food waste and $52.85 \%$ for office paper.

\section{a. With radio button on "Part of $\mathrm{CO} 2 \ldots$..."}

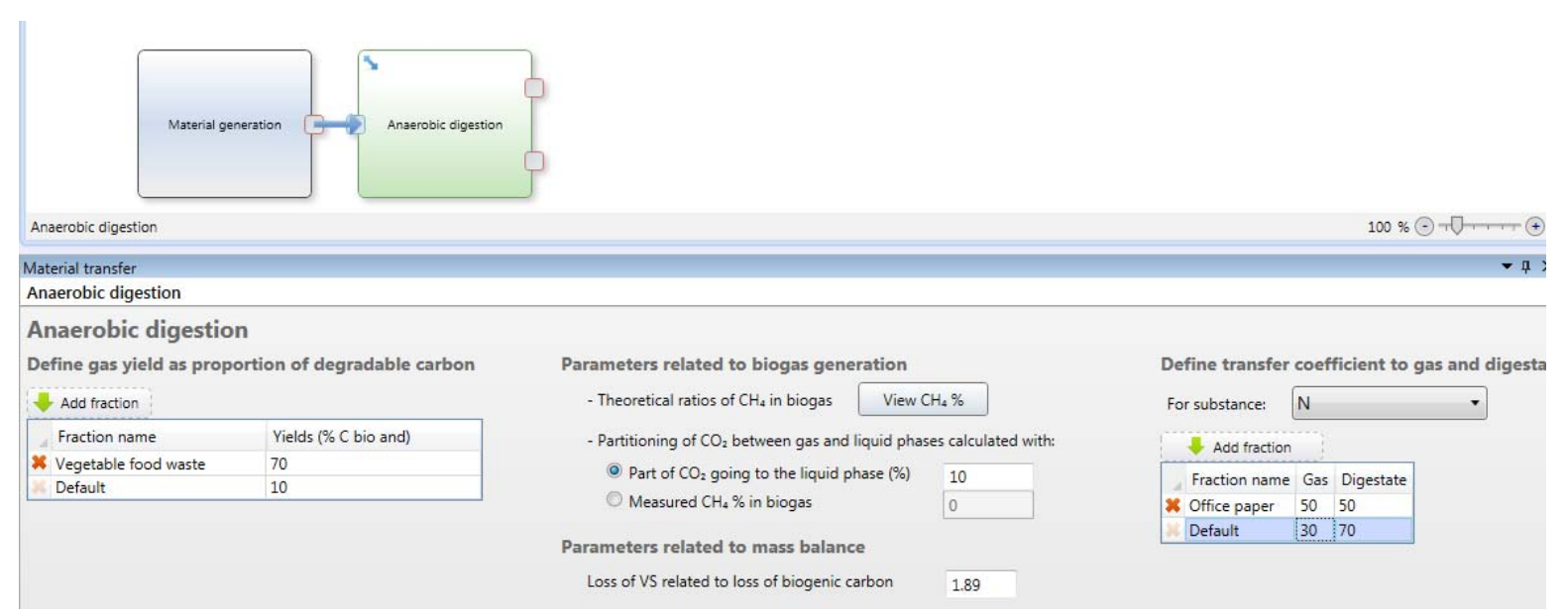

Figure S26: Material transfer of the “anaerobic digestion” process

The value "Measured $\mathrm{CH} 4 \%$ in biogas" is:

$100 *(70 / 100 * 2.043 * 54.45 / 100+10 / 100 * 1.693 * 52.85 / 100) /[(70 / 100 * 2.043 * 54.45 / 100+10 / 100 *$ $1.693 * 52.85 / 100)+(70 / 100 * 2.043 *(1-54.45 / 100)+10 / 100 * 1.693 *(1-52.85 / 100)) *(1-10 / 100)]=$ 56.88

The gas output is:

- $\quad$ C bio $[\mathrm{kg}]=70 / 100 * 2.043 *(1-10 / 100 *(1-54.45 / 100))+10 / 100 * 1.693 *(1-10 / 100 *(1-52.85 / 100))$ $=1.526 \mathrm{~kg}$ 
- $\quad \mathrm{CH} 4[\mathrm{~m} 3]=(70 / 100 * 2.043 * 54.45 / 100+10 / 100 * 1.693 * 52.85 / 100) * 22.4 / 12=1.621 \mathrm{~m}^{3}$

- $\quad \mathrm{CO} 2[\mathrm{~m} 3]=(70 / 100 * 2.043 *(1-54.45 / 100)+10 / 100 * 1.693 *(1-52.85 / 100)) *(1-10 / 100) * 22.4 / 12$ $=1.228 \mathrm{~m}^{3}$

- $\quad \mathrm{N}[\mathrm{kg}]: 0.09177 * 30 / 100+0.008217 * 50 / 100=0.03164 \mathrm{~kg}$

\begin{tabular}{|c|c|c|c|c|c|c|c|c|c|c|c|}
\hline \multicolumn{12}{|c|}{ Composition } \\
\hline \multicolumn{12}{|c|}{ Anaerobic digestion - Gas } \\
\hline \multicolumn{12}{|l|}{ Display } \\
\hline Fraction name & Energy (MJ) & C bio (kg) & C fossil $(\mathrm{kg})$ & $\mathrm{CH} 4\left(m^{\wedge} 3\right)$ & $\mathrm{CO} 2\left(m^{\wedge} 3\right)$ & $f(\mathrm{~kg})$ & $\mathrm{K}(\mathrm{kg})$ & $\mathrm{N}(\mathrm{kg})$ & $\mathrm{Na}(\mathrm{kg})$ & $O(\mathrm{~kg})$ & $P C$ \\
\hline Sum & 0 & 1.526 & $\mathbf{0}$ & 1.621 & 1.228 & 1 & 0 & 0.03164 & 0 & 0 & 0 \\
\hline Mix & 0 & 1.526 & 0 & 1.621 & 1.228 & & 0 & 0.03164 & 0 & 0 & 0 \\
\hline
\end{tabular}

Figure S27: Composition of the gas output

The digestate output is:

- $\quad$ C bio $(v f w)=2.294-2.043 * 70 / 100 *(1-10 / 100 *(1-54.45 / 100))=0.929 \mathrm{~kg}$ $($ ofp $)=3.065-1.693 * 10 / 100 *(1-10 / 100 *(1-52.85 / 100))=2.904 \mathrm{~kg}$

- $\quad$ C bio and $(\mathrm{vfw})=2.043 *(1-70 / 100)=0.613 \mathrm{~kg}$ $($ ofp $)=1.693 *(1-10 / 100)=1.524 \mathrm{~kg}$

- $\quad \operatorname{VS}(\mathrm{vfw})=4.579-1.89 * 2.043 * 70 / 100=1.876 \mathrm{~kg}$ $($ ofp $)=6.516-1.89 * 1.693 * 10 / 100=6.196 \mathrm{~kg}$

- $\quad$ LHV dry $(\mathrm{vfw})=88.389 / 4.579 *(4.579-1.89 * 2.043 * 70 / 100)=36.21 \mathrm{MJ}$ $($ ofp $)=103 / 6.516 *(6.516-1.89 * 1.693 * 10 / 100)=97.94 \mathrm{MJ}$

- $\quad \mathrm{N}(\mathrm{vfw})=0.09177 * 70 / 100=0.06424 \mathrm{~kg}$ (ofp) $=0.008217 * 50 / 100=0.004109 \mathrm{~kg}$

- All other properties are equal to the input

\begin{tabular}{|c|c|c|c|c|c|c|c|c|c|c|c|c|c|c|c|c|c|c|c|}
\hline \multicolumn{20}{|c|}{$\begin{array}{l}\text { Composition } \\
\text { Anaerobic digestion - Digestate }\end{array}$} \\
\hline Display & Default & $\nabla$ & & & & & & & & & & & & & & & & & \\
\hline \multicolumn{2}{|c|}{ Fraction name } & Total Wet Weight $(\mathrm{kg})$ & TS $(\mathrm{kg})$ & Water (kg) & VS (kg) & Ash (kg) & Energy (MJ) & C bio $(\mathrm{kg})$ & $\mathrm{C}$ bio and $(\mathrm{kg})$ & C fossil (kg) & $\mathrm{Ca}(\mathrm{kg})$ & $\mathrm{Cl}(\mathrm{kg})$ & $F(\mathrm{~kg})$ & $H(\mathrm{~kg})$ & $\mathrm{K}(\mathrm{kg})$ & $\mathrm{N}(\mathrm{kg})$ & $\mathrm{Na}(\mathrm{kg})$ & $O(\mathrm{~kg})$ & $P(\mathrm{~kg})$ \\
\hline \multicolumn{2}{|c|}{ Sum } & 26.98 & 10.02 & 16.96 & 8.072 & 1.952 & 134.1 & 3.833 & 2.136 & 0.02699 & 0.6653 & 0.0328 & 0.001305 & 0.7296 & 0.06231 & 0.06835 & 0.02143 & 4.923 & 0.01147 \\
\hline \multicolumn{2}{|c|}{ Vegetable food waste } & 18.29 & 2.127 & 16.17 & 1.876 & 0.2512 & 36.21 & 0.9292 & 0.6129 & 0.01154 & 0.02681 & 0.02705 & 0.000483 & 0.3188 & 0.06134 & 0.06424 & 0.01507 & 1.908 & 0.011160 \\
\hline \multicolumn{2}{|c|}{ Office paper } & 8.685 & 7.897 & 0.7875 & 6.196 & 1.701 & 97.9 & 2.904 & 1.523 & 0.01545 & 0.6385 & 0.005752 & 0.0008217 & 0.4109 & 0.0009696 & 0.004109 & 0.00636 & 3.016 & 0.00031390 \\
\hline
\end{tabular}

Figure S28: Composition of the digestate output

b. With radio button on "Part of $\mathrm{CO} 2 . .$. " (only this changes)

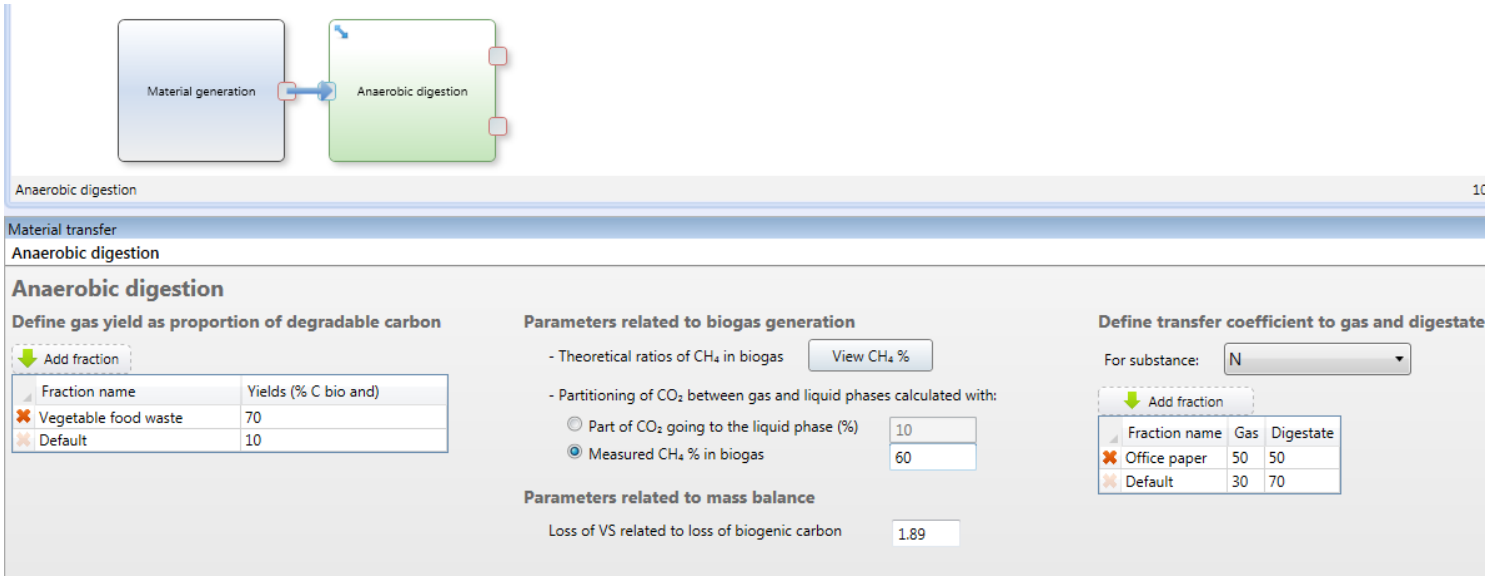

Figure S29: Material transfer of the "anaerobic digestion” process

The value "Part of $\mathrm{CO} 2$ going..." is: 
$100-100 *(100-60) / 60 *(70 / 100 * 2.043 * 54.45 / 100+10 / 100 * 1.693 * 52.85 / 100) /(70 / 100 * 2.043 *(1-$ $54.45 / 100)+10 / 100 * 1.693 *(1-52.85 / 100))=20.84$

All the other calculations are the same as before. The gas output is:

- $\quad$ C bio $[\mathrm{kg}]=70 / 100 * 2.043 *(1-20.84 / 100 *(1-54.45 / 100))+10 / 100 * 1.693 *(1-20.84 / 100 *(1-52.85 / 100))$ $=1.447 \mathrm{~kg}$

- $\quad \mathrm{CH} 4[\mathrm{~m} 3]=(70 / 100 * 2.043 * 54.45 / 100+10 / 100 * 1.693 * 52.85 / 100) * 22.4 / 12=1.621 \mathrm{~m}^{3}$

- $\quad \mathrm{CO} 2[\mathrm{~m} 3]=(70 / 100 * 2.043 *(1-54.45 / 100)+10 / 100 * 1.693 *(1-52.85 / 100)) *(1-$ $20.84 / 100) * 22.4 / 12=1.0805 \mathrm{~m}^{3}$

- $\quad \mathrm{N}$ [kg]: $0.09177 * 30 / 100+0.008217 * 50 / 100=0.03164 \mathrm{~kg}$

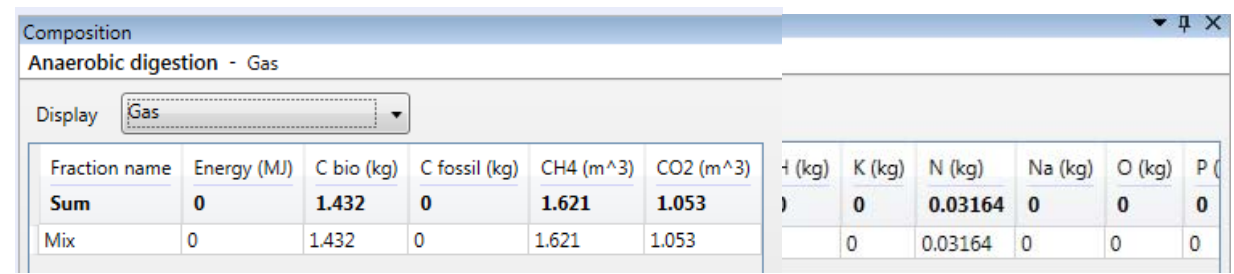

Figure S30: Composition of the gas output

The digestate output is:

- $\quad$ C bio $(v f w)=2.294-2.043 * 70 / 100 *(1-20.84 / 100 *(1-54.45 / 100))=0.9997 \mathrm{~kg}$

$($ ofp $)=3.065-1.693 * 10 / 100 *(1-20.84 / 100 *(1-52.85 / 100))=2.912 \mathrm{~kg}$

- $\quad$ C bio and $(\mathrm{vfw})=2.043 *(1-70 / 100)=0.613 \mathrm{~kg}$ $($ ofp $)=1.693 *(1-10 / 100)=1.524 \mathrm{~kg}$

- $\quad$ VS $(v f w)=4.579-1.89 * 2.043 * 70 / 100=1.876 \mathrm{~kg}$ $($ ofp $)=6.516-1.89 * 1.693 * 10 / 100=6.196 \mathrm{~kg}$

- $\quad$ LHV dry $(\mathrm{vfw})=88.389 / 4.579 *(4.579-1.89 * 2.043 * 70 / 100)=36.21 \mathrm{MJ}$ $($ ofp $)=103 / 6.516 *(6.516-1.89 * 1.693 * 10 / 100)=97.94 \mathrm{MJ}$

- $\quad \mathrm{N}(\mathrm{vfw})=0.09177 * 70 / 100=0.06424 \mathrm{~kg}$ (ofp) $=0.008217 * 50 / 100=0.004109 \mathrm{~kg}$

- All other properties are equal to the input

\begin{tabular}{|c|c|c|c|c|c|c|c|c|c|c|c|c|c|c|c|c|}
\hline \multicolumn{17}{|c|}{ Composition } \\
\hline \multicolumn{17}{|c|}{ Anaerobic digestion - Digestate } \\
\hline Display & Default & $\bullet$ & & & & & & & & & & & & & & \\
\hline \multicolumn{2}{|c|}{ Fraction name } & Total Wet Weight $(\mathrm{kg})$ & TS (kg) & Water $(\mathrm{kg})$ & vS (kg) & Ash (kg) & Energy (MJ) & C bio (kg) & $\mathrm{C}$ bio and $(\mathrm{kg})$ & C fossil $(\mathrm{kg})$ & $\mathrm{Ca}(\mathrm{kg})$ & $\mathrm{Cl}(\mathrm{kg})$ & $F(\mathrm{~kg})$ & $H(k g)$ & $\mathrm{K}(\mathrm{kg})$ & $\mathrm{N}(\mathrm{kg})$ \\
\hline \multicolumn{2}{|c|}{ Sum } & 26.98 & 10.02 & 16.96 & 8.072 & 1.952 & 134.1 & 3.927 & 2.136 & 0.02699 & 0.6653 & 0.0328 & 0.001305 & 0.7296 & 0.06231 & 0.06835 \\
\hline \multicolumn{2}{|c|}{ Vegetable food waste } & 18.29 & 2.127 & 16.17 & 1.876 & 0.2512 & 36.21 & 1.013 & 0.6129 & 0.01154 & 0.02681 & 0.02705 & 0.000483 & 0.3188 & 0.06134 & 0.06424 \\
\hline \multicolumn{2}{|c|}{ Office paper } & 8.685 & 7.897 & 0.7875 & 6.196 & 1.701 & 97.9 & 2.914 & 1.523 & 0.01545 & 0.6385 & 0.005752 & 0.0008217 & 0.4109 & 0.0009696 & 0.004109 \\
\hline
\end{tabular}

Figure S31: Composition of the digestate output

Figure S32 provides explanations about the calculations happening in the anaerobic digestion process. 


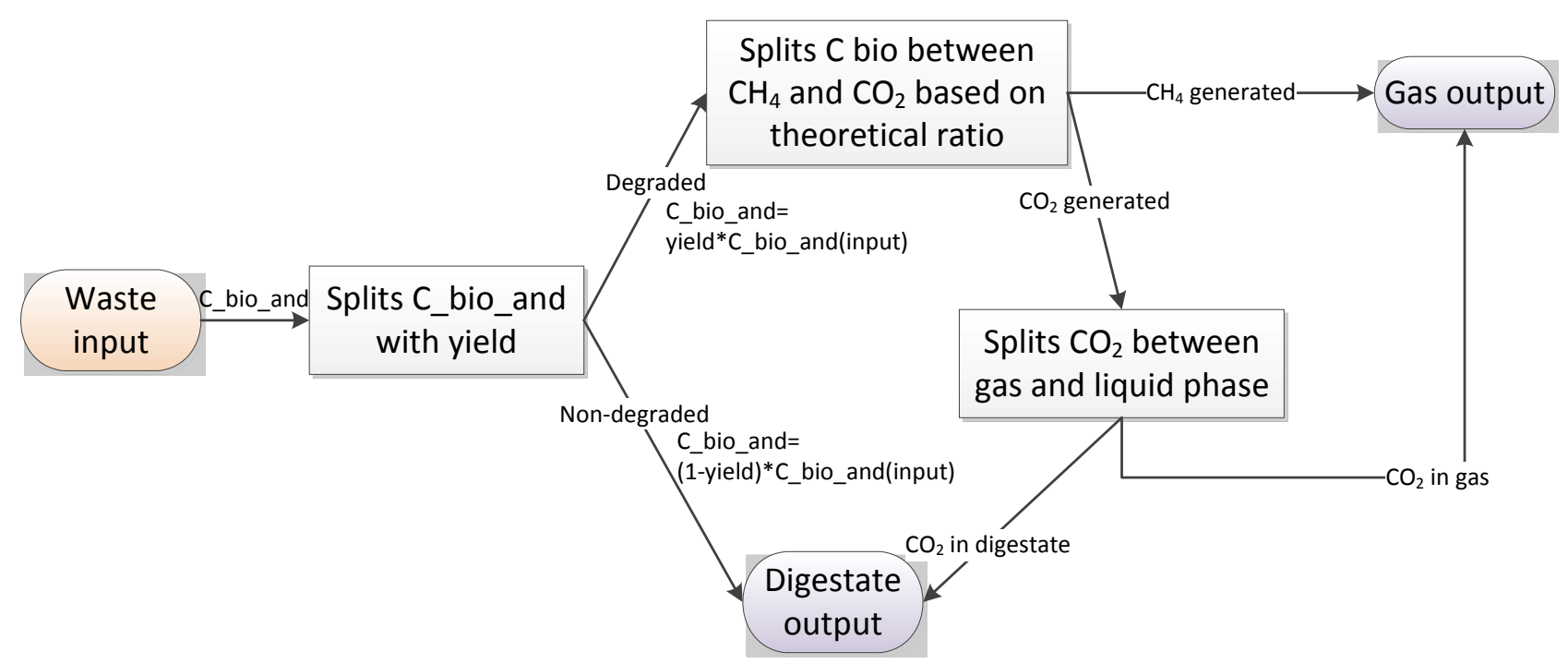

Figure S32: Calculations in the “Anaerobic digestion” process

\subsection{Use-on-land}

If the tickbox is ticked in "Material transfer", the process has one output defined as the exact opposite of the input, i.e. for each material property of the input of value $\mathrm{x}$, the material property of the output has a value "$\mathrm{x}$ ". If the tickbox is not ticket, there is no output. 


\section{LCA calculations in all processes: process-specific emissions and external processes}

Here we explain how the calculations are performed in material processes and external processes, concerning all data specified in the "Process exchanges" tab. Note that some material processes templates include also emissions happening in the "Material transfer" tab, these calculations are detailed in Section 3. The steps of characterization, normalization and weighting are always the same, and are thus only explained in Section 2.

The example which will be used in Section 2 is presented in Figure S33. Throughout the example we will use an impact category called "IPCC 2007, climate change, GWP 100a" which has characterisation factors of 1 for "carbon dioxide, fossil, air, unspecified" and 25 for "Methane, fossil, air, unspecified" (kg $\mathrm{CO}_{2}$-eq/kg).

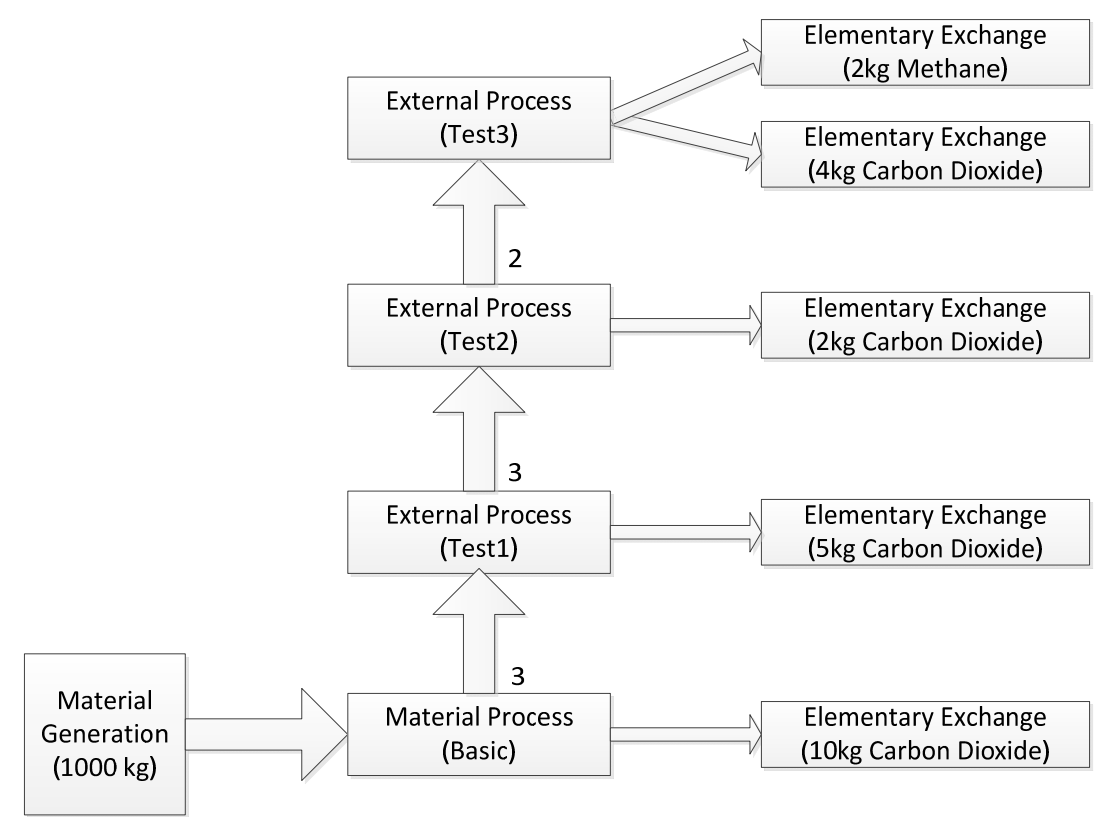

Figure S33: Example used in Section 2

\subsection{An external process with only process-specific emissions: test3}

The external process "test3" is presented in Figure S34. It has two process-specific emissions (we call all elementary exchanges in the "Process exchanges" tab of a process "process-specific" as they are related to the process being operated):

\begin{tabular}{|c|c|c|c|c|c|}
\hline \multicolumn{6}{|l|}{ Process exchanges } \\
\hline \multicolumn{6}{|c|}{ - External processes } \\
\hline \multicolumn{6}{|c|}{ Add external process } \\
\hline \multicolumn{6}{|c|}{ - Elementary exchanges } \\
\hline \multicolumn{6}{|c|}{ Add elementary exchange } \\
\hline Name & Compartment & Sub compartment & Amount & Unit & Comment \\
\hline ( Carbon dioxide, fossil & air & unspecified & 4 & $\mathrm{~kg}$ & \\
\hline X Methane, fossil & air & unspecified & 2 & $\mathrm{~kg}$ & \\
\hline
\end{tabular}

Figure S34: Process exchanges in external process test3

The LCI of an external process such as "test3" is presented in Figure S35 and calculated as: 
- All elementary exchanges which are directly in the "Process exchange" tab of "test3" are called "Process-specific emissions" and are simply put directly in the LCI (see the $6^{\text {th }}$ column below).

- For each external process used (in "test3" none), bring the LCI of the process (explained in Section 2.2 with "test2" process).

- The total column $\left(5^{\text {th }}\right.$ column$)$ shows simply the sum for all columns for the functional unit for the process.

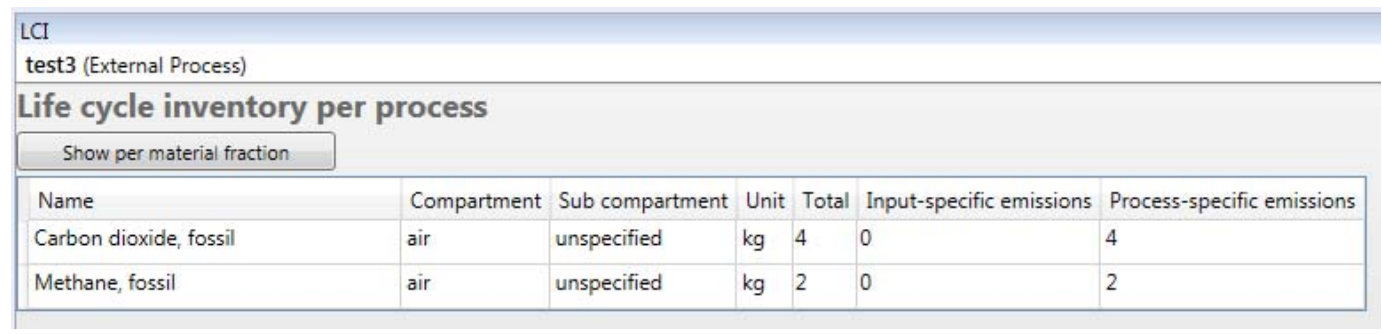

Figure S35: LCI of external process test3

In the characterized impacts, "per substance" view, the calculation is taking the LCI line by line: for each elementary exchange of the LCI, multiply the total amount by the characterization factor of the impact category. So for "test3" characterised impacts are presented in Figure S36 and calculated as:

- Carbon dioxide: amountOfCarbonDioxideInLCI*CharacterisationFactorOfCarbonDioxide $=4 * 1=4$

- Methane, fossil: amountOfMethaneInLCI $*$ CharacterisationFactorOfMethane $=2 * 25=50$

\begin{tabular}{|c|c|c|c|c|}
\hline \multicolumn{3}{|c|}{ Charact. imp. } & \multicolumn{2}{|c|}{ test3 (External Process) } \\
\hline \multicolumn{5}{|c|}{ Life cycle impact assessment: characterised impacts } \\
\hline LCIA Method: & the & d & Show per pro & cess view \\
\hline \multicolumn{2}{|l|}{ Name } & Compartment & Sub compartment & $\begin{array}{l}\text { IPCC 2007, climate change, GWP } 100 a \\
\mathrm{~kg} \mathrm{CO} 2-\mathrm{Eq}\end{array}$ \\
\hline \multicolumn{2}{|l|}{ Sum } & & & 54 \\
\hline \multicolumn{2}{|c|}{ Carbon dioxide, fossil } & air & unspecified & 4 \\
\hline \multicolumn{2}{|c|}{ Methane, fossil } & air & unspecified & 50 \\
\hline
\end{tabular}

Figure S36: Characterised impacts, per substance, of external process test3

In the characterized impacts, "per process" view, we take the LCI results column per column: for each subprocess, calculate the total impact as the sum (for all elementary exchanges) of their amount multiplied by the characterization factor.

In "test3", there is only one sub-process called "Process-specific emissions" and it is contributing to: amountOfCarbonDioxideInLci(Process specific emissions)*CharacterisationFactorOfCarbonDioxide + amountOfMethaneInLCI(Process specific emissions) $*$ CharacterisationFactorOfMethane $=4 * 1+2 * 25=54$

Results are shown in Figure S37. If "test3" was calling another external process, we would do the same calculation for this process (see the example in section 2.2). 


\begin{tabular}{l} 
Charact, imp. \\
test3 (External Process) \\
\hline Life cycle impact assessment: characterised impacts \\
\begin{tabular}{|l|l|}
\hline LCIA Method: & theTestingMethod \\
\hline Name & $\begin{array}{l}\text { IPCC 2007, climate change, GWP 100a } \\
\mathrm{kg} \mathrm{CO2-Eq}\end{array}$ \\
\hline Sum & 54 \\
\hline Process-specific emissions & 54 \\
\hline Input-specific emissions & 0 \\
\hline
\end{tabular}
\end{tabular}

Figure S37: Characterised impacts, per process, of external process test3

\subsection{An external process with process-specific emissions and one external process: test2}

Figure S38 presents the external process "test2".

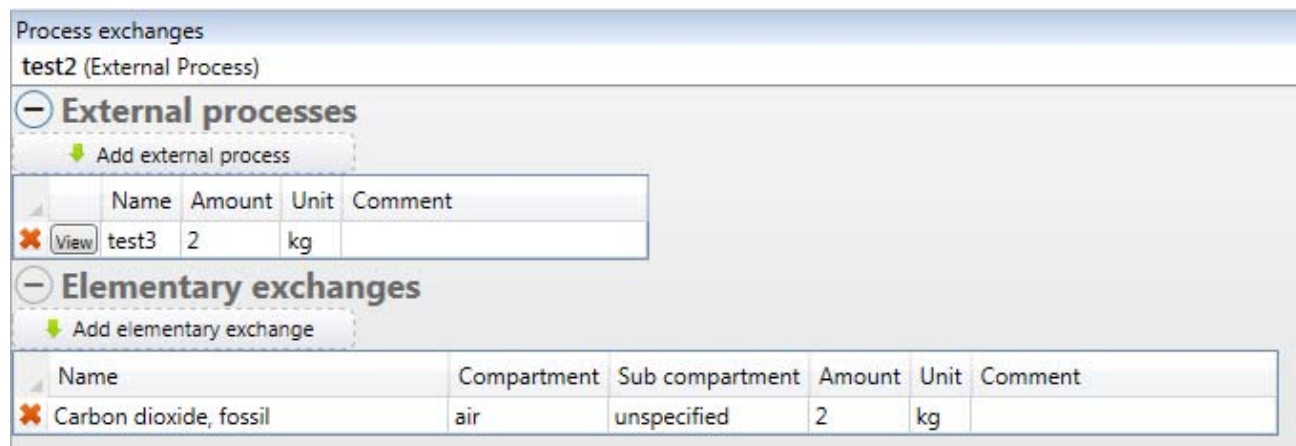

Figure S38: Process exchanges in external process test2

The LCI of "test2" has now two subprocesses: "Process specific emissions" and "test3". It is shown in Figure S39 and calculated as:

- All elementary exchanges which are directly in the "Process exchanges" tab of "test2" are called "Process-specific emissions" and are simply put directly in the LCI (see the $6^{\text {th }}$ column below),

- For each external process used, you have to multiply the LCI of the process by the amount. In our example, "test 2 " uses $2 \mathrm{~kg}$ of test 3 so in the column "test 3 " we have:

o Carbon dioxide: amount(test3UsedInTest2)* amountOfCarbonDioxideInLci(test3) $=2 * 4=8$.

o Methane: amount(test3UsedInTest2) $*$ amountOfMethaneInLci(test3) $=2 * 2=4$.

LCI
test2 (External Process)
\begin{tabular}{|l|l|l|l|l|l|l|l|}
\hline Life cycle inventory per process \\
\begin{tabular}{|l|l|l|l|l|l|l|}
\hline \multicolumn{1}{|l|}{ Show per material fraction } \\
\hline Name
\end{tabular} & Compartment & Sub compartment & Unit & Total & Input-specific emissions & Process-specific emissions & test3 \\
\hline Carbon dioxide, fossil & air & unspecified & $\mathrm{kg}$ & 10 & 0 & 2 & 8 \\
\hline Methane, fossil & air & unspecified & $\mathrm{kg}$ & 4 & 0 & 0 & 4 \\
\hline
\end{tabular}

Figure S39: LCI of external process test2

In the characterized impacts per substance (Figure S40) the calculation is the following:

- Carbon dioxide: amountOfCarbonDioxideInLCI*CharacterisationFactorOfCarbonDioxide $=10 * 1=10$.

- Methane: amountOfMethaneInLCI*CharacterisationFactorOfMethane $=4 * 25=100$. 


Charact. imp.
test2 (External Process)
\begin{tabular}{l|l|l|l|}
\hline Life cycle impact assessment: characterised impacts \\
LCIA Method: & Compartment & Sub compartment & $\begin{array}{l}\text { IPCC 2007, climate change, GWP 100a } \\
\mathrm{kg} \mathrm{CO2-Eq}\end{array}$ \\
\hline theTtingMethod & & $\mathbf{1 1 0}$ \\
\hline Name & & Show per process view \\
\hline Sum & air & unspecified & 10 \\
\hline Carbon dioxide, fossil & air & unspecified & 100 \\
\hline Methane, fossil & & & \\
\hline
\end{tabular}

Figure S40: Characterised impacts, per substance, of external process test2

In the characterized impacts per process (Figure S41) the details of each subprocess "test3" and "processspecific emission" are calculated:

- For the subprocess "test3":

amountOfCarbonDioxideInLCIPerProcess(Test3)*CharacterisationFactorOfCarbonDioxide + amountOfMethaneInLCIPerProcess(Test 3$) *$ CharacterisationFactorOfMethane $=8 * 1+$ $4 * 25=108$

- For Process-specific emissions: amountOfCarbonDioxideInLCIPerProcess(ProcessSpecific)*CharacterisationFactorOfCarbonDi oxide + amountOfMethaneInLCIPerProcess(ProcessSpecific)*CharacterisationFactorOfMethane $=2 * 1+0 * 25=2$

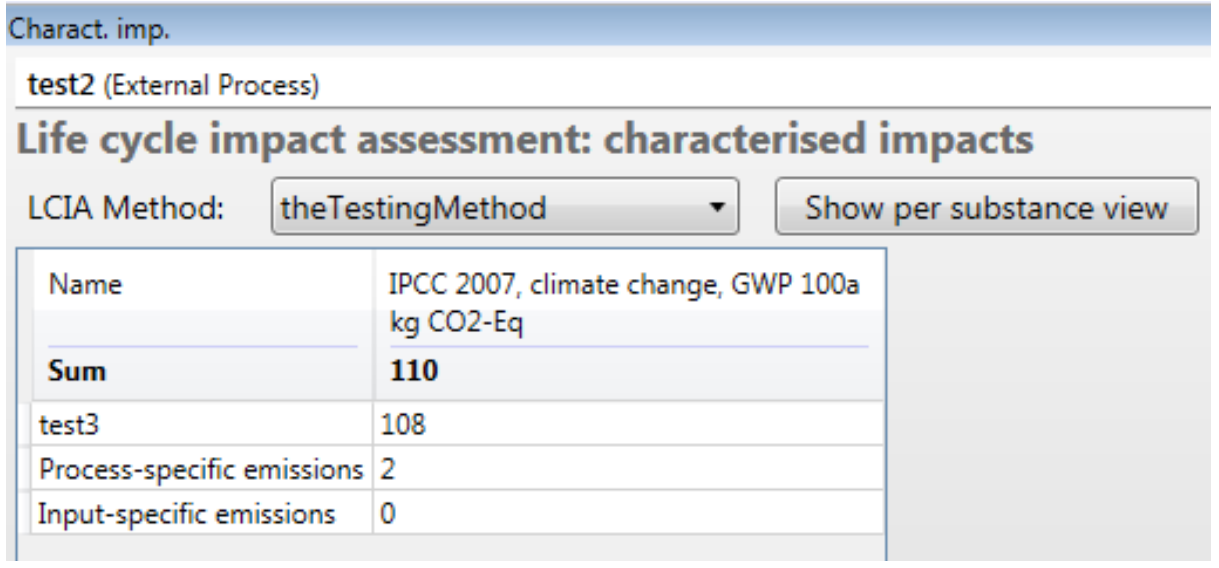

Figure S41: Characterised impacts, per process, of external process test2

\subsection{An external process with process-specific emissions and an external process that uses another external process: test1}

Figure S42 presents "test1" an external process that uses "test2". 


\begin{tabular}{|c|c|c|c|c|c|c|c|c|c|}
\hline \multicolumn{10}{|c|}{$\begin{array}{l}\text { Process exchanges } \\
\text { test1 (External Process) }\end{array}$} \\
\hline \multirow{2}{*}{\multicolumn{10}{|c|}{$\begin{array}{l}\text { - External processes } \\
\text { Add external process }\end{array}$}} \\
\hline & & & & & & & & & \\
\hline$\Delta$ & Name & Amount & Unit & \multicolumn{2}{|c|}{ Comment } & & & & \\
\hline & View test2 & 3 & $\mathrm{~kg}$ & & & & & & \\
\hline \multirow{2}{*}{\multicolumn{10}{|c|}{ - Elementary exchanges }} \\
\hline \multicolumn{5}{|c|}{ Add elementary exchange } & & & & & \\
\hline \multicolumn{5}{|c|}{ Name } & Compartment & Sub compartment & Amount & Unit & Comment \\
\hline \multicolumn{5}{|c|}{ * Carbon dioxide, fossil } & air & unspecified & 5 & $\mathrm{~kg}$ & \\
\hline
\end{tabular}

Figure S42: Process exchanges in external process test1

The LCI of "test1" is shown in Figure S43(again it has two sub-processes). The calculation is the same as in section 2.2:

- All elementary exchanges which are directly in the "Process exchanges" tab of "test1" are called "Process-specific emissions" and are simply put directly in the LCI (see the $6^{\text {th }}$ column below),

- For each external process used, you have to multiply the LCI of the process by the amount. In our example, "test 1 " uses $3 \mathrm{~kg}$ of test 2 so in the column "test 2 " we have:

o Carbon dioxide: amount(test2UsedInTest1)* amountOfCarbonDioxideInLCI(test 2$)=3 * 10=30$

o Methane: amount(test2UsedInTest 1$) *$ amountOfMethaneInLCI(test2) $=3 * 4=12$

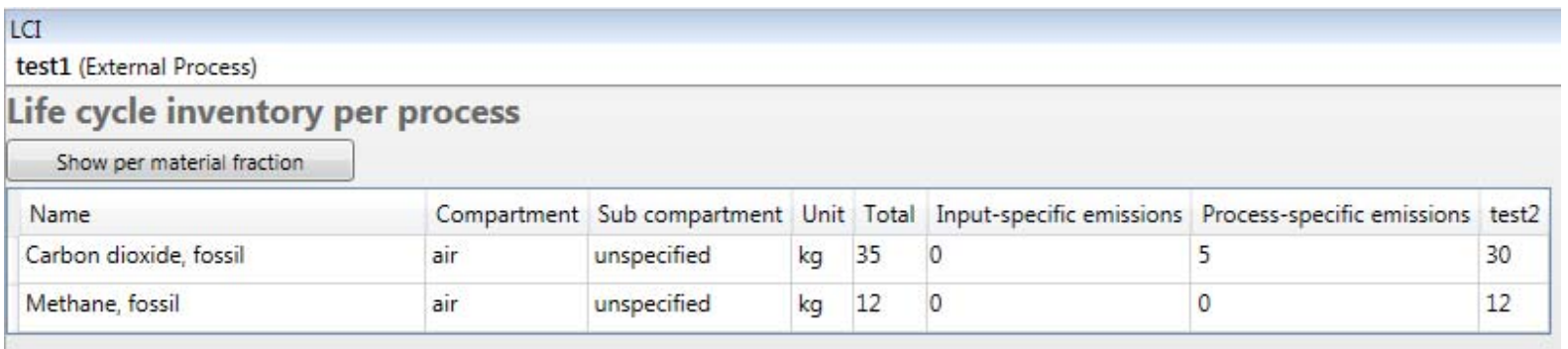

Figure S43: LCI of external process test1

In the characterized impacts per substance (Figure S44) the calculation is:

- Carbon dioxide: amountOfCarbonDioxideInLci*CharacterisationFactorOfCarbonDioxide $=35 * 1=35$

- Methane: amountOfMethaneInLci*CharacterisationFactorOfMethane $=12 * 25=300$

\begin{tabular}{|c|c|c|c|c|}
\hline \multicolumn{5}{|c|}{ test1 (External Process) } \\
\hline \multicolumn{5}{|c|}{ Life cycle impact assessment: characterised impacts } \\
\hline LCIA Method: & the & $d$ & Show per pro & cess view \\
\hline \multicolumn{2}{|l|}{ Name } & Compartment & Sub compartment & $\begin{array}{l}\text { IPCC 2007, climate change, GWP } 100 \mathrm{a} \\
\mathrm{kg} \mathrm{CO} 2-\mathrm{Eq}\end{array}$ \\
\hline \multicolumn{2}{|l|}{ Sum } & & & 335 \\
\hline \multicolumn{2}{|c|}{ Carbon dioxide, fossil } & air & unspecified & 35 \\
\hline \multicolumn{2}{|c|}{ Methane, fossil } & air & unspecified & 300 \\
\hline
\end{tabular}

Figure S44: Characterised impacts, per substance, of external process test1 
In the characterized impacts per process (Figure S45) the details of each subprocess: "test2" and "processspecific emission" are calculated:

- Test2: amountOfCarbonDioxideInLCIiPerProcessOfTest $2 *$ CharacterisationFactorOfCarbonDioxide + amountOfMethaneInLCIPerProcessOfTest $2 *$ CharacterisationFactorOfMethane $=30 * 1+$ $12 * 25=330$

- Process specific emissions: amountOfCarbonDioxideInLCIPerProcessOfProcessSpecific*CharacterisationFactorOfCarbonDioxi de + amountOfMethaneInLCIPerProcessOfProcessSpecific $*$ CharacterisationFactorOfMethane $=5 * 1$ $+0 * 25=5$

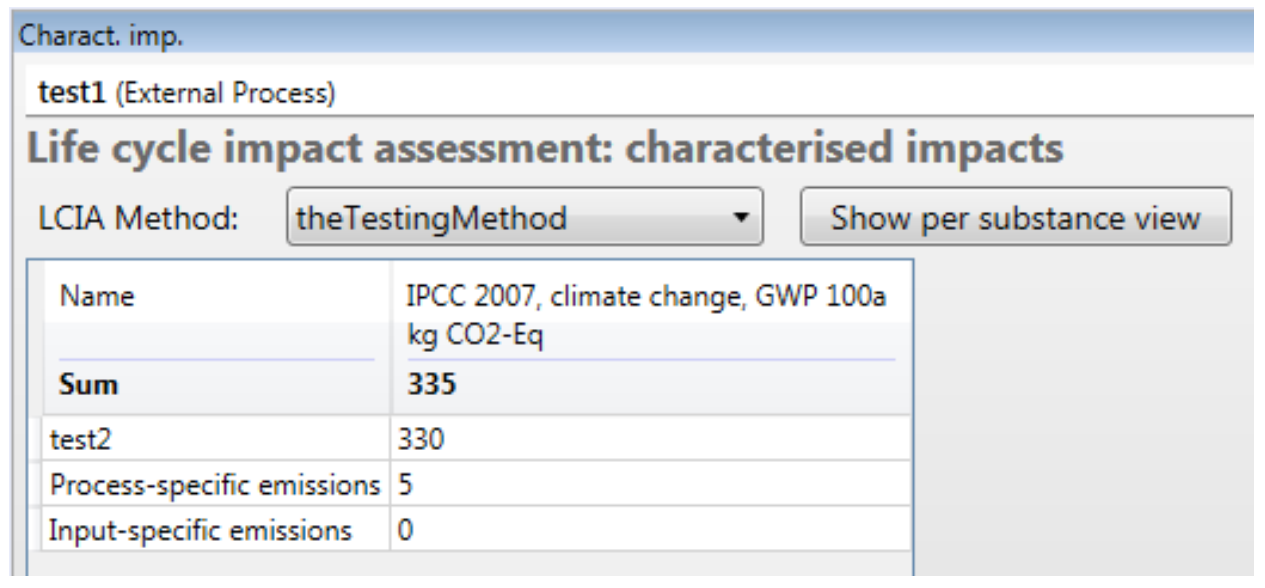

Figure S45: Characterised impacts, per process, of external process test1

\subsection{A material process uses this external process}

The scenario presented in Figure S46 has $1000 \mathrm{~kg}$ waste (100\% vegetable food waste) going to a basic process that uses $-3 \mathrm{~kg}$ of test 1 per MJ energy input and emits $10 \mathrm{~kg}$ of carbon dioxide.

Scenario 1

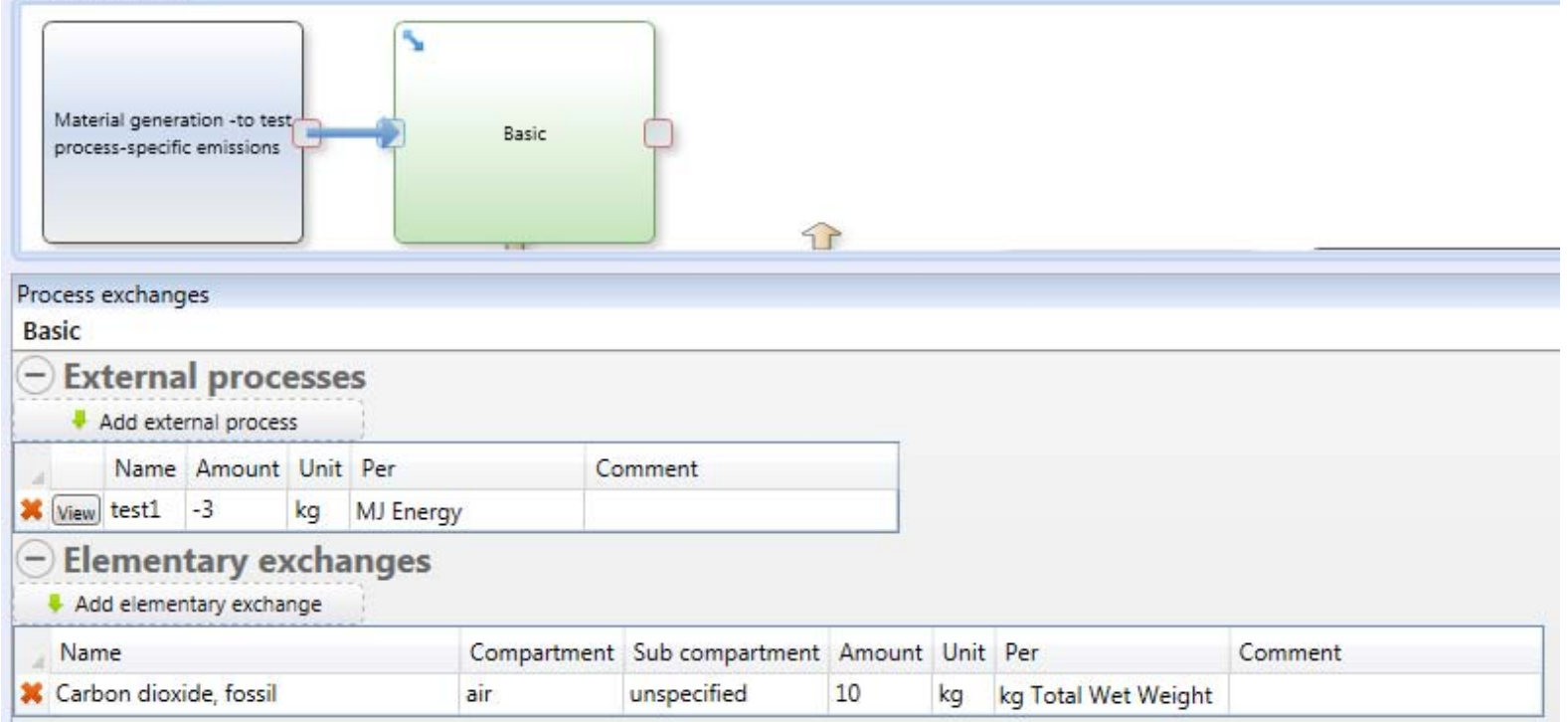

Figure S46: Process exchanges in basic process

The LCI of material processes is similar to the one of external processes (Figure S47):

- All elementary exchanges which are in the "Process exchanges" tab of "Basic" are called "Processspecific emissions". Their amount in the LCI is: 
“Amount”ffield *amount_of_the_selected_material_property_in_input_material

In our example, we emit $10 \mathrm{~kg}$ carbon dioxide per $\mathrm{kg}$ total wet weight (here equal to 1000) so we emit: $10 * 1000=1 \mathrm{E} 4 \mathrm{~kg}$.

- For each external process used, we get its LCI by:

LCI_of_the_external_process * “Amount”_field

*amount_of_the_selected_material_property_in_input_material

In our example, we use $-3 \mathrm{~kg}$ of test 1 per MJ of Energy of the input (here equal to $4209 \mathrm{MJ}$ ), so we calculate in the $6^{\text {th }}$ column:

o Carbon dioxide: amountOfCarbonDioxideInLCI(test1) *amount(test1UsedInBasic) $*$ Energy (input) $=35 *(-3) * 4209=-4.419 \mathrm{E} 5$

o Methane: amountOfMethaneInLCI(test1) *amount(test1UsedInBasic) * Energy(input) $=12$ $*(-3) * 4209=-1.515 \mathrm{E} 5$

\begin{tabular}{|c|c|c|c|c|c|c|c|}
\hline \multicolumn{8}{|l|}{ LCI } \\
\hline \multicolumn{8}{|l|}{ Basic } \\
\hline \multicolumn{8}{|c|}{ Life cycle inventory per process } \\
\hline \multicolumn{8}{|l|}{ Show per material fraction } \\
\hline Name & Compartment & Sub compartment & Unit & Total & Input-specific emissions & Process-specific emissions & test1 \\
\hline Carbon dioxide, fossil & air & unspecified & $\mathrm{kg}$ & $-4.319 E+05$ & 0 & 9999 & $-4.419 \mathrm{E}+05$ \\
\hline Methane, fossil & air & unspecified & $\mathrm{kg}$ & $-1.515 E+05$ & 0 & 0 & $-1.515 E+05$ \\
\hline
\end{tabular}

Figure S47: LCI of basic process

In the characterized impacts per substance (Figure S48) the calculation is the following:

- Carbon dioxide: amountOfCarbonDioxideInLCI $*$ CharacterisationFactorOfCarbonDioxide $=$ $-4.319 \mathrm{E} 5 * 1=-4.319 \mathrm{E} 5$

- Methane: amountOfMethaneInLci*CharacterisationFactorOfMethane $=-1.515 \mathrm{E} 5 * 25=-3.787 \mathrm{E} 6$

\begin{tabular}{|c|c|c|c|c|}
\hline \multicolumn{5}{|l|}{ Charact, imp. } \\
\hline \multicolumn{5}{|l|}{ Basic } \\
\hline \multicolumn{5}{|c|}{ Life cycle impact assessment: characterised impacts } \\
\hline LCIA Method: & \multicolumn{2}{|c|}{ theTestingMethod } & \multicolumn{2}{|c|}{ Show per process view } \\
\hline Name & & Compartment & Sub compartment & $\begin{array}{l}\text { IPCC 2007, climate change, GWP } 100 \mathrm{a} \\
\mathrm{kg} \mathrm{CO} 2-\mathrm{Eq}\end{array}$ \\
\hline Sum & & & & $-4.22 \mathrm{E}+06$ \\
\hline Carbon dioxide, fo & ssil & air & unspecified & $-4.319 E+05$ \\
\hline Methane, fossil & & air & unspecified & $-3.788 E+06$ \\
\hline
\end{tabular}

Figure S48: Characterised impacts, per substance, of basic process

In the characterized impacts per process (Figure S49) the details of each subprocess: "test1" and "processspecific emission" are calculated:

- Test1: amountOfCarbonDioxideInLCIPerProcess(Test1)*CharacterisationFactorOfCarbonDioxide + amountOfMethaneInLCIPerProcess $($ Test 1$) *$ CharacterisationFactorOfMethane $=-4.419 \mathrm{E} 5 * 1+$ $(-1.515 \mathrm{E} 5) * 25=-4.229 \mathrm{E} 6$

- Process specific emissions: amountOfCarbonDioxideInLciPerProcess(ProcessSpecific)*CharacterisationFactorOfCarbonDioxid 
e + amountOfMethaneInLciPerProcess $($ ProcessSpecific) $*$ CharacterisationFactorOfMethane $=$ $9999 * 1+0 * 25=1 \mathrm{E} 4$

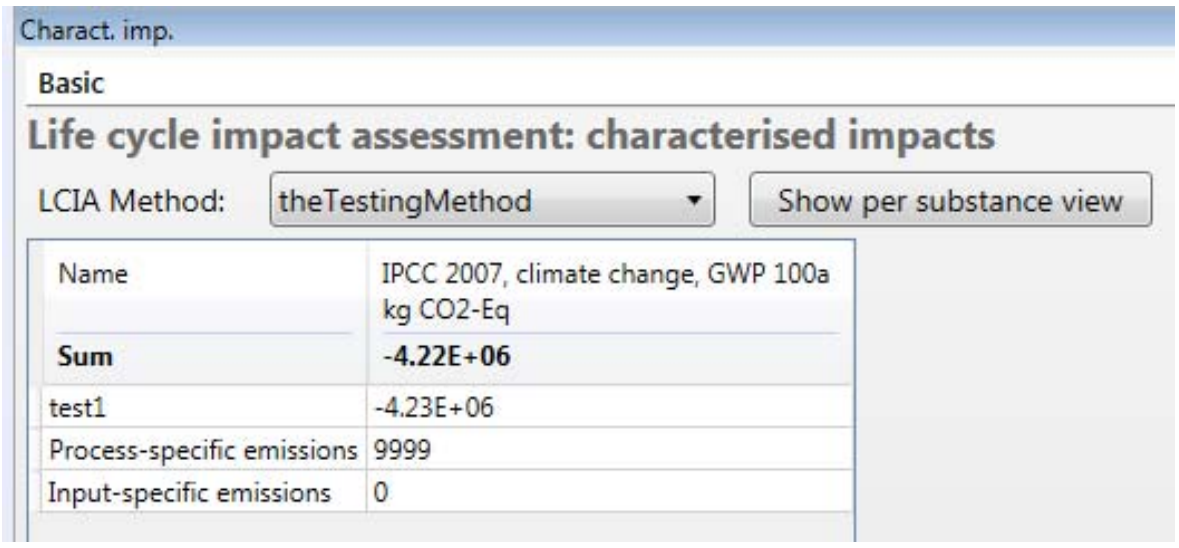

Figure S49: Characterised impacts, per process, of basic process

\subsection{Normalised and weighted impacts}

The tabs "Norm. imp" and "Weight. Imp." are very similar to "Charact. Imp." with the same "per substance" and "per process" views. Figure S50 presents the normalization and weighting factors used.

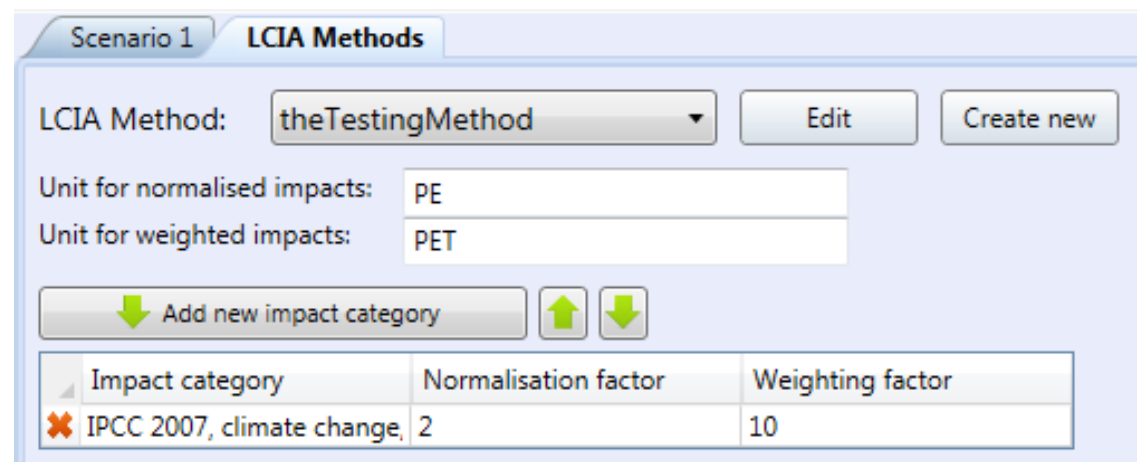

Figure S50: Normalisation and weighting factors used

The normalized impacts are obtained by dividing each number in the characterized impacts by the normalization factor of the impact category.

In the example of the scenario, we calculate based on characterized impact values (Figure S51):

- Carbon dioxide: we had -4.32E5 kg so the normalised impact for the category "IPCC 2007, climate change, GWP 100 a" is: $-4.32 \mathrm{E} 5 / 2=-2.16 \mathrm{E} 5 \mathrm{PE}$

- Methane: we had 3.79E6 kg so normalised impact for the category "IPCC 2007, climate change, GWP 100 a" is: $-3.79 \mathrm{E} 6 / 2=-1.9 \mathrm{E} 6 \mathrm{PE}$

Norm. imp.
Basic
\begin{tabular}{l|l|l|l|}
\hline Life cycle impact assessment: normalised impacts \\
LCIA Method: & theTestingMethod & Show per process view \\
\hline Name & Compartment & Sub compartment & \multicolumn{1}{|l|}{$\begin{array}{l}\text { IPCC 2007, climate change, GWP 100a } \\
\text { PE }\end{array}$} \\
\hline Sum & & & $-2.11 E+06$ \\
\hline Carbon dioxide, fossil & air & unspecified & $-2.16 \mathrm{E}+05$ \\
\hline Methane, fossil & air & unspecified & $-1.894 \mathrm{E}+06$ \\
\hline
\end{tabular}


Figure S51: Normalised impacts, per substance, of basic process

And we also divide the characterised impacts in the "per process" view (Figure S52).

\begin{tabular}{|c|c|c|c|}
\hline Norm. imp. & & & \\
\hline Basic & & & \\
\hline Life cycle im & pact a & assessment: normal & d in \\
\hline LCIA Method: & theTes & tingMethod & \\
\hline Name & & $\begin{array}{l}\text { IPCC } 2007 \text {, climate change, } \\
\text { PE }\end{array}$ & $100 a$ \\
\hline Sum & & $-2.11 E+06$ & \\
\hline test1 & & $-2.115 E+06$ & \\
\hline Process-specific & nissions & 4999.5 & \\
\hline Input-specific em & ssions & 0 & \\
\hline
\end{tabular}

Figure S52: Normalised impacts, per process, of basic process

And the weighted impacts are obtained by multiplying each number in the normalised impacts by the weighting factor of the impact category.

In the example of the scenario, in the normalised imp. per substance view, we had for:

- Carbon dioxide: -2.16E5 kg so the weighted impact for the category "IPCC 2007, climate change, GWP 100 a" is: $-2.16 \mathrm{E} 5 * 10=-2.16 \mathrm{E} 6 \mathrm{PE}$

- Methane: -1.9E6 kg so normalised impact for the category "IPCC 2007, climate change, GWP 100 a" is: $-1.9 \mathrm{E} 6 * 10=-1.9 \mathrm{E} 7 \mathrm{PE}$

Figure S53 and S54 show the weighted impacts, per substance and per process, respectively.

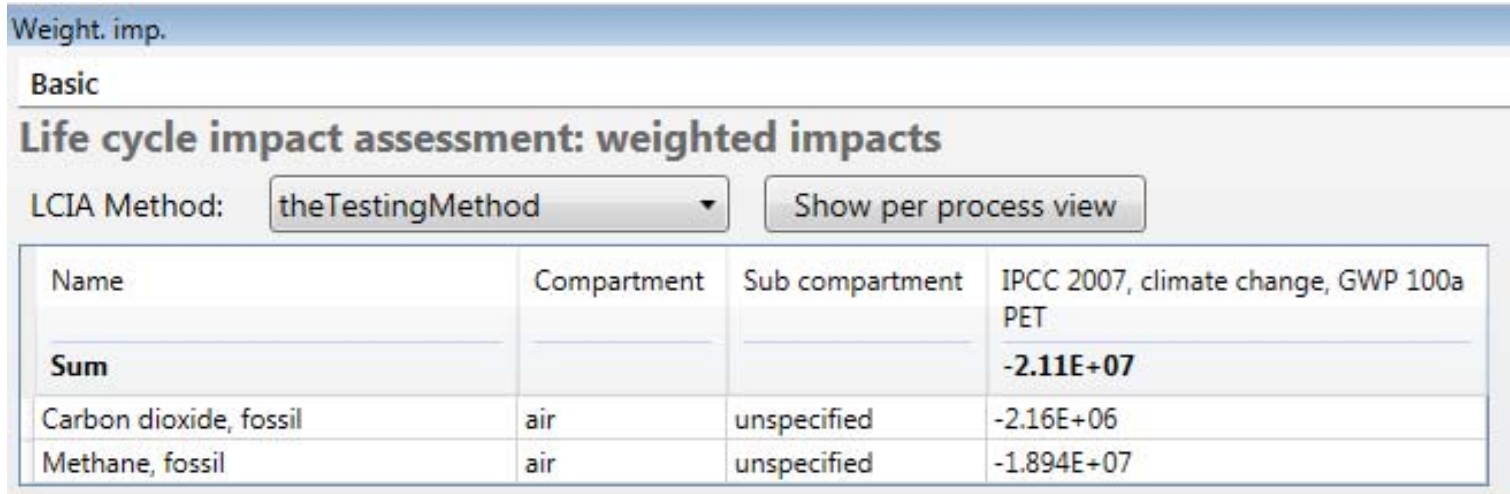

Figure S53: Weighted impacts, per substance, of basic process

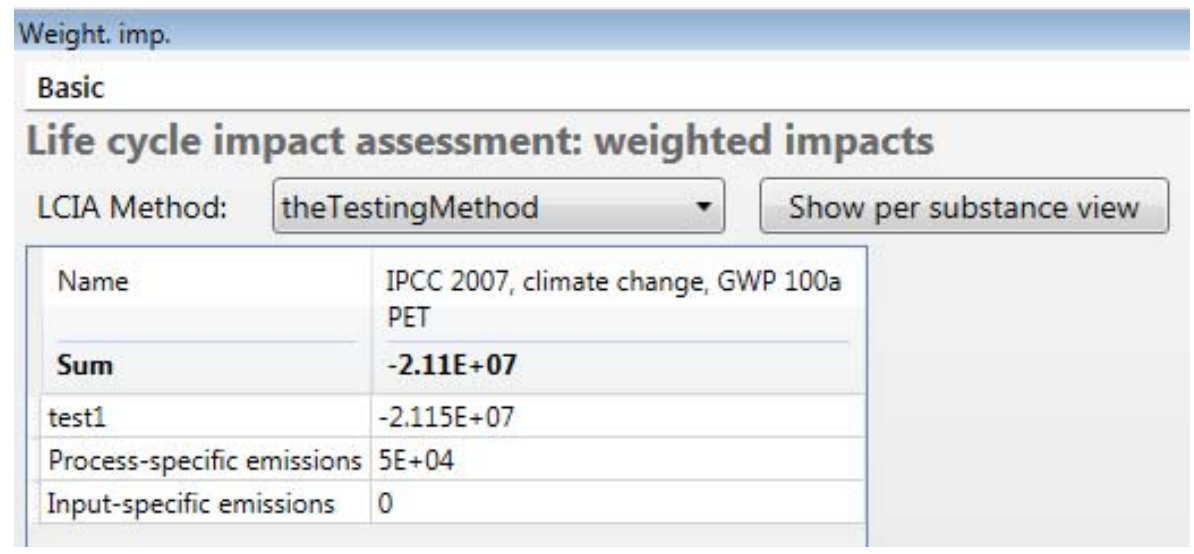


Figure S54: Weighted impacts, per process, of basic process

\subsection{Particular case: Material generation}

In the material generation process, the user can attach the use of an external process to each material fraction by ticking the tick box "Include upstream impacts" (See Figure S55).

\begin{tabular}{|c|c|c|c|c|c|}
\hline \multicolumn{6}{|l|}{$\begin{array}{l}\text { Material transfer } \\
\text { Material qeneration }\end{array}$} \\
\hline \multicolumn{6}{|c|}{ Material generation: amount and fractions } \\
\hline \multicolumn{6}{|l|}{ Total amount $(\mathrm{kg}) \quad 30$} \\
\hline \multicolumn{6}{|c|}{$\checkmark$ Include upstream impacts } \\
\hline Add fraction & Norma & se composition to 10 & & & \\
\hline Material fraction & $\%$ & Upstream impacts & Amount pr kg fraction & Unit & \\
\hline * Vegetable food waste & 70 & test3 & 2 & $\mathrm{~kg}$ & View \\
\hline Office paper & 30 & test1 & 3 & $\mathrm{~kg}$ & View \\
\hline
\end{tabular}

Figure S55: Process exchanges in material generation process

The LCI calculation is for each external process:

LCI $=$ Total_amount $*$ Percentage_field $/ 100 *$ AmountPerKgFraction *LCI(external_process) In the example, let's calculate for test3:

- $\quad$ Carbon dioxide: $30 * 70 / 100 * 2 * 4=168 \mathrm{~kg}$

- $\quad$ Methane: $30 * 70 / 100 * 2 * 2=84 \mathrm{~kg}$

And for test1:

- $\quad$ Carbon dioxide: $30 * 30 / 100 * 3 * 35==945 \mathrm{~kg}$

- $\quad$ Methane: $30 * 30 / 100 * 3 * 12=324 \mathrm{~kg}$

\begin{tabular}{|c|c|c|c|c|c|c|c|}
\hline \multicolumn{8}{|l|}{ LCI } \\
\hline \multicolumn{8}{|l|}{ Material generation } \\
\hline \multicolumn{8}{|c|}{ Life cycle inventory per process } \\
\hline \multicolumn{8}{|c|}{ Show per material fraction } \\
\hline Name & Compartment & Sub compartment & Unit & Total & Input-specific emissions & test3 & test1 \\
\hline Carbon dioxide, fossil & air & unspecified & $\mathrm{kg}$ & 1113 & 0 & 168 & 945.1 \\
\hline Methane, fossil & air & unspecified & $\mathrm{kg}$ & 408 & 0 & 84.01 & 324 \\
\hline
\end{tabular}

Figure S56: LCI of material generation process

Characterised impact per substance works at process level and at scenario level are calculated as usual by multiplying the total amounts by the characterization factors (Figure S57).

\begin{tabular}{|c|c|c|c|c|}
\hline \multicolumn{5}{|l|}{ Charact. imp. } \\
\hline \multicolumn{5}{|c|}{ Material generation } \\
\hline \multicolumn{5}{|c|}{ Life cycle impact assessment: characterised impacts } \\
\hline LCIA Method: & theTestingMethoc & - & Show per pro & cess view \\
\hline \multicolumn{2}{|l|}{ Name } & Compartment & Sub compartment & $\begin{array}{l}\text { IPCC 2007, climate change, GWP 100a } \\
\mathrm{kg} \mathrm{CO2-Eq}\end{array}$ \\
\hline \multicolumn{2}{|c|}{ Sum } & & & $1.131 \mathrm{E}+04$ \\
\hline \multicolumn{2}{|c|}{ Carbon dioxide, fossil } & air & unspecified & 1113 \\
\hline \multicolumn{2}{|c|}{ Methane, fossil } & air & unspecified & $1.02 \mathrm{E}+04$ \\
\hline
\end{tabular}


Figure S57: Characterised impact, per substance, of material generation process

Characterised impact per process is calculated by calculating the impact for each external process:

sum_for_each_ele_exch [Total_amount *Percentage_field/100*AmountPerKgFraction

*LCI(external_process) *characterization_factor(elem. exch)]

In our example, we use an impact category with the characterization factor of 1 for "carbon dioxide" and 25 for "methane", so:

$$
\begin{aligned}
& \text { o test3: } 30 * 70 / 100 * 2 * 4 * 1+30 * 70 / 100 * 2 * 2 * 25=168 * 1+84 * 25=2268 \\
& \text { o test } 1: 30 * 30 / 100 * 3 * 35 * 1+30 * 30 / 100 * 3 * 12 * 25=945 * 1+324 * 25=9045
\end{aligned}
$$

So the characterized impacts are as shown in Figure S58 at process level.

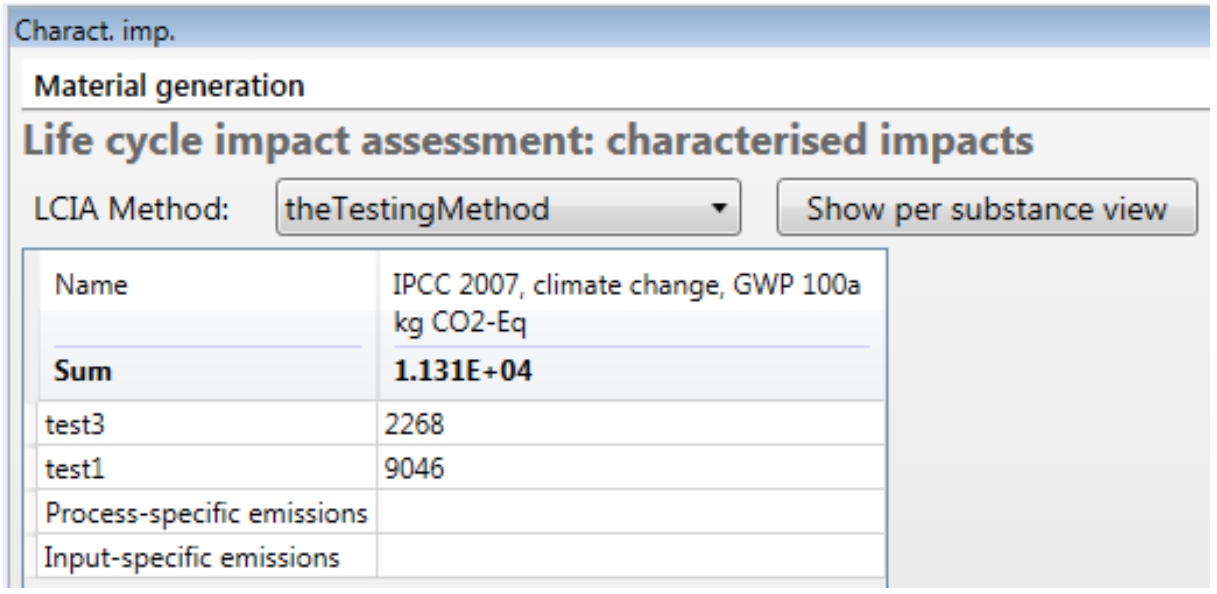

Figure S58: Characterised impact, per process, of material generation process

\subsection{Particular case: Energy generation}

This process is similar to material generation process except that we need to back-calculate the "Total

\begin{tabular}{|c|c|c|c|c|c|c|c|}
\hline \multicolumn{8}{|c|}{ Material transfer } \\
\hline \multicolumn{8}{|c|}{ Energy generation: amount and fractions } \\
\hline \multicolumn{4}{|c|}{ Total amount (MJ) 30} & & & & \\
\hline \multicolumn{8}{|c|}{$\checkmark$ Include upstream impacts } \\
\hline \multicolumn{2}{|c|}{ Add fraction } & \multicolumn{6}{|c|}{ Normalise composition to $100 \%$} \\
\hline Mass & Material & iction & $\%$ & Upstream impacts & Amount pr $\mathrm{kg}$ fraction & Unit & \\
\hline$* \square$ & Vegetab & ood waste & 70 & test3 & 2 & $\mathrm{~kg}$ & View \\
\hline$\square$ & Office pa & & 30 & & 0 & & View \\
\hline
\end{tabular}
amount" of input.

Figure S59: Process exchanges in energy generation process

The LCI calculation is for each external process:

Total_amount(MJ) *Percentage_field(fraction)/100 /energy\%(fraction, MJ/kg) *100/TS\%(fraction) *AmountPerKgFraction *LCI(external_process)

where energy $\%$ and TS\% are the properties of the material fraction as found in the library of material fractions. 
For vegetable food waste test 3 emits: $30 * 70 / 100 / 18.3 * 100 / 23 * 2 *[4 \mathrm{~kg} \mathrm{CO} 2 ; 2 \mathrm{~kg} \mathrm{CH} 4]=[39.91 \mathrm{~kg} \mathrm{CO} 2$; $19.95 \mathrm{~kg} \mathrm{CH} 4]$

\begin{tabular}{|c|c|c|c|c|c|c|}
\hline \multicolumn{7}{|l|}{$\mathrm{LCI}$} \\
\hline \multicolumn{7}{|l|}{ Energy generation } \\
\hline \multicolumn{7}{|c|}{ Life cycle inventory per process } \\
\hline \multicolumn{7}{|c|}{ Show per material fraction } \\
\hline Name & Compartment & Sub compartment & Unit & Total & Input-specific emissions & test3 \\
\hline Carbon dioxide, fossil & air & unspecified & $\mathrm{kg}$ & 39.91 & 0 & 39.91 \\
\hline Methane, fossil & air & unspecified & $\mathrm{kg}$ & 19.96 & 0 & 19.96 \\
\hline
\end{tabular}

Figure S60: LCI of energy generation process

The characterised impacts per substance are for CO2: 39.91 and for $\mathrm{CH} 4: 19.96 * 25=499$.

$\begin{aligned} & \text { Charact. imp. } \\
& \text { Energy generation }\end{aligned}$
\begin{tabular}{l|l|l|l|} 
Life cycle impact assessment: characterised impacts \\
LCIA Method: & theTestingMethod & Show per process view \\
\hline Name & Compartment & Sub compartment & $\begin{array}{l}\text { IPCC 2007, climate change, GWP 100a } \\
\mathrm{kg} \mathrm{CO2-Eq}\end{array}$ \\
\hline Sum & & & 538.8 \\
\hline Carbon dioxide, fossil & air & unspecified & 39.91 \\
\hline Methane, fossil & air & unspecified & 498.9 \\
\hline
\end{tabular}

Figure S61: Characterised impact, per substance, of energy generation process

Charact, imp.
Energy generation
Life cycle impact assessment: characterised impacts
LCIA Method: $\quad$ theTestingMethod
\begin{tabular}{|l|l|}
\hline Name & $\begin{array}{l}\text { IPCC } 2007, \text { climate change, GWP 100a } \\
\mathrm{kg} \mathrm{CO} 2-\mathrm{Eq}\end{array}$ \\
\hline Sum & 538.8 \\
\hline test3 & 538.8 \\
\hline Process-specific emissions & \\
\hline Input-specific emissions & \\
\hline
\end{tabular}

Figure S62: Characterised impact, per process, of energy generation process

\section{Input-specific emissions in four material processes}

In this section, we explain how the LCI calculations are performed in the material processes templates that include emissions happening in the "Material transfer" tab. These emissions are called "input-specific". Remember that all processes can have "process-specific" emissions due to data in the "Process exchanges" tab (explained in Section I). The 4 processes that can have "input-specific" emissions are:

- Substance transfer per fraction.

- Substance transfer default.

- Use on land.

- Emissions to the environment. 
Figure S32 shows the example used where we connect a material generation process each time to a different material process.

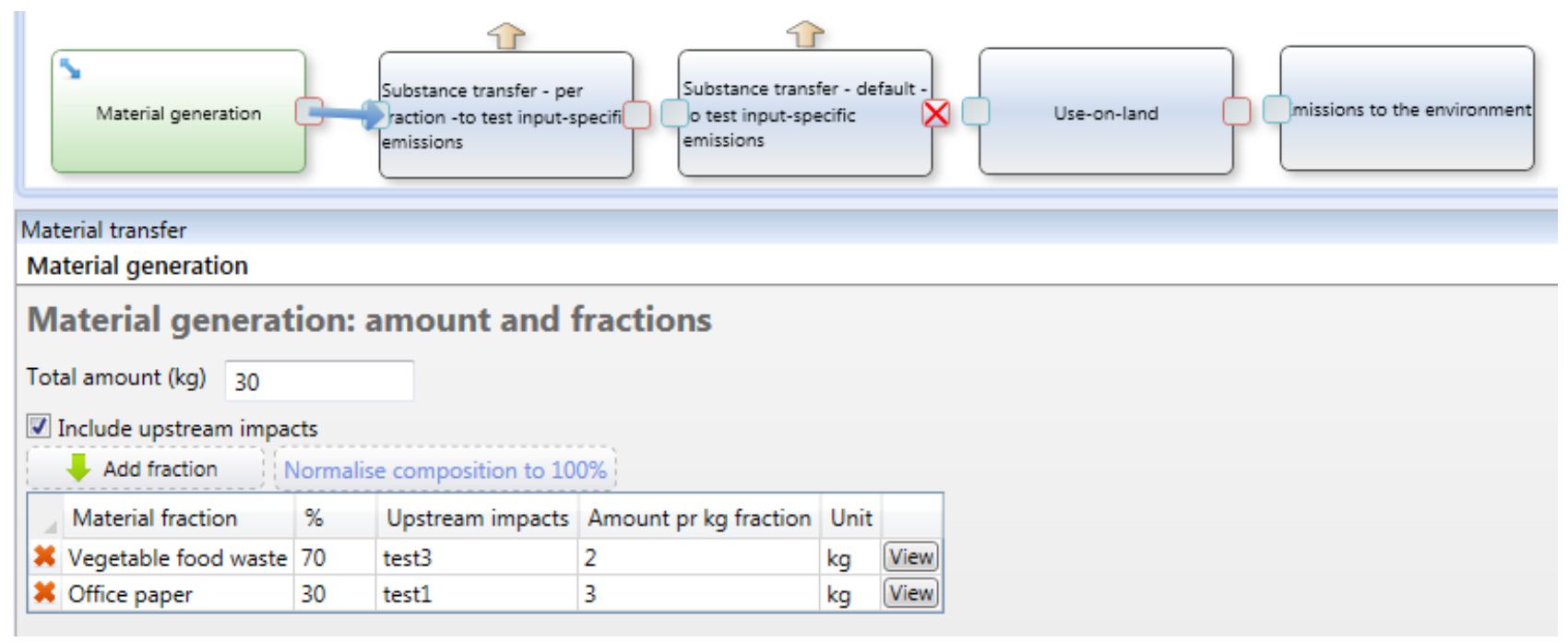

Figure S63: Scenario used to show the calculations of input-specific emissions

This is the composition calculated out of the material generation process.

\begin{tabular}{|c|c|c|c|c|c|c|c|c|c|c|c|c|}
\hline $\begin{array}{l}\text { Fraction } \\
\text { name }\end{array}$ & $\begin{array}{l}\text { Total } \\
\text { Wet } \\
\text { Weight } \\
\text { (kg) }\end{array}$ & TS (kg) & $\begin{array}{l}\text { Water } \\
\text { (kg) }\end{array}$ & VS (kg) & $\begin{array}{l}\text { Ash } \\
\text { (kg) }\end{array}$ & $\begin{array}{l}\text { Energy } \\
\text { (MJ) }\end{array}$ & $\begin{array}{l}\text { C bio } \\
\text { (kg) }\end{array}$ & $\begin{array}{l}\text { C bio } \\
\text { and } \\
(\mathrm{kg})\end{array}$ & $\begin{array}{l}\text { C fossil } \\
\text { (kg) }\end{array}$ & Ca (kg) & Cl (kg) & F (kg) \\
\hline $\begin{array}{l}\text { Vegetable } \\
\text { food waste }\end{array}$ & 21 & 4.83 & 16.17 & 4.579 & 0.2512 & 88.389 & 2.294 & 2.043 & 0.01154 & 0.02681 & 0.02705 & 0.000483 \\
\hline Office paper & 9.005 & 8.217 & 0.7875 & 6.516 & 1.701 & 103 & 3.065 & 1.693 & 0.01545 & 0.6385 & 0.005752 & 0.0008217 \\
\hline
\end{tabular}

\begin{tabular}{|l|l|l|l|l|l|l|l|l|l|l|}
\hline $\begin{array}{l}\text { Fraction } \\
\text { name }\end{array}$ & $\mathbf{H}(\mathbf{k g})$ & $\mathbf{K}(\mathbf{k g})$ & $\mathbf{N}(\mathbf{k g})$ & $\mathbf{N a}(\mathbf{k g})$ & $\mathbf{O}(\mathbf{k g})$ & $\mathbf{P}(\mathbf{k g})$ & $\mathbf{S}(\mathbf{k g})$ & $\mathbf{A g}(\mathbf{k g})$ & $\mathbf{A l}(\mathbf{k g})$ & As (kg) \\
\hline $\begin{array}{l}\text { Vegetable } \\
\text { food waste }\end{array}$ & 0.3188 & 0.06134 & 0.09177 & 0.01507 & 1.908 & 0.01116 & 0.008887 & 0 & 0.004975 & $1.265 \mathrm{E}-06$ \\
\hline Office paper & 0.4109 & 0.0009696 & 0.008217 & 0.00636 & 3.016 & 0.0003139 & 0.005284 & 0 & 0.01076 & $1.75 \mathrm{E}-06$ \\
\hline
\end{tabular}

\subsection{Substance transfer per fraction}

Figure S64 shows the added emissions to the "air unspecified" compartment:

- For Cfossil, 2\% goes to the air except for the fraction "Vegetable food waste" for which it goes at $15 \%$. Al goes at $40 \%$ to the air.

- And we have some process-specific emissions of aluminium and methane, and the use of test3. 


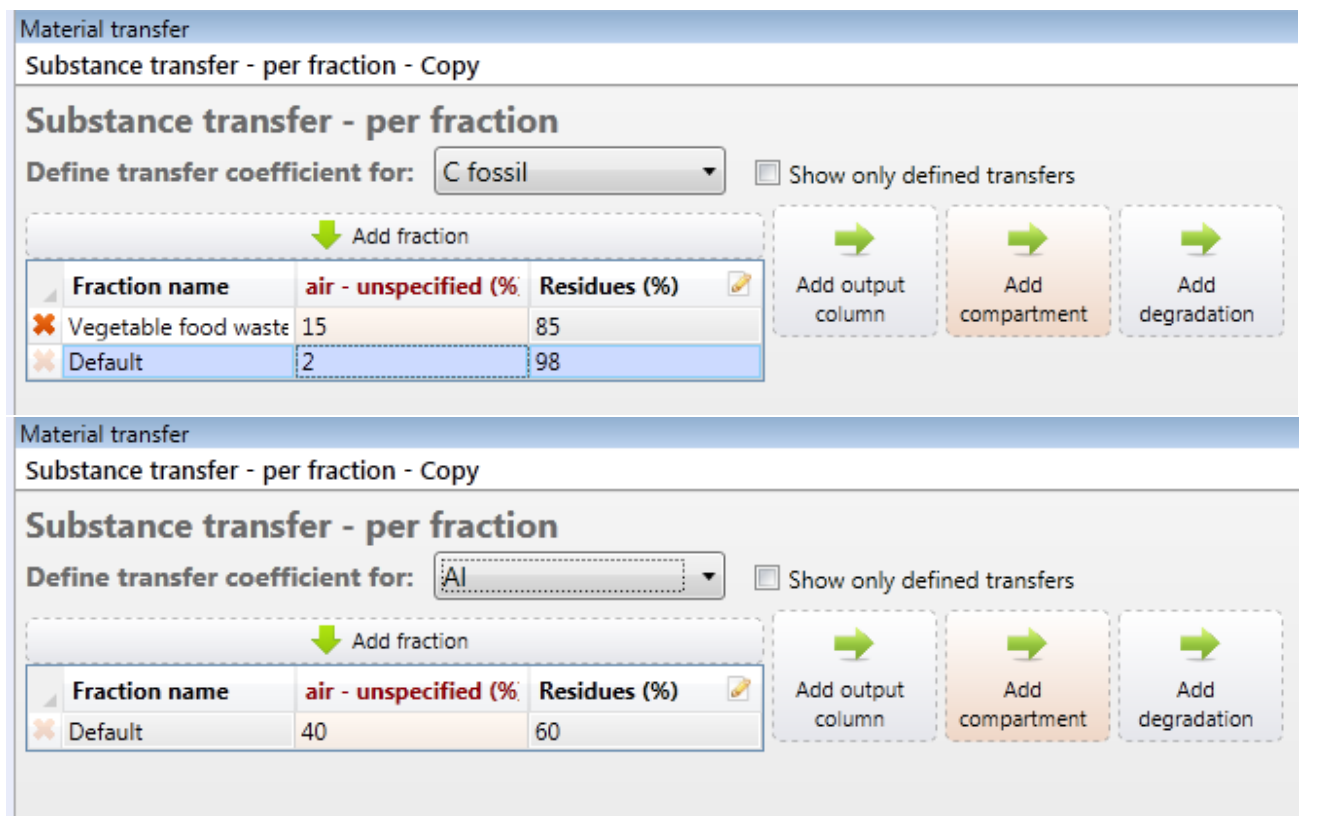

Figure S64: Material transfer for the "substance transfer per fraction” process

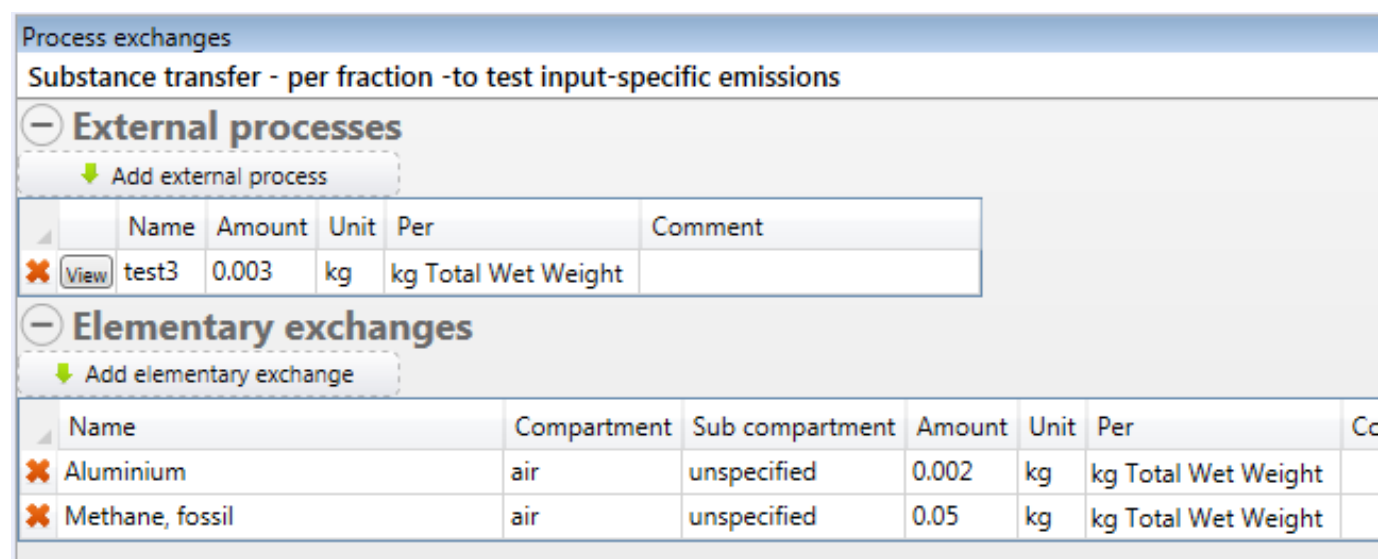

Figure S65: Process exchanges for the "substance transfer per fraction" process

Note that we need an "interface" to explain to EASETECH how Cfossil is emitted: it is emitted as carbon dioxide with a conversion factor of 44/12 (this interface is here by default, just check if you have the right numbers) (see Figure S66).

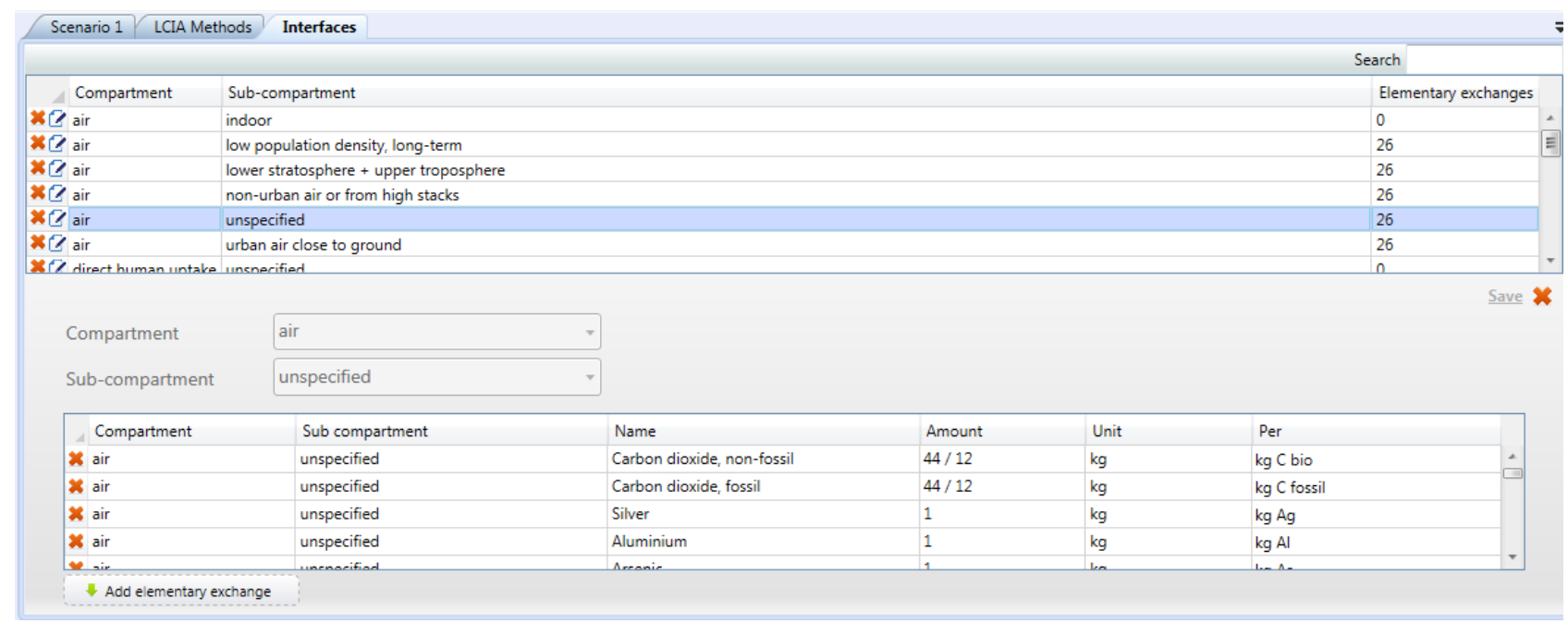

Figure 66: Interface “air - unspecified” 
So the LCI of these Material transfer emissions is calculated for each material property in the dropdown list as: SumForAllFractionsOf[ TransferCoefficientToCompartment(fraction) *AmountProperty(fraction)] * ConversionFactorInInterface

So in our example:

- Carbon dioxide, air, unspecified: [0.15*input.cfossil(vegetablefoodwaste) + $0.02 *$ input.cfossil(officepaper) $] * 44 / 12=[0.15 * 0.01154+0.02 * 0.01545] * 44 / 12=0.00748 \mathrm{~kg}$

- Aluminium, air, unspecified: [0.4*input.al(vegetablefoodwaste) $+0.4 *$ input.al (officepaper) $] * 1$ $=[0.4 * 0.004975+0.4 * 0.01076]^{*} 1=0.006294 \mathrm{~kg}$

And of course the contributions of the "Process exchanges" tab:

- Process-specific:

o Aluminium, air, unspecified: $0.002 * 30=0.06$

o Methane fossil, air, unspecified: $0.05 * 30=1.5$

- Test3: $0.003 * 30 *\{2 \mathrm{~kg} \mathrm{CH} 4 ; 4 \mathrm{~kg} \mathrm{CO} 2\}=\{0.18 \mathrm{~kg} \mathrm{CH} 4 ; 0.36 \mathrm{~kg} \mathrm{CO} 2\}$.

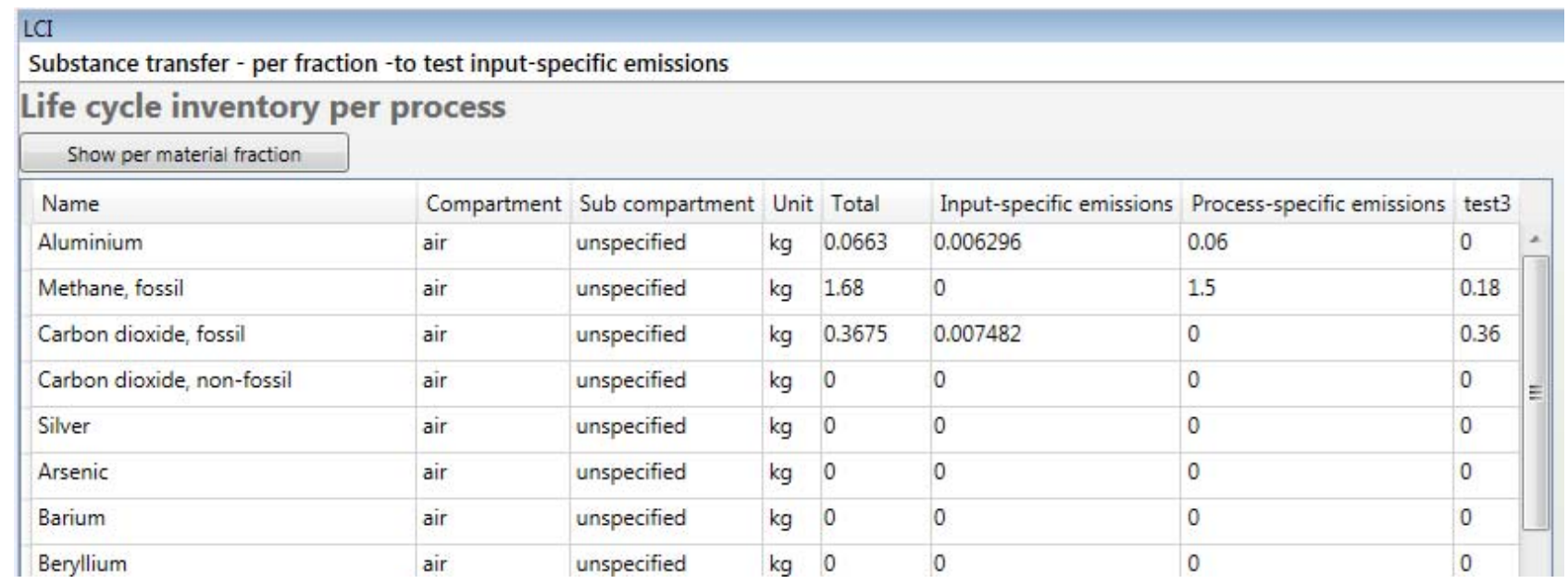

Figure S67: LCI of the "substance transfer per fraction” process

Charact, imp.
Substance transfer - per fraction -to test input-specific emissions
\begin{tabular}{l|l|l|l|}
\hline Life cycle impact assessment: characterised impacts \\
LCIA Method: & theTestingMethod & Show per process view \\
\hline Name & Compartment & Sub compartment & $\begin{array}{l}\text { IPCC 2007, climate change, GWP 100a } \\
\text { kg CO2-Eq }\end{array}$ \\
\hline Sum & & & 42.37 \\
\hline Aluminium & air & unspecified & 0 \\
\hline Methane, fossil & air & unspecified & 42 \\
\hline Carbon dioxide, fossil & air & unspecified & 0.3675 \\
\hline Carbon dioxide, non-fossil & air & unspecified & 0 \\
\hline Silver & air & unspecified & 0 \\
\hline Arranir & air & unsmerified & $n$ \\
\hline
\end{tabular}

Figure S68: Characterised impacts (subs) of the "substance transfer per fraction" process 


\begin{tabular}{l} 
Charact, imp. \\
Substance transfer - per fraction -to test input-specific emissions \\
\hline Life cycle impact assessment: characterised impacts \\
\begin{tabular}{|l|l|}
\hline LCIA Method: & theTestingMethod \\
\hline Name & $\begin{array}{l}\text { IPCC } 2007 \text {, climate change, GWP 100a } \\
\mathrm{kg} \mathrm{CO} 2-\mathrm{Eq}\end{array}$ \\
\hline Sum & \begin{tabular}{l}
42.37 \\
\hline test3
\end{tabular} \\
\hline Process-specific emissions & 37.86 \\
\hline Input-specific emissions & 0.007482 \\
\hline
\end{tabular}
\end{tabular}

Figure S69: Characterised impacts (process) of the "substance transfer per fraction" process

\subsection{Substance transfer default}

We implement the same values as in "substance transfer per fraction" into a new process based on template "substance transfer default". The only difference is that in this process the user cannot specify different transfer coefficients for different material fractions.

\begin{tabular}{|c|c|c|c|c|}
\hline \multicolumn{5}{|c|}{$\begin{array}{l}\text { Material transfer } \\
\text { Substance transfer - default -to test input-specific emissions }\end{array}$} \\
\hline \multicolumn{5}{|c|}{ Substance transfer - default } \\
\hline \multicolumn{5}{|c|}{ Define transfer coefficient (applied to all material fractions) } \\
\hline \multicolumn{3}{|c|}{ Add material property } & $\Rightarrow$ & $\Rightarrow$ \\
\hline Material property & air - unspecified $(\%$ & Degradation (\%) & $\begin{array}{l}\text { Add output } \\
\text { column }\end{array}$ & $\begin{array}{c}\text { Add } \\
\text { compartment }\end{array}$ \\
\hline C fossil & 2 & 98 & & \\
\hline * Al & 40 & 60 & & \\
\hline
\end{tabular}

Figure S70: Material transfer for the "substance transfer default" process

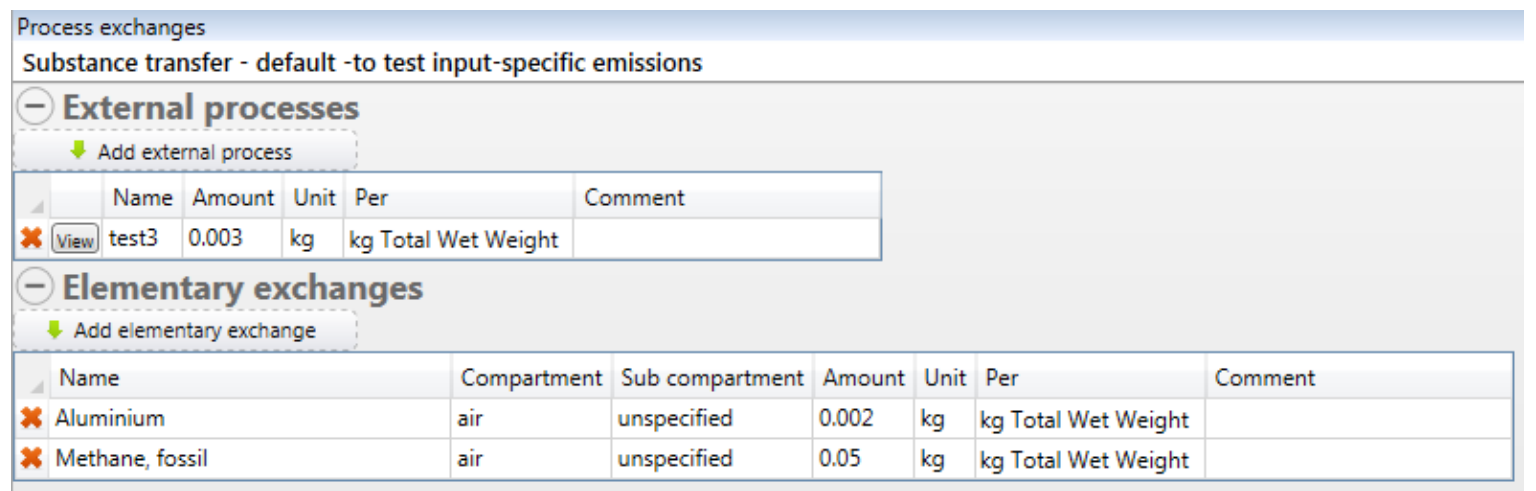

Figure S71: Process exchanges for the "substance transfer default” process

The calculation of characterised impacts also relies on the interfaces.

Very similarly to "substance transfer per fraction", the LCI of these input-specific emissions is calculated for each material property in the dropdown list as: TransferCoefficientToCompartment * SumForAllFractionsOf (AmountProperty) * ConversionFactorInInterface

So in our example:

- Carbon dioxide, air, unspecified: $0.02 *$ (input.cfossil(vegetablefoodwaste) + input.cfossil(officepaper) $] * 44 / 12=0.02 *(0.01154+0.01545]^{* 44 / 12}=0.001979 \mathrm{~kg}$ 
- Aluminium, air, unspecified: $0.4 *$ (input.al(vegetablefoodwaste) + input.al (officepaper) ${ }^{*} 1=$ $0.4 *[0.004975+0.01076] * 1=0.006294 \mathrm{~kg}$

And the contributions of the "process exchange" tab:

- Process-specific:

O Aluminium, air, unspecified: $0.002 * 30=0.06$

o Methane fossil, air, unspecified: $0.05 * 30=1.5$

- Test3: $0.003 * 30 *\{2 \mathrm{~kg} \mathrm{CH} 4 ; 4 \mathrm{~kg} \mathrm{CO} 2\}=\{0.18 \mathrm{~kg} \mathrm{CH} 4 ; 0.36 \mathrm{~kg} \mathrm{CO} 2\}$.

\begin{tabular}{|c|c|c|c|c|c|c|c|c|}
\hline \multicolumn{9}{|c|}{$\begin{array}{l}\text { LCI } \\
\text { Substance transfer - default -to test input-specific emissions }\end{array}$} \\
\hline \multicolumn{9}{|c|}{ Life cycle inventory per process } \\
\hline \multicolumn{9}{|l|}{ Show per material fraction } \\
\hline Name & Compartment & Sub compartment & Unit & Total & Input-specific emissions & Process-specific emissions & test3 & \\
\hline Aluminium & air & unspecified & $\mathrm{kg}$ & 0.0663 & 0.006296 & 0.06 & 0 & $\therefore$ \\
\hline Methane, fossil & air & unspecified & $\mathrm{kg}$ & 1.68 & 0 & 1.5 & 0.18 & \\
\hline Carbon dioxide, fossil & air & unspecified & $\mathrm{kg}$ & 0.362 & 0.001979 & 0 & 0.36 & \\
\hline Carbon dioxide, non-fossil & air & unspecified & $\mathrm{kg}$ & 0 & 0 & 0 & 0 & $=$ \\
\hline Silver & air & unspecified & $\mathrm{kg}$ & 0 & 0 & 0 & 0 & \\
\hline Arsenic & air & unspecified & $\mathrm{kg}$ & 0 & 0 & 0 & 0 & \\
\hline Barium & air & unspecified & $\mathrm{kg}$ & 0 & 0 & 0 & 0 & \\
\hline
\end{tabular}

Figure S72: LCI of the "substance transfer default” process

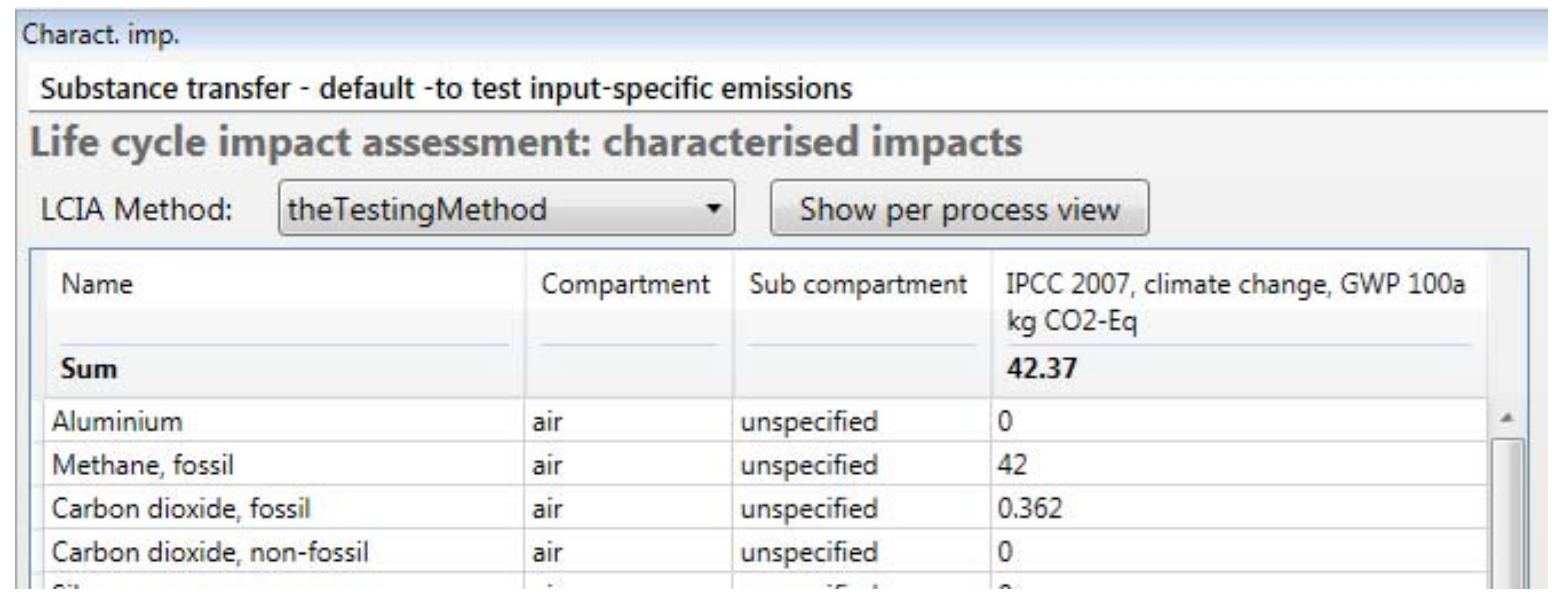

Figure S73: Characterised impacts (subs) of the "substance transfer default" process

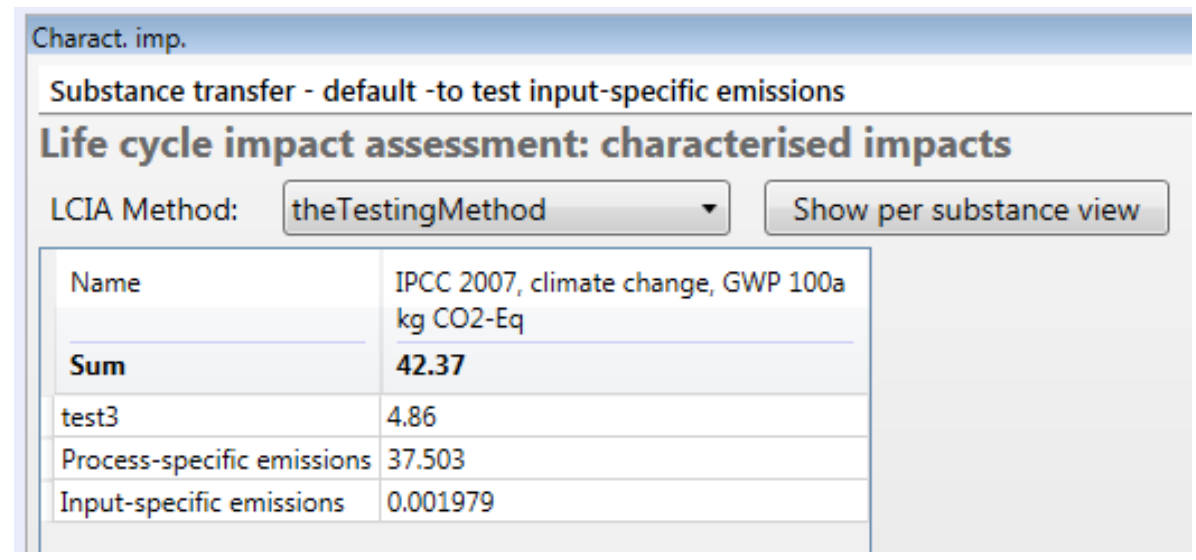

Figure S74: Characterised impacts (process) of the "substance transfer default” process 


\subsection{Use on land (UOL)}

The material transfer tab of the UOL process contains all data to calculate the "input-specific" emissions. "Input-specific emissions" is the sub-process of all emissions coming from data in the Material transfer tab. As explained in Section I, "process-specific emissions" are elementary exchanges in the "Process exchanges" tab and each external process used is a subprocess as well.

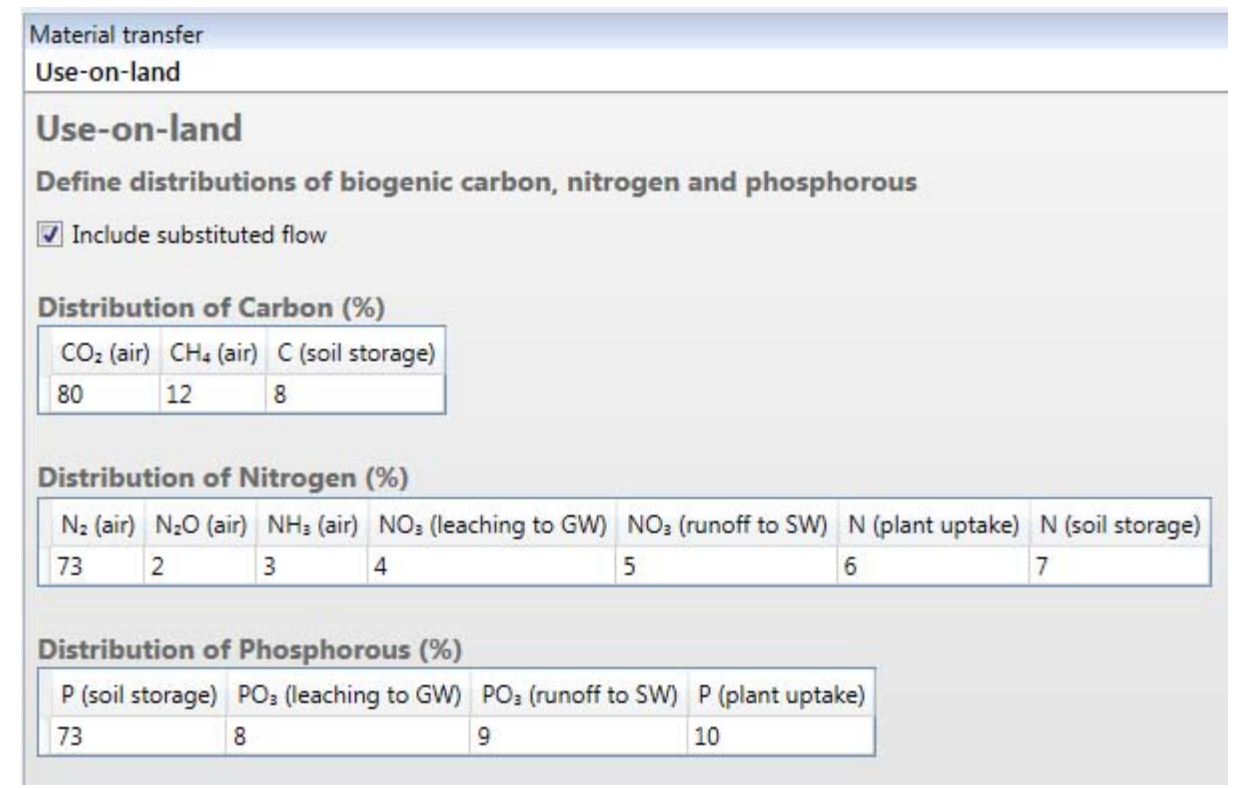

Figure S75: Material transfer for the UOL process

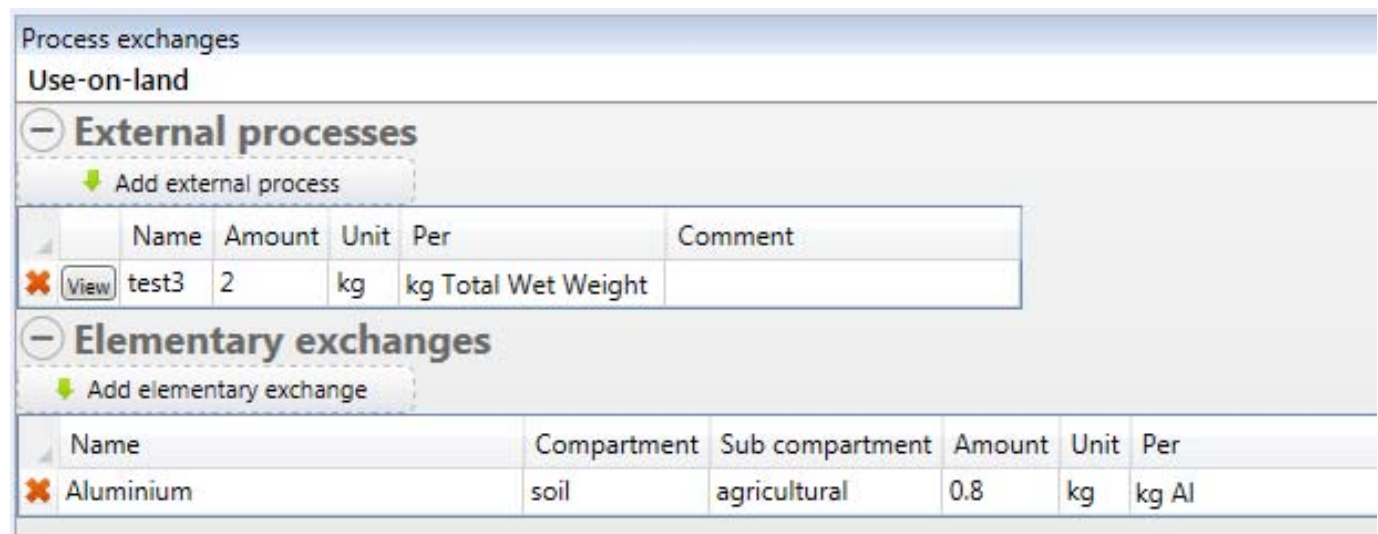

Figure S76: Process exchanges for the UOL process

If I call a, b, c, d...n the values input in the 3 tables in the material transfer tab of UOL, the following inputspecific emissions have to be included in the LCI:

- $\quad$ "Carbon dioxide, non-fossil, air, unspecified": input.cbio * a/100*(2*M_O+M_C $) / M_{-} C$

- "Methane, non-fossil, air, unspecified": input.cbio * b/100*(4*M_H+M_C $) /$ M_C

- $\quad$ "Carbon dioxide, fossil, air, unspecified" = input.cbio * c/ $100 *(2 *$ M_O+M_C $) /$ M_C * (-1)

- "Dinitrogen monoxide, air, unspecified": input.n * e/100* $\left(2 * \mathrm{M} \_\mathrm{N}+\mathrm{M} \_\mathrm{O}\right) /\left(2 * \mathrm{M} \_\mathrm{N}\right)$

- "Ammonia, air, unspecified": input.n*f/100*(3*M_H+M_N $/ \mathrm{M} \_\mathrm{N}$

- "Nitrates, water, ground-": input.n * g/100*(3*M_O+M_N $) / \mathrm{M} \_\mathrm{N}$

- "Nitrates, water, surface water": input.n*h/100*(3*M_O+M_N $) / \mathrm{M} \_\mathrm{N}$

- "Phosphate, water, ground-": input.p * 1/100*(3*M_O+M_P)/M_P

- "Phosphate, water, surface water": input.p * m/100 * $\left(3 * \mathrm{M} \_\mathrm{O}+\mathrm{M} \_\mathrm{P}\right) / \mathrm{M} \_\mathrm{P}$ 
Note that M_C, M_O, M_P and M_H are constants of the catalogue of constants and they are the molar masses of carbon, oxygen, phosphorous and hydrogen.

So the LCI of the subprocess "Input-specific" is calculated in the example like this:

- $\quad$ "Carbon dioxide, non-fossil, air, unspecified": $(2.294+3.065) * 80 / 100 *(2 * 15.999+12.011) / 12.011$ $=15.71 \mathrm{~kg}$

- $\quad$ "Methane, non-fossil, air, unspecified": $(2.294+3.065) * 12 / 100 *(4 * 1.008+12.011) / 12.011=0.859$ $\mathrm{kg}$

- $\quad$ "Carbon dioxide, fossil, air, unspecified" $=(2.294+3.065) * 8 / 100 *(2 * 15.999+12.011) / 12.011 *(-1)$ $=-1.57 \mathrm{~kg}$

- $\quad$ "Dinitrogen monoxide, air, unspecified": $(0.09177+0.008217) * 2 / 100 *(2 * 14.007+15.999)$ $/(2 * 14.007)=0.00314 \mathrm{~kg}$

- "Ammonia, air, unspecified": $(0.09177+0.008217) * 3 / 100 *(3 * 1.008+14.007) / 14.007=0.00364 \mathrm{~kg}$

- "Nitrates, water, ground-": $(0.09177+0.008217) * 4 / 100 *(3 * 15.999+14.007) / 14.007=0.0177 \mathrm{~kg}$

- $\quad$ "Nitrates, water, surface water": $(0.09177+0.008217) * 5 / 100 *(3 * 15.999+14.007) / 14.007=0.0221$ $\mathrm{kg}$

- $\quad$ "Phosphate, water, ground-": $(0.01116+0.0003139) * 8 / 100 *(3 * 15.999+30.974) / 30.974=0.00234$ $\mathrm{kg}$

- $\quad$ "Phosphate, water, surface water": $(0.01116+0.0003139) * 9 / 100 *(3 * 15.999+30.974) / 30.974$ $=0.00263 \mathrm{~kg}$

The process "test3" has also emissions as explained in part I: $2 * 30 *\{4 \mathrm{~kg} \mathrm{CO} 2 ; 2 \mathrm{kgCH} 4\}=\{240 \mathrm{~kg} \mathrm{CO} 2$; $120 \mathrm{~kg} \mathrm{CH} 4\}$.

And in "Process-specific emissions", we have one emission of aluminium of $0.8 \mathrm{~kg} / \mathrm{kg} \mathrm{Al}=$ $0.8 *(0.004975+0.01076)=0.01259 \mathrm{~kg}$.

\begin{tabular}{|c|c|c|c|c|c|c|c|}
\hline \multicolumn{8}{|l|}{$\mathrm{LCI}$} \\
\hline \multicolumn{8}{|l|}{ Use-on-land } \\
\hline \multicolumn{8}{|c|}{ Life cycle inventory per process } \\
\hline \multicolumn{8}{|l|}{ Show per material fraction } \\
\hline Name & Compartment & Sub compartment & Unit & Total & Input-specific emissions & Process-specific emissions & test3 \\
\hline Carbon dioxide, non-fossil & air & unspecified & $\mathrm{kg}$ & 15.71 & 15.71 & 0 & 0 \\
\hline Carbon dioxide, fossil & air & unspecified & $\mathrm{kg}$ & 238.4 & -1.571 & 0 & 240 \\
\hline Methane, non-fossil & air & unspecified & $\mathrm{kg}$ & 0.859 & 0.859 & 0 & 0 \\
\hline Dinitrogen monoxide & air & unspecified & $\mathrm{kg}$ & 0.003142 & 0.003142 & 0 & 0 \\
\hline Ammonia & air & unspecified & $\mathrm{kg}$ & 0.003647 & 0.003647 & 0 & 0 \\
\hline Nitrate & water & ground- & $\mathrm{kg}$ & 0.0177 & 0.0177 & 0 & 0 \\
\hline Nitrate & water & surface water & $\mathrm{kg}$ & 0.02213 & 0.02213 & 0 & 0 \\
\hline Phosphate & water & ground- & $\mathrm{kg}$ & 0.00234 & 0.00234 & 0 & 0 \\
\hline Phosphate & water & surface water & $\mathrm{kg}$ & 0.002632 & 0.002632 & 0 & 0 \\
\hline Aluminium & soil & agricultural & $\mathrm{kg}$ & 0.01259 & 0 & 0.01259 & 0 \\
\hline Methane, fossil & air & unspecified & $\mathrm{kg}$ & 120 & 0 & 0 & 120 \\
\hline
\end{tabular}

\section{Figure S77: LCI of the UOL process}

For characterised impacts per substance, let's look only at the impact category "Climate change" that has characterisation factors for "carbon dioxide, fossil, air" of 1, for "Methane, air" of 25, for "dinitrogen monoxide" of 293: 
- Carbon dioxide, fossil:

amountOfCarbonDioxideFossilInLCI $*$ CharacterisationFactorOfCarbonDioxide $=238.4 * 1=238.4$

- Methane, fossil: amountOfMethaneFossilInLCI*CharacterisationFactorOfMethane $=120 * 25=3000$

- Methane, non-fossil: amountOfMethaneNonFossilInLCI*CharacterisationFactorOfMethane $=0.859 * 25=21.47 \mathrm{~kg}$

- Dinitrogen monoxide: amountOfDinitrogenMonoxideInLCI*CharacterisationFactorOfDinitrogenMonoxide $=0.003142 * 298=0.9363 \mathrm{~kg}$

\begin{tabular}{|c|c|c|c|c|}
\hline \multicolumn{5}{|l|}{ Charact. imp. } \\
\hline \multicolumn{5}{|l|}{ Use-on-land } \\
\hline \multicolumn{5}{|c|}{ Life cycle impact assessment: characterised impacts } \\
\hline LCIA Method: & \multicolumn{2}{|c|}{ theTestingMethod } & \multicolumn{2}{|c|}{ Show per process view } \\
\hline \multicolumn{2}{|l|}{ Name } & Compartment & Sub compartment & $\begin{array}{l}\text { IPCC 2007, climate change, GWP } 100 a \\
\mathrm{~kg} \mathrm{CO} 2-\mathrm{Eq}\end{array}$ \\
\hline \multicolumn{2}{|l|}{ Sum } & & & 3261 \\
\hline \multicolumn{2}{|c|}{ Carbon dioxide, non-fossil } & air & unspecified & 0 \\
\hline \multicolumn{2}{|c|}{ Carbon dioxide, fossil } & air & unspecified & 238.4 \\
\hline \multicolumn{2}{|c|}{ Methane, non-fossil } & air & unspecified & 21.47 \\
\hline \multicolumn{2}{|c|}{ Dinitrogen monoxide } & air & unspecified & 0.9363 \\
\hline \multicolumn{2}{|c|}{ Ammonia } & air & unspecified & 0 \\
\hline \multicolumn{2}{|l|}{ Nitrate } & water & ground- & 0 \\
\hline \multicolumn{2}{|l|}{ Nitrate } & water & surface water & 0 \\
\hline \multicolumn{2}{|l|}{ Phosphate } & water & ground- & 0 \\
\hline \multicolumn{2}{|l|}{ Phosphate } & water & surface water & 0 \\
\hline \multicolumn{2}{|l|}{ Aluminium } & soil & agricultural & 0 \\
\hline \multicolumn{2}{|l|}{ Methane, fossil } & air & unspecified & 3000.24 \\
\hline
\end{tabular}

Figure S78: Characterised impacts (subs) of the UOL process

In the characterized impacts per process the details of each subprocess: "test3", "process-specific emission" are calculated:

- For the subprocess "test3":

amountOfCarbonDioxideInLCIPerProcess(Test3)*CharacterisationFactorOfCarbonDioxide + amountOfMethaneInLCIPerProcess(Test3) $*$ CharacterisationFactorOfMethane $=240 * 1+$ $120 * 25=3240 \mathrm{~kg}$

- For Process-specific emissions:

amountOfCarbonDioxideFossilInLCIPerProcess(ProcessSpecific)*CharacterisationFactorOfCar bonDioxide +

amountOfMethaneInLCIPerProcess(ProcessSpecific)*CharacterisationFactorOfMethane + amountOfDinitrogenMonoxideInLCIPerProcess(ProcessSpecific)*CharacterisationFactorOfDini trogenMonoxide

$=-1.571 * 1+0.859 * 25+0.003142 * 298=20.84 \mathrm{~kg}$ 


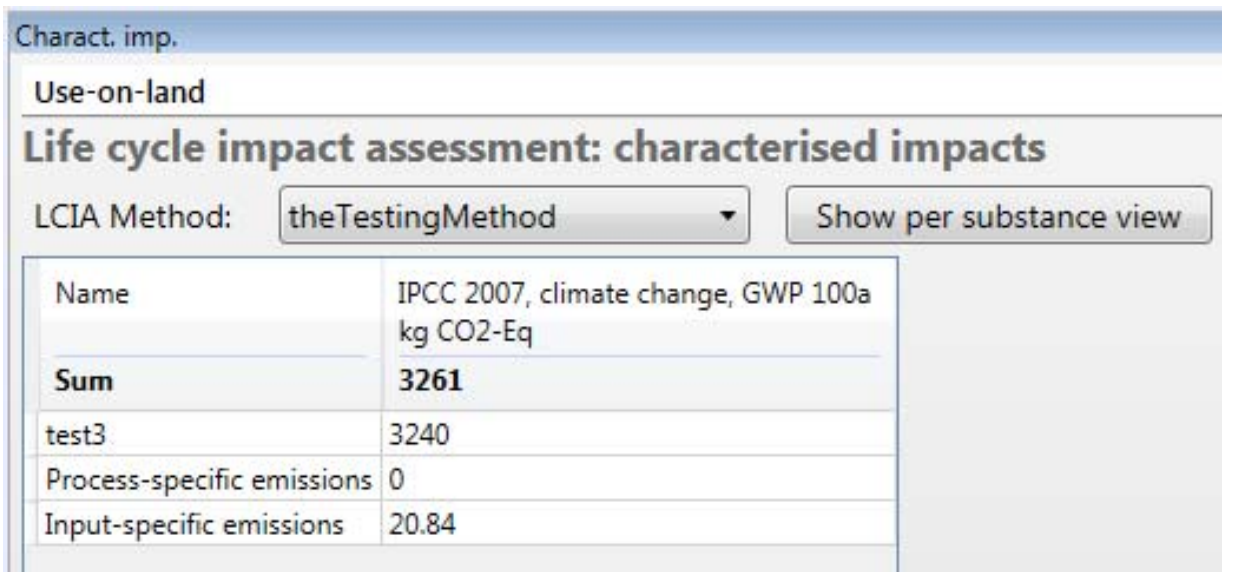

Figure S79: Characterised impacts (process) of the UOL process

\subsection{Emissions to the environment}

This process has also a material transfer tab that creates input-specific emissions. In the example following we see that 2 emissions are coming from the "Material transfer" tab (input-specific emission), while one is coming from the "Process exchanges" tab (process-specific emission) and we use one external process. So we have 3 sub-processes.

\begin{tabular}{|c|c|c|c|c|c|c|}
\hline \multicolumn{7}{|c|}{ Material transfer } \\
\hline \multicolumn{7}{|c|}{ Emissions to the environment } \\
\hline \multicolumn{7}{|c|}{ Define emissions to the environment as transformation of substances } \\
\hline \multicolumn{7}{|c|}{ Add new transformation } \\
\hline Material property & Transformed at (\%) into & Elementary exchange & Compartment & Sub compartment & With the conversion factor & Comr \\
\hline * $\mathrm{kg} \mathrm{Al}$ & 25 & Aluminium & soil & agricultural & 1 & \\
\hline kg C bio & 80 & Carbon dioxide, fossil & air & unspecified & $-44 / 12$ & \\
\hline
\end{tabular}

Figure S80: Material transfer for the Emissions to the environment process

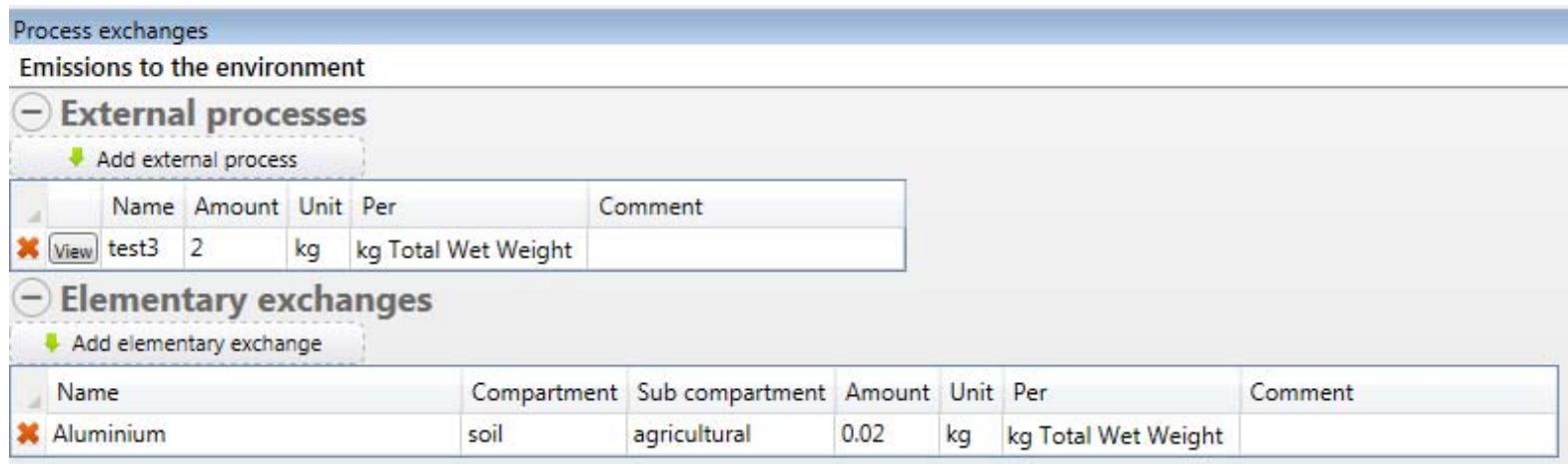

Figure S81: Process exchanges for the Emissions to the environment process

The LCI of the emissions happening in the material transfer is calculated for each line as amountOfPropertyInInput *TransformedAtPercent/100*ConversionFactor

So for our two emissions, it gives:

- Carbon dioxide, fossil, air, unspecified : input.Cbio*80/100*(-44/12) $=-15.72 \mathrm{~kg}$

- Aluminium, soil, agricultural: input.A1*25/100*1=0.003935 kg 
For the other emissions, it happens as explained in part I: we have an (additional) emission of aluminium of $0.02 * 30=0.6 \mathrm{~kg}$ and emissions from test 3 of $2 * 30 *\{2 \mathrm{~kg} \mathrm{CH} 4 ; 4 \mathrm{~kg} \mathrm{CO} 2\}=\{120 \mathrm{~kg} \mathrm{CH} 4 ; 240 \mathrm{~kg} \mathrm{CO} 2\}$.

\begin{tabular}{|c|c|c|c|c|c|c|c|}
\hline \multicolumn{8}{|l|}{ LCI } \\
\hline \multicolumn{8}{|c|}{ Emissions to the environment } \\
\hline \multicolumn{8}{|c|}{ Life cycle inventory per process } \\
\hline \multicolumn{8}{|c|}{ Show per material fraction } \\
\hline Name & Compartment & Sub compartment & Unit & Total & Input-specific emissions & Process-specific emissions & test3 \\
\hline Aluminium & soil & agricultural & $\mathrm{kg}$ & 0.604 & 0.003935 & 0.6 & 0 \\
\hline Carbon dioxide, fossil & air & unspecified & $\mathrm{kg}$ & 224.3 & -15.72 & 0 & 240 \\
\hline Methane, fossil & air & unspecified & $\mathrm{kg}$ & 120 & 0 & 0 & 120 \\
\hline
\end{tabular}

Figure S82: LCI of the Emissions to the environment process

The "characterised impact per substance" tab shows as usual for each elementary exchange, the total amount multiplied by the characterisation factor.

Charact. imp.
Emissions to the environment
\begin{tabular}{l|l|l|l|}
\hline Life cycle impact assessment: characterised impacts \\
LCIA Method: & theTestingMethod & Show per process view \\
\hline Name & Compartment & Sub compartment & $\begin{array}{l}\text { IPCC 2007, climate change, GWP 100a } \\
\mathrm{kg} \mathrm{CO2-Eq}\end{array}$ \\
\hline Sum & & & 3225 \\
\hline Aluminium & soil & agricultural & 0 \\
\hline Carbon dioxide, fossil & air & unspecified & 224.3 \\
\hline Methane, fossil & air & unspecified & 3000.24 \\
\hline
\end{tabular}

Figure S83: Characterised impacts (subs) of the Emissions to the environment process

And the characterised impact per process shows for each subprocess, the sum for all elementary exchanges of amount multiplied by characterisation factor:

- For the subprocess "test3":

amountOfCarbonDioxideInLCIPerProcess(Test3)*CharacterisationFactorOfCarbonDioxide + amountOfMethaneInLCIPerProcess(Test 3$) *$ CharacterisationFactorOfMethane $=240 * 1+$ $120 * 25=3240 \mathrm{~kg}$

- For input-specific emissions: amountOfCarbonDioxideFossilInLCIPerProcess(ProcessSpecific)*CharacterisationFactorOfCar bonDioxide $=-15.72 * 1=-15.72 \mathrm{~kg}$ 


\begin{tabular}{l} 
Charact. imp. \\
Emissions to the environment \\
\hline Life cycle impact assessment: characterised impacts \\
\begin{tabular}{|l|l|}
\hline LCIA Method: & theTestingMethod \\
\hline Name & $\begin{array}{l}\text { IPCC } 2007 \text {, climate change, GWP 100a } \\
\text { kg CO2-Eq }\end{array}$ \\
\hline Sum & 3225 \\
\hline test3 & 3240 \\
\hline Process-specific emissions & 0 \\
\hline Input-specific emissions & -15.72 \\
\hline
\end{tabular}
\end{tabular}

Figure S84: Characterised impacts (process) of the Emissions to the environment process 


\section{PART IV: CASE STUDY}

In this document are presented screenshots of how the systems were implemented in EASETECH. Please refer to the original paper by Clavreul et al. (2012) for further details.

\section{Scenario construction and data input}

The name of the template used to build each module is provided, as well as screenshots showing the data. Note that parameters were used in some number fields, there value is given in the Section 3 of this Part III.

\subsection{Incineration scenario}

Material generation, based on "Material generation" template:

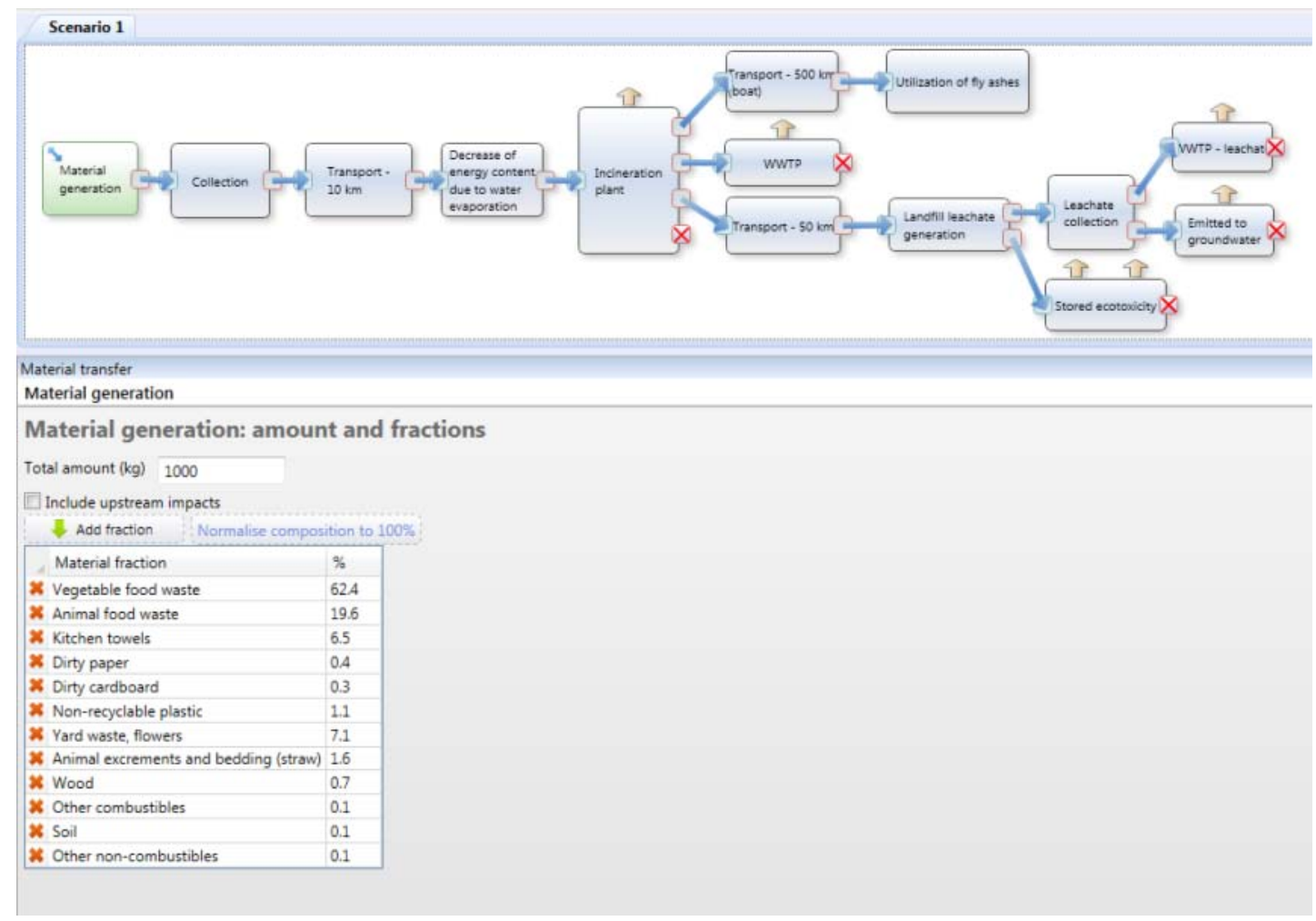

Collection, based on the "Basic process" template:

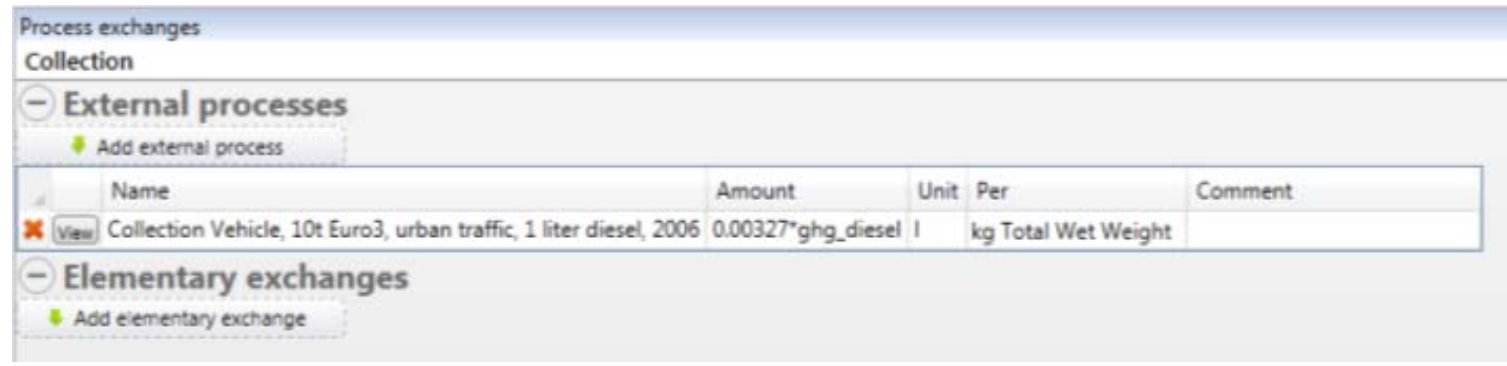

Transport, based on the "Basic process" template:

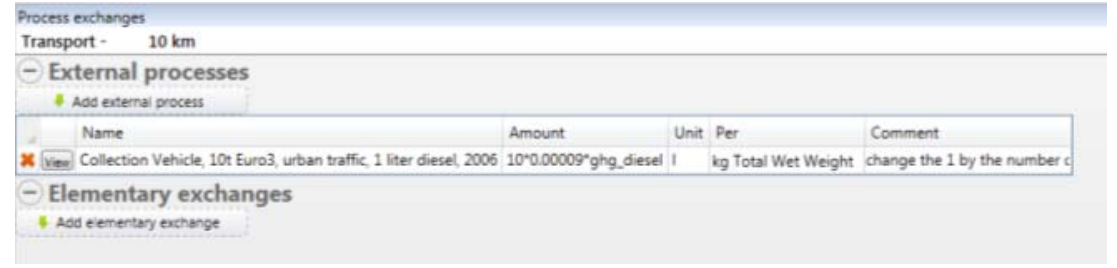


Decrease of energy content due to water evaporation, based on the "Change of energy content" template:

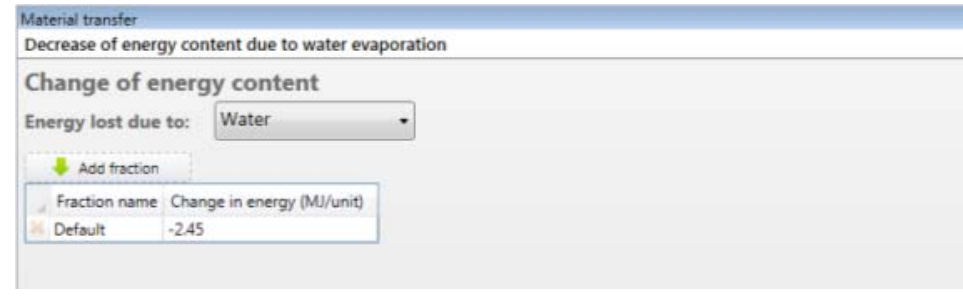

Incineration plant, based on the "Substance transfer, default" template (note that the template "Substance transfer, per fraction" could have been used instead offering the possibility of giving different values to different material fractions):

\begin{tabular}{|c|c|c|c|c|c|c|c|c|c|c|c|c|c|}
\hline \multicolumn{14}{|l|}{$\begin{array}{l}\text { Material transfer } \\
\text { Incineration plant }\end{array}$} \\
\hline \multicolumn{14}{|c|}{ Substance transfer - default } \\
\hline \multicolumn{14}{|c|}{ Define transfer coefficient (applied to all material fractions) } \\
\hline \multicolumn{7}{|c|}{ \& Ade materia probets } & \multirow{3}{*}{\multicolumn{2}{|c|}{$\underset{\text { Adc outpot }}{\text { column }}$}} & \multirow{3}{*}{\multicolumn{2}{|c|}{$\underset{\substack{\text { Aod } \\
\text { compartment }}}{\Rightarrow}$}} & & & \\
\hline Material property & Fly ashes (\%) & \multicolumn{2}{|c|}{ air - unspecified (\% } & Waste water (\%) ? & \multirow{2}{*}{ Bottom ashes is) } & \multirow{2}{*}{$\begin{array}{l}\text { Degradation (x) } \\
100\end{array}$} & & & & & & & \\
\hline $\begin{array}{l}\mathbf{X} \text { Water } \\
\mathbf{X} \text { vs }\end{array}$ & $\therefore$ & & 0 & & & & & & & & & \\
\hline $\begin{array}{l}\boldsymbol{x} \text { vs } \\
\boldsymbol{X} \text { Ash }\end{array}$ & $\begin{array}{l}0 \\
126\end{array}$ & 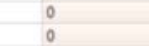 & & $\vdots$ & 0.1 & $\begin{array}{l}999 \\
874\end{array}$ & & & & & & & \\
\hline $\begin{array}{l}\text { X } \\
\text { Ash } \\
\mathbf{X} \text { Energy }\end{array}$ & 0 & 0 & & 0 & 0 & 100 & & & & & & & \\
\hline X C bio & 0 & \multicolumn{2}{|l|}{100} & 0 & 0 & 0 & & & & & & & \\
\hline$\alpha C$ bio and & 0 & \multicolumn{2}{|l|}{0} & 0 & 0 & 100 & & & & & & & \\
\hline X C fossil & 0 & \multirow{2}{*}{\multicolumn{2}{|c|}{$\begin{array}{l}100 \\
0.1073\end{array}$}} & 0 & 0 & 0 & & & & & & & \\
\hline$x a$ & 32.13 & & & 6246 & 5.303 & .0 .0003 & & & & & & & \\
\hline$x 5$ & 60.91 & \multicolumn{2}{|l|}{0.099} & 15 & 23.991 & $7105 t-15$ & & & & & & & \\
\hline$X$ As & 5892 & \multicolumn{2}{|l|}{0.0121} & 0.4554 & 40.61 & 0,0025 & & & & & & & \\
\hline$X \mathrm{Cd}$ & 88.13 & \multirow{2}{*}{\multicolumn{2}{|c|}{0.7475}} & 0.0311 & 11.83 & 0.0025 & & & & & & & \\
\hline X $\mathrm{Hg}_{9}$ & 9625 & & & 0.0936 & 2.909 & .0 .0001 & & & & & & & \\
\hline $\boldsymbol{X C t}$ & 26.77 & \multicolumn{2}{|l|}{0.0394} & 0.0454 & 83.15 & -0.0048 & & & & & & & \\
\hline $\boldsymbol{x} \mathrm{Cu}$ & 735 & \multicolumn{2}{|l|}{0.00261} & 0.0157 & 92.63 & 0.00169 & & & & & & & \\
\hline X Fe & 306 & \multicolumn{2}{|l|}{0} & 0.018 & 96.622 & 0.3 & & & & & & & \\
\hline $\boldsymbol{x}$ Mo & 254 & \multirow{2}{*}{\multicolumn{2}{|c|}{0.0329}} & 0.8517 & 96.61 & .0 .0017 & & & & & & & \\
\hline X $\mathrm{Ni}$ & 12.56 & & & 0.0873 & 87.32 & .00002 & & & & & & & \\
\hline X p & 51.29 & 0.00081 & & 0.2384 & 48.47 & 0.00079 & & & & & & & \\
\hline X st & 59.84 & 0.0119 & & 1234 & 38.91 & 0.0041 & & & & & & & \\
\hline$x$ sn & 48.18 & 0 & & 0.0643 & 51.76 & $1-0.0043$ & & & & & & & \\
\hline Material transfer Proce & as exchanges $D_{0}$ & ocumentation La $\mathrm{C}$ & Charact & t imp. Norm. imp & Weight imp. Composit & sition & & & & & & & \\
\hline View UIStrict me & eatıng, marg & ginaı average & $e_{i}$ lur & $\mathrm{N}, \mathrm{KWvn}, \mathrm{OU} / 2$ & & & & & & at_rec/. & $/ 1$ UU/s.o gng_neat $(-1)$ & Kvvn & MIJ thi \\
\hline View sodium hy & droxide, 50 & $0 \%$ in $\mathrm{H} 2 \mathrm{O}$, pr & orodu & uction mix, at & t plant, RER & & & & & $E-05$ & & $\mathrm{~kg}$ & $\mathrm{~kg}$ Tot \\
\hline View lime, hydr & ated, packe & ed, at plant, C & & & & & & & & 0034 & & $\mathrm{~kg}$ & $\mathrm{~kg}$ Tot \\
\hline View limestone & milled, pac & cked, at plant & $\mathrm{ht}, \mathrm{CH}$ & & & & & & & 0567 & & $\mathrm{~kg}$ & $\mathrm{~kg}$ Tot \\
\hline View polyethyle & ane, HDPE, & granulate, at & t plan & nt, RER & & & & & $6 \mathrm{E}-$ & -07 & & $\mathrm{~kg}$ & $\mathrm{~kg}$ Tot \\
\hline View hydrochlo & ric acid, fro & om the reactic & ion of & f hydrogen w & with chlorine, at & t plant, RER & & & & $E-06$ & & $\mathrm{~kg}$ & $\mathrm{~kg}$ Tot \\
\hline View Marginal & Electricity C & Consumption & incl. & Fuel Product & tion, Coal, Ener & rgy Quality, D & $\mathrm{kWh}$ & 2006 & elec & $c_{-}$rec $/ 1$ & $/ 100 / 3.6^{\star}$ ghg_elec $(-1)$ & kWh & MJ Enı \\
\hline View Marginal & Electricity C & Consumption & incl. & Fuel Product & tion, Coal, Ener & rgy Quality, D & $\mathrm{kWh}$ & 2006 & & C_cons & $15 / 1000^{*}$ ghg_elec & kWh & $\mathrm{kg}$ Tot \\
\hline Elementa & ry exch & hanges & & & & & & & & & & & \\
\hline Add elementa & y exchange & & & & & & & & & & & & \\
\hline Name & & & & mpartment & Sub compartm & nent & & Amou & unt & Unit & Per & Comm & ment \\
\hline Carbon monox & de, fossil & & air & & non-urban air $c$ & or from high & tacks & $3.3 \mathrm{E}-0^{5}$ & & $\mathrm{~kg}$ & kg Total Wet Weight & & \\
\hline Dioxins, measu & red as $2,3,7$ & 7,8-tetrachlor & air & & non-urban air $c$ & or from high & tacks & $1.8 \mathrm{E}-1$ & & $\mathrm{~kg}$ & kg Total Wet Weight & & \\
\hline Hydrogen chlo & ride & & air & & non-urban air $c$ & or from high & $\operatorname{tacks}$ & $5.3 \mathrm{E}-0$ & 6 & $\mathrm{~kg}$ & kg Total Wet Weight & & \\
\hline
\end{tabular}

Transport $500 \mathrm{~km}$ (boat), based on the "Basic process" template: 


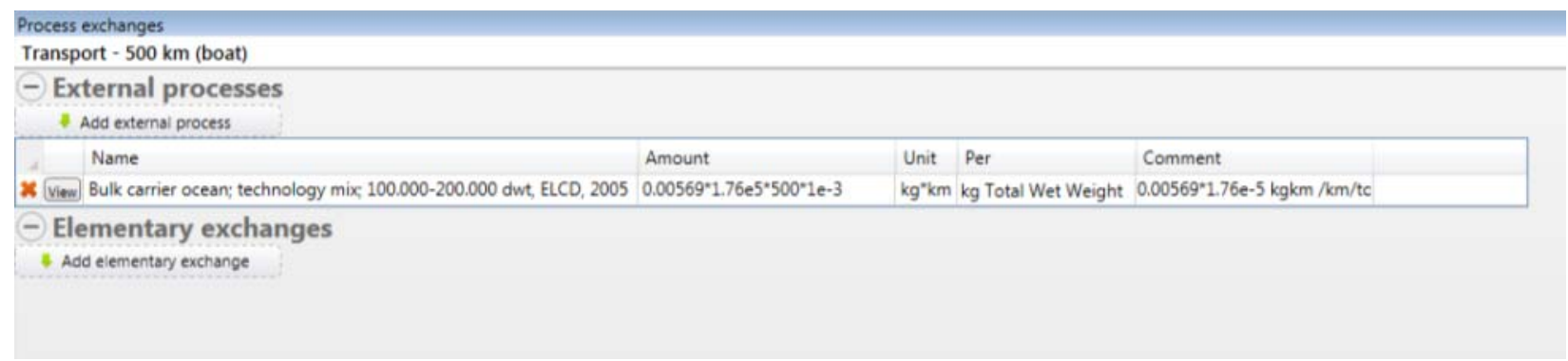

Utilisation of fly ashes, based on the "Basic process" template:

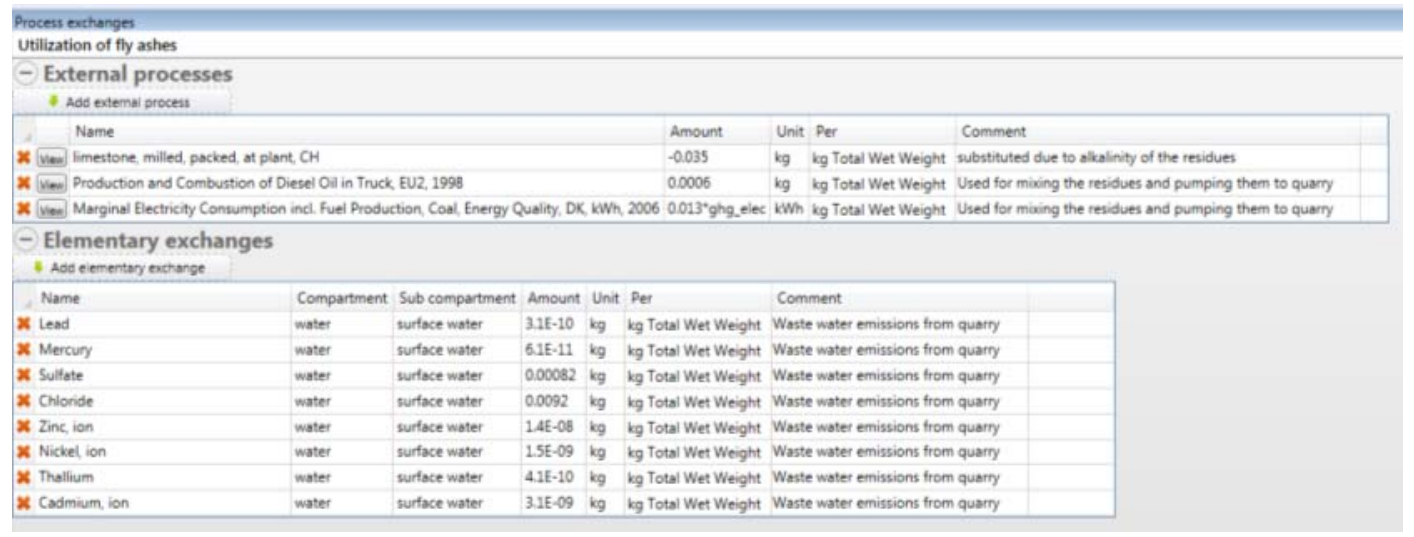

Waste water treatment plant, based on the "Substance transfer - default" template:

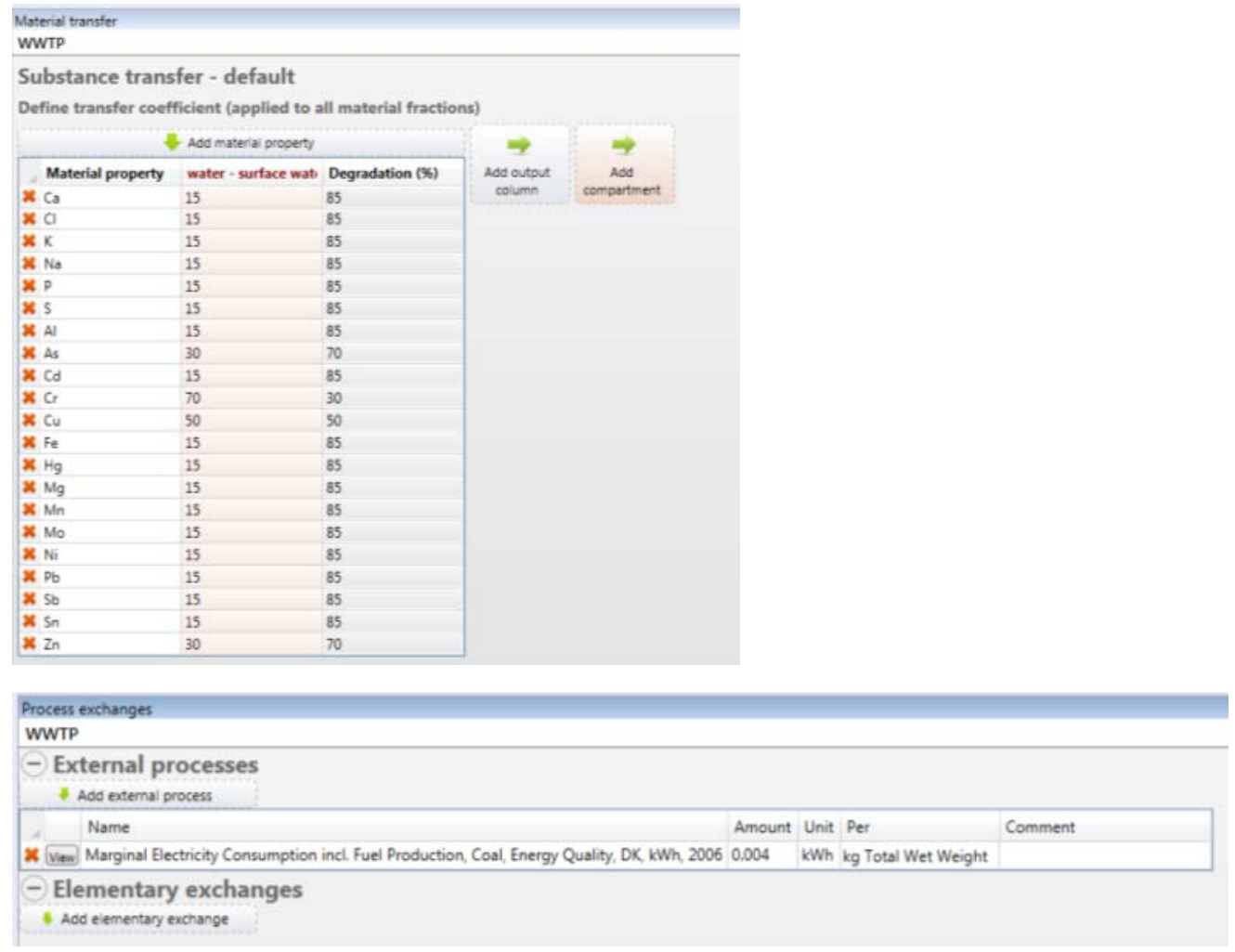

Transport - $50 \mathrm{~km}$, based on the "Basic process" template: 


\begin{tabular}{|c|c|c|c|c|c|}
\hline \multicolumn{6}{|c|}{$\begin{array}{l}\text { Process exchanges } \\
\text { Transport - } 50 \mathrm{~km}\end{array}$} \\
\hline \multirow{2}{*}{\multicolumn{6}{|c|}{$\begin{array}{l}\text { - External processes } \\
+ \text { Adc extenal process }\end{array}$}} \\
\hline & & & & & \\
\hline 2 & Name & Amount & Unit & Per & Comment \\
\hline$x$ Vien & Road, Long haul truck Euro3, 25t, Generic, 2006 & $50^{*} 0.00003$ & 1 & $\mathrm{~kg}$ Total Wet Weight & adjust km \\
\hline \multicolumn{6}{|c|}{ - Elementary exchanges } \\
\hline \multicolumn{6}{|c|}{ IAdd eementary exchange } \\
\hline
\end{tabular}

Landfill leachate generation, based on the "Leachate generation" template:

\begin{tabular}{|c|c|c|c|c|}
\hline \multicolumn{5}{|l|}{$\begin{array}{l}\text { Process exchanges } \\
\text { Landfill leachate generation }\end{array}$} \\
\hline \multirow{2}{*}{\multicolumn{5}{|c|}{$\begin{array}{l}\text { - External processes } \\
\text { Add external process }\end{array}$}} \\
\hline & & & & \\
\hline 2. Name & Amount & Unit & Per & Comment \\
\hline X View Marginal Electricity Consumption incl. Fuel Production, Coal, Energy Quality, DK, kWh, 2006 & $0.003^{*}$ ghg_elec & $\mathrm{kWh}$ & $\mathrm{kg}$ Total Wet Weight & \\
\hline $\boldsymbol{\alpha}$ Viaw diesel, at regional storage, RER & 0.001 & $\mathrm{~kg}$ & $\mathrm{~kg}$ Total Wet Weight & \\
\hline \multicolumn{5}{|l|}{ - Elementary exchanges } \\
\hline 4 Add elementary exchange : & & & & \\
\hline
\end{tabular}

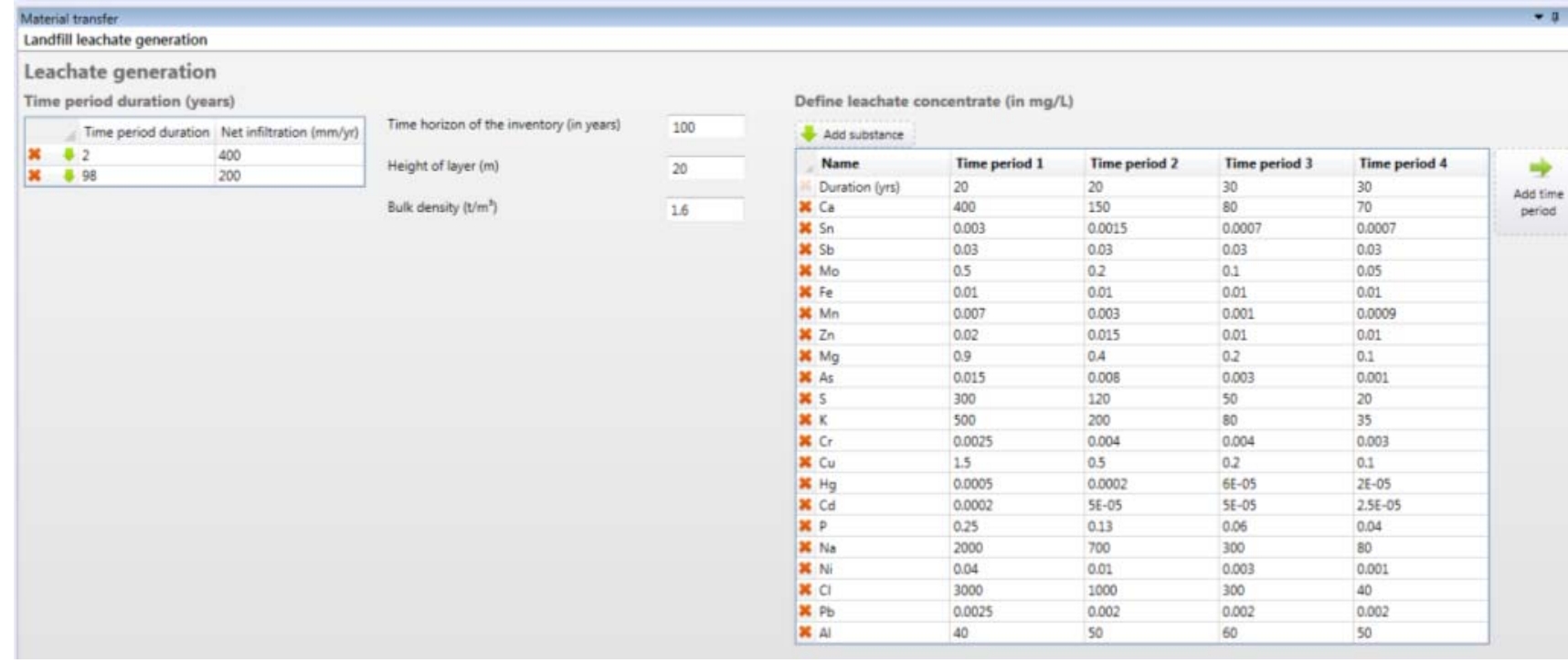

Stored ecotoxicity, based on the "Substance transfer - default" template: 


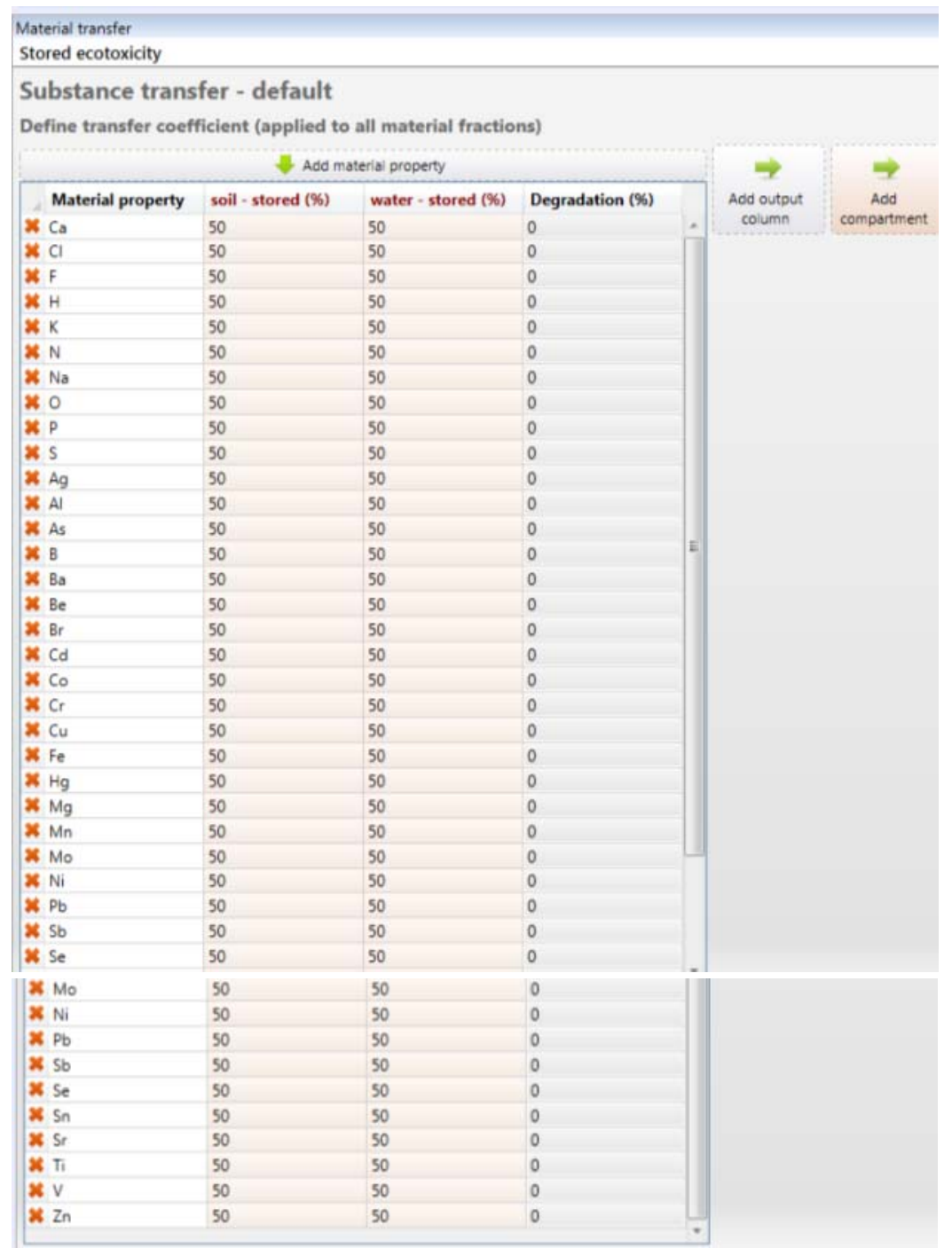

Leachate collection, based on the "Mass transfer over years" template:

\begin{tabular}{|c|c|c|c|c|c|c|}
\hline \multicolumn{7}{|c|}{ Material transfer } \\
\hline \multicolumn{7}{|c|}{ Mass transfer over years } \\
\hline \multicolumn{7}{|c|}{ Time period duration (years) } \\
\hline & $\Delta$ & Time period duratic & Collected $\%$ & 2 & Not collected \% & \multirow{4}{*}{$\begin{array}{l}\text { Add output } \\
\text { column }\end{array}$} \\
\hline $\mathbf{x}$ & $\sqrt{2}$ & 10 & 97 & & 3 & \\
\hline * & $\pi$ & 35 & 90 & & 10 & \\
\hline * & $\pi$ & 55 & 80 & & 20 & \\
\hline
\end{tabular}

Waste water treatment plant, based on the "substance transfer - default" template: 


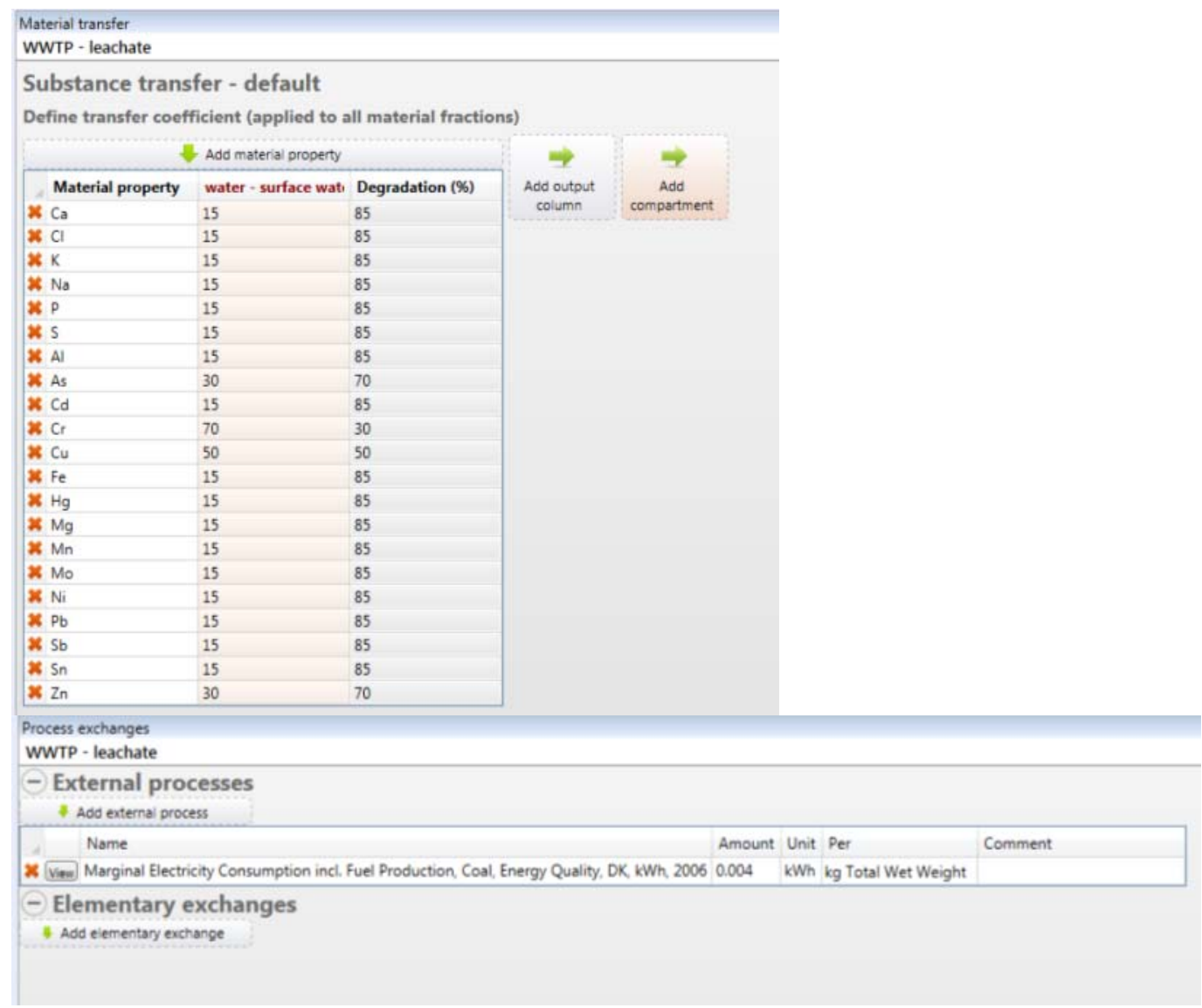

Emissions to groundwater, based on the "substance transfer - default" template:

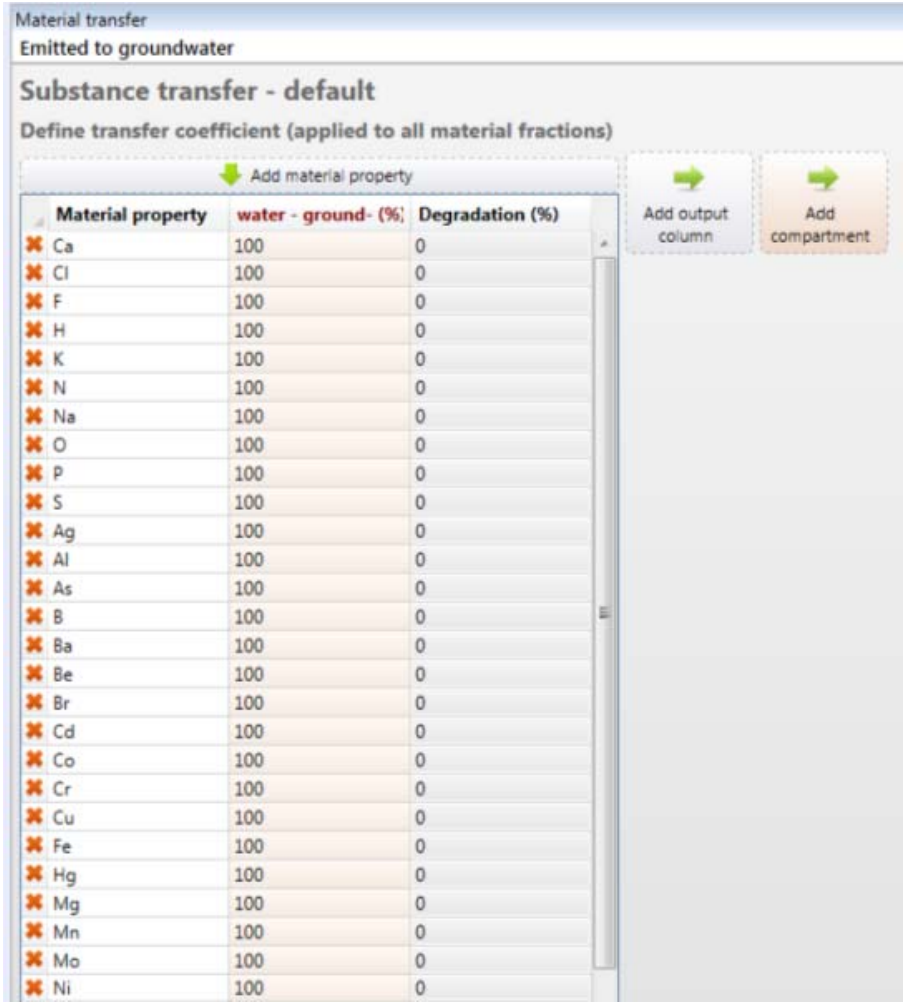




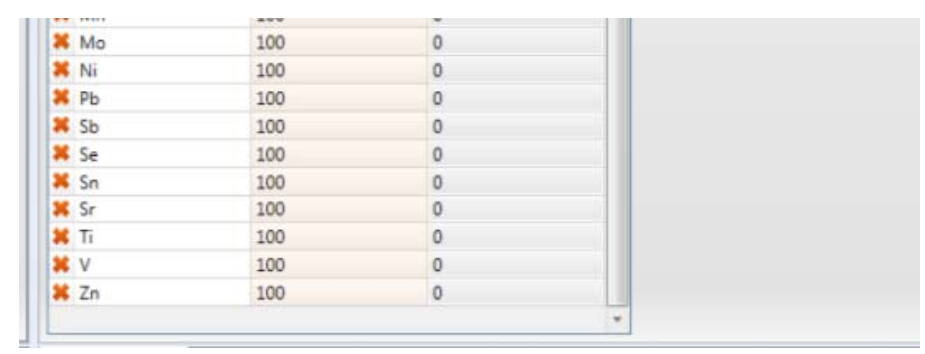

\subsection{Anaerobic digestion (AD) scenario}

Material generation, based on "Material generation" template:

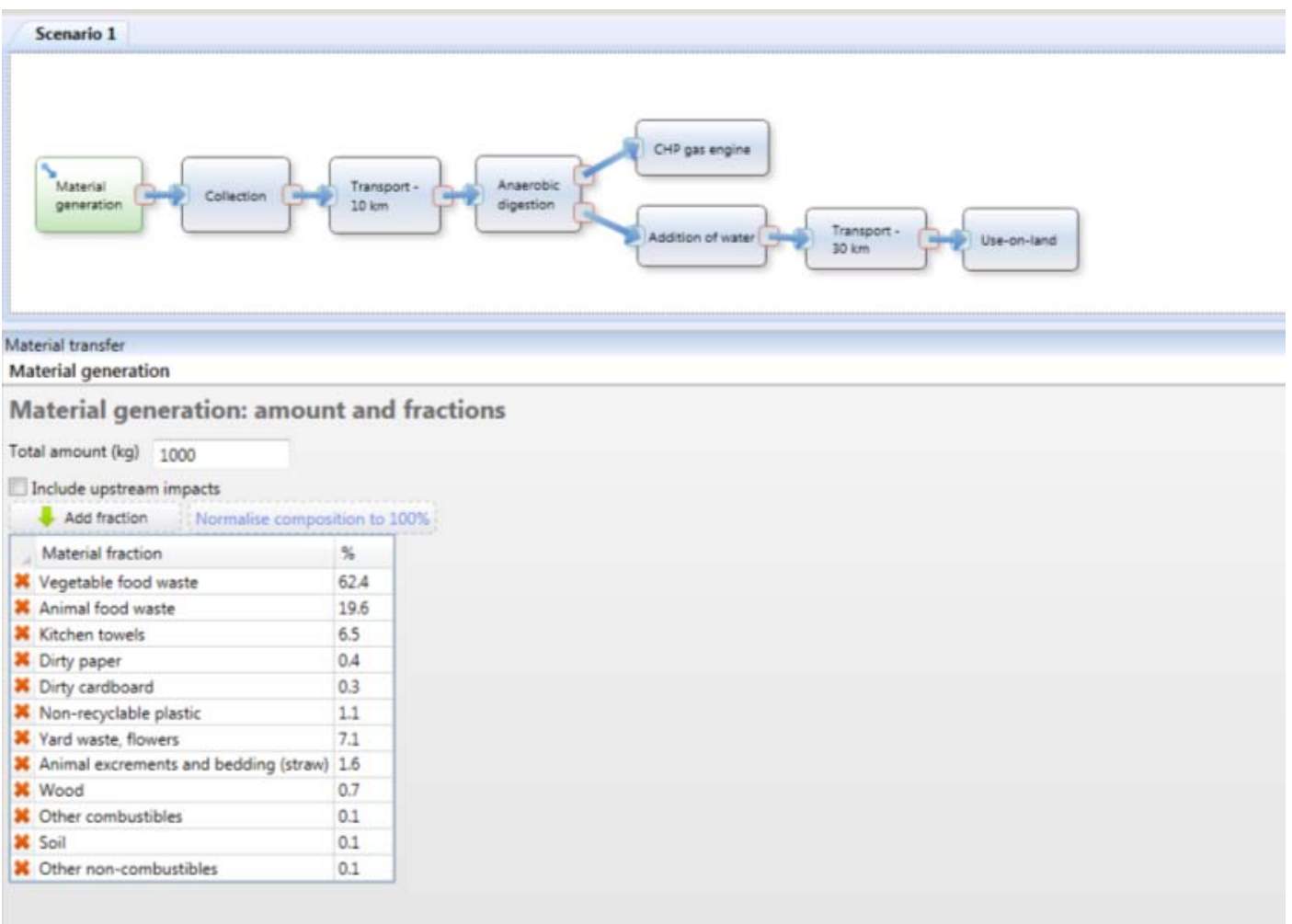

Collection, based on the "basic process" template:

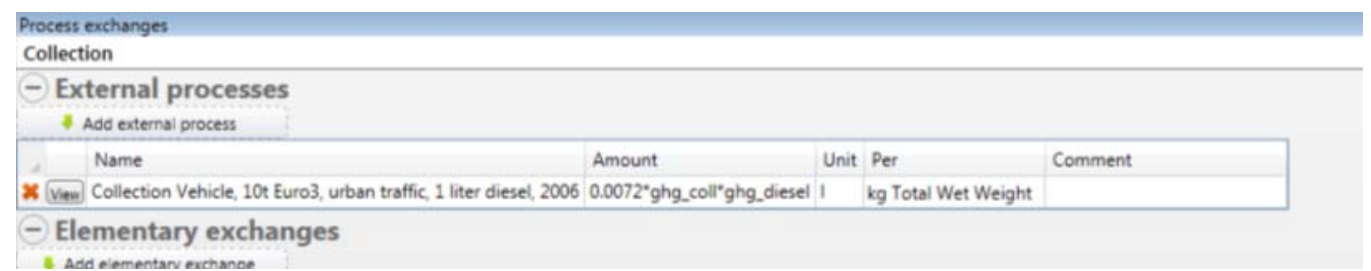

Transport, based on the "basic process" template:

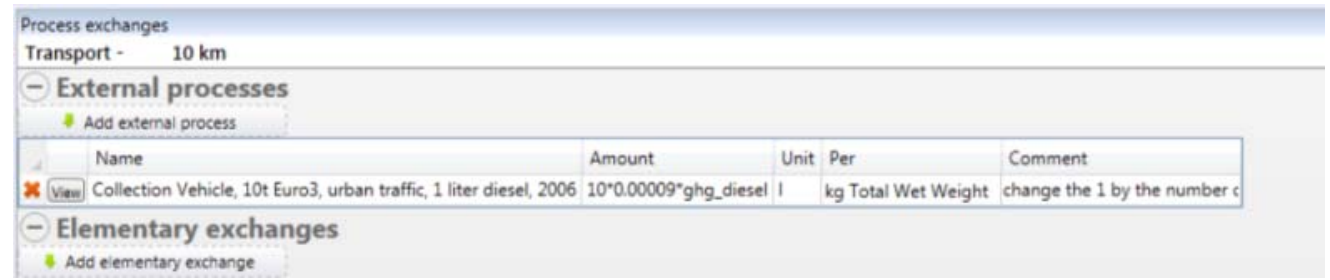

Anaerobic digestion, based on the "Anaerobic digestion" template: 


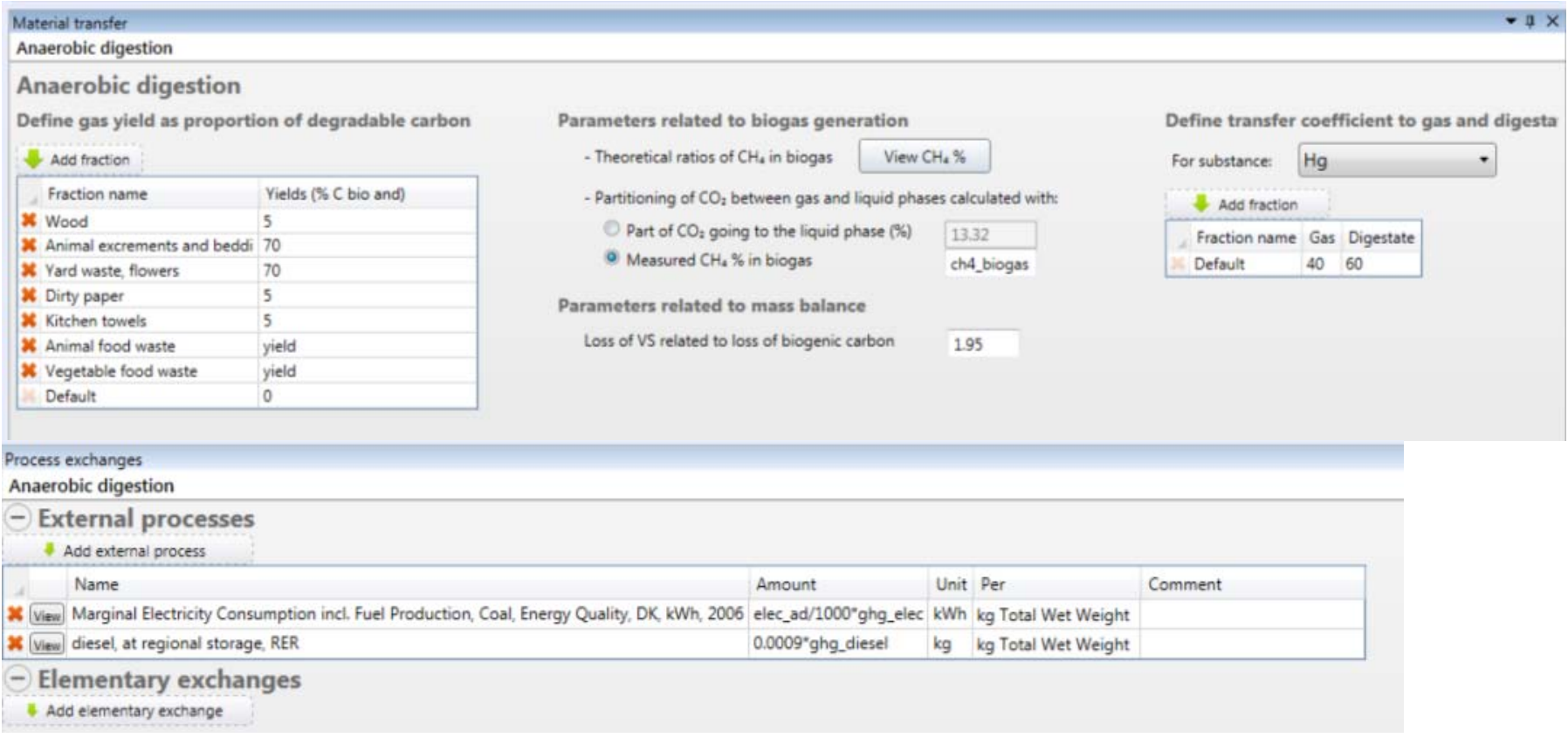

CHP gas engine, based on "Emissions to the environment" template:

\begin{tabular}{|c|c|c|c|c|c|c|}
\hline \multicolumn{7}{|l|}{$\begin{array}{l}\text { Material transfer } \\
\text { CHP gas engine }\end{array}$} \\
\hline \multicolumn{7}{|c|}{ Emissions to the environment } \\
\hline \multicolumn{7}{|c|}{ Define emissions to the environment as transformation of substances } \\
\hline \multicolumn{7}{|c|}{ Add new transtormation } \\
\hline Material property & Transformed at $(\mathrm{S})$ into & Elementary exchonge & Compartment & Sub compartment & With the conversion factor & Comment \\
\hline$x m^{\wedge} 3 \mathrm{CH}_{4}$ & unburnt_ch4 & Methane, non-fossil & air & non-urban air or from high stacks & $16 / 224$ & Unburnt methane \\
\hline$\approx \mathrm{m}^{\wedge} 3 \mathrm{CH} 4$ & 98 & Carbon dioxide, non-fossil & air & non-urban air or from high stacks & $44 / 224$ & Burnt methane \\
\hline $\mathrm{x} \mathrm{m}^{\wedge} 3 \mathrm{CO} 2$ & 100 & Carbon dioxide, non-fossil & air & non-urban air or from high stacks & $44 / 22.4$ & \\
\hline X kg Hg & 100 & Mercury & air & unspecified & 1 & \\
\hline
\end{tabular}

\begin{tabular}{|c|c|c|c|c|c|c|c|c|}
\hline \multicolumn{9}{|l|}{$\begin{array}{l}\text { Process exchanges } \\
\text { CHP gas engine }\end{array}$} \\
\hline \multicolumn{9}{|l|}{ - External processes } \\
\hline \multicolumn{9}{|l|}{ Ad Ad extemal process } \\
\hline \multicolumn{4}{|l|}{ Name } & \multicolumn{3}{|c|}{ Amount } & Unit Per & Comment \\
\hline \multicolumn{4}{|c|}{ Marginal Electricity Consumption incl. Fuel Production Coal, Energy Quality, DK, kWh 2006} & \multicolumn{3}{|c|}{ (1-unburnt_ch $4 / 100)^{*}$ elec Jec_ad/100" $(-1)^{*} \mathrm{CH} 4$ _LHV/3.6"ghg_elec } & $\mathrm{kWh} \mathrm{m}^{\wedge} 3 \mathrm{CH} 4$ & Elec rec $39 \%$ with $2 \%$ lea \\
\hline \multicolumn{4}{|c|}{ X vam District Heating, marginal average, (DK), kWh, 2012} & \multicolumn{3}{|c|}{ 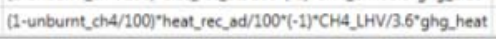 } & $\mathrm{kWh} \mathrm{m}^{\wedge} 3 \mathrm{CH}_{4}$ & Heat rec $46 \%$ with $2 \%$ le \\
\hline$\cdot$ & & & & m & & & & $\quad \cdot$ \\
\hline \multicolumn{9}{|c|}{ - Elementary exchanges } \\
\hline \multicolumn{9}{|c|}{ Aod elementary exchange } \\
\hline Name & Compartment & Sub compartment & Amount & it Unit & Per & Comment & & \\
\hline x Nitrogen oxides & air & non-urban air or from high stacks & 0.00268 & $\mathrm{~kg}$ & $m^{\wedge} 3 \mathrm{CH}_{4}$ & & & \\
\hline x Dinitrogen monoxide & air & non-urban air or from high stacks & 2.45E-06 & $6 \mathrm{~kg}$ & $m^{\wedge} 3 \mathrm{CH}_{4}$ & & & \\
\hline X Sulfur dioxide & air & non-urban air or from high stacks & 9.5E-05 & $\mathrm{kg}$ & $m^{\wedge} 3 \mathrm{CH} 4$ & & & \\
\hline X Methane, non-fossil & air & non-urban air or from high stacks & 0.0016 & $\mathrm{~kg}$ & $m^{\wedge} 3 \mathrm{CH}_{4}$ & & & \\
\hline X Carbon monoxide, non-fossil & air & non-urban air or from high stacks & 0.001354 & $4 \mathrm{~kg}$ & $m^{\wedge} 3 \mathrm{CH}_{4}$ & & & \\
\hline
\end{tabular}

Addition of water, based on the "Water content" template:

\begin{tabular}{l}
\hline Material transfer \\
\hline Addition of water \\
\hline Water content \\
Define the new water content \\
$\qquad$\begin{tabular}{|l|l|}
\hline Fraction name fraction \\
\hline Default & $\%$ of wet weight \\
\hline
\end{tabular} \\
\hline
\end{tabular}

Transport of digestate, based on the "Basic process" template: 


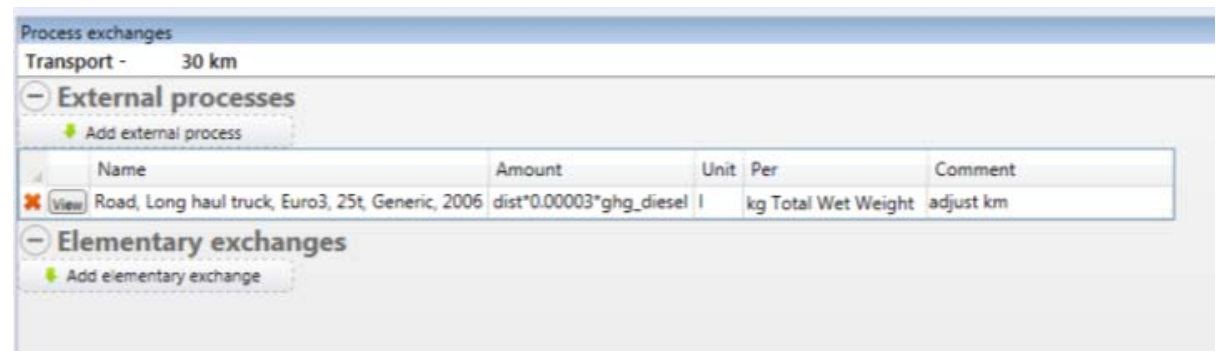

Use on land, based on the "Use on land" template:

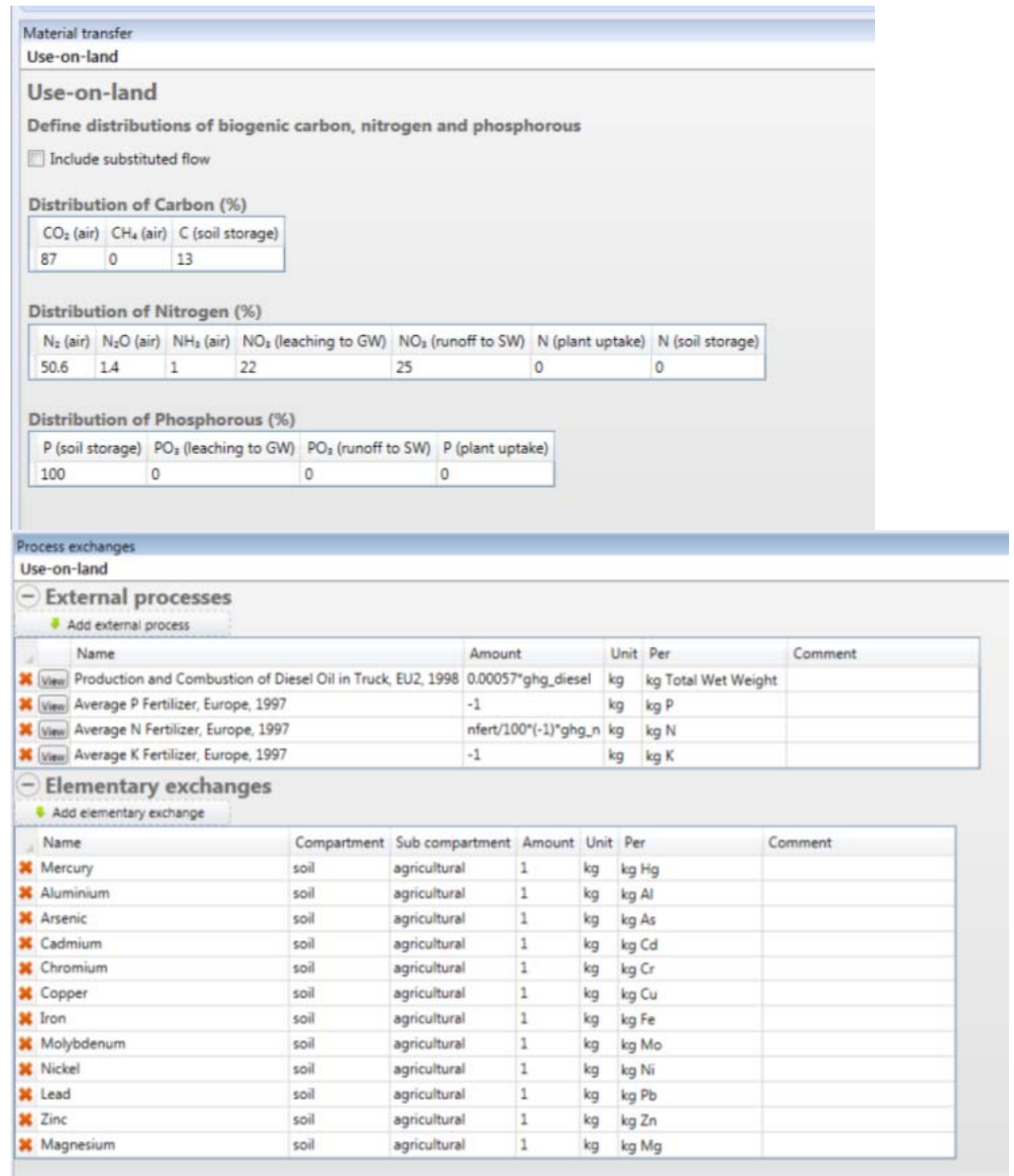




\section{LCIA methods used}

Table S2: Environmental impact categories and normalization references of the ILCD recommended methods. References given are first to method, next to normalization references.

\begin{tabular}{|c|c|c|c|c|}
\hline Impact category & Method & Unit & $\begin{array}{l}\text { Normali- } \\
\text { sation factor }\end{array}$ & $\begin{array}{l}\text { Year and space of normalisation, } \\
\text { reference, remark }\end{array}$ \\
\hline Climate change & $\begin{array}{l}\text { IPCC } \\
\text { (Forster et al., 2007) }\end{array}$ & $\mathrm{kg} \mathrm{CO}_{2}-\mathrm{Eq}$ & 7730 & Laurent et al., 2011a \\
\hline Ozone depletion & $\begin{array}{l}\text { EDIP97 (WMO) } \\
\text { (Wenzel et al., 1997) }\end{array}$ & $\begin{array}{l}\mathrm{kg} \text { CFC-11- } \\
\mathrm{Eq}\end{array}$ & $2.05 \mathrm{E}-2$ & Laurent et al., 2011a \\
\hline $\begin{array}{l}\text { Human toxicity, cancer } \\
\text { effects }\end{array}$ & $\begin{array}{l}\text { USEtox (Rosenbaum et } \\
\text { al., 2008) }\end{array}$ & CTUh & $3.25 \mathrm{E}-5$ & Laurent et al., 2011b \\
\hline $\begin{array}{l}\text { Human toxicity, non- } \\
\text { cancer effects }\end{array}$ & $\begin{array}{l}\text { USEtox (Rosenbaum et } \\
\text { al., 2008) }\end{array}$ & CTUh & 8.14E-4 & Laurent et al., 2011b \\
\hline $\begin{array}{l}\text { Particulate matter/ } \\
\text { respiratory inorganics }\end{array}$ & $\begin{array}{l}\text { Updated from Humbert } \\
\text { (2009), from SI of } \\
\text { Laurent et al. (2012) }\end{array}$ & $\mathrm{kg} \mathrm{PM}_{2.5}$-eq & 4.71 & From SI of Laurent et al. (2012) \\
\hline Acidification & $\begin{array}{l}\text { ReCiPe } \\
\text { (Van Zelm et al., 2008) }\end{array}$ & $\mathrm{kg} \mathrm{SO}_{2}$-Eq & 49.9 & Sleeswijk et al., 2008 \\
\hline $\begin{array}{l}\text { Eutrophication, } \\
\text { terrestrial }\end{array}$ & $\begin{array}{l}\text { CML } \\
\text { (Guinée et al. 2002) }\end{array}$ & kg NOx-Eq & 356 & $\begin{array}{l}\text { Huijbregts et al, } 2003 \text { and } \\
\text { CML(2012) }{ }^{3}\end{array}$ \\
\hline $\begin{array}{l}\text { Photochemical ozone } \\
\text { formation }\end{array}$ & $\begin{array}{l}\text { ReCiPe } \\
\text { (Van Zelm et al., 2008) }\end{array}$ & kg NMVOC & 52.9 & Sleeswijk et al., 2008 \\
\hline $\begin{array}{l}\text { Eutrophication, } \\
\text { freshwater }\end{array}$ & $\begin{array}{l}\text { ReCiPe } \\
\text { (Van Zelm et al., 2008) }\end{array}$ & kg P-Eq & 0.69 & Sleeswijk et al., 2008 \\
\hline $\begin{array}{l}\text { Ecotoxicity } \\
\text { (freshwater) }\end{array}$ & $\begin{array}{l}\text { USEtox } \\
\text { (Rosenbaum et al., 2008) }\end{array}$ & CTUe & 5060 & Laurent et al., 2011b \\
\hline $\begin{array}{l}\text { Resource depletion, } \\
\text { mineral and fossil }\end{array}$ & CML(Guinée et al., 2002) & $\begin{array}{l}\text { kg antimony- } \\
\mathrm{Eq}\end{array}$ & 0.95 & Guinée et al., $2002^{1}$ \\
\hline
\end{tabular}

${ }^{1}$ Calculated based on population in EU-15 1995 assumed to: 380 million, and the total value for 1995: 1.4E+11 kg PO43- eq. / yr

\section{Uncertainty propagation}

In this section we present briefly how uncertainty data is input in EASETECH, how systems are parameterized and how results are displayed.

\subsection{The table of parameters}

Parameters are added simply by specifying a name to the parameter, a default value and a list of values to be used when running calculations in "sensitivity analysis" mode. 


\begin{tabular}{|c|c|c|c|}
\hline & & & $\underline{x}$ \\
\hline \multicolumn{4}{|c|}{ Search } \\
\hline$\triangle$ Name & Default Value & SA Values & Selected \\
\hline *】 plastic & 1.12 & $1.228,1.46,0.8386,1.454,1.236,1.291,0.795$ & $\nabla$ \\
\hline *⿻ w w & 67.1 & $60.27,74.15,67.67,64.16,65.68,67.5,70.11,7$ & $\nabla$ \\
\hline *ै] hv & 19.21 & $19.14,19.63,18.39,17.97,17.89,19.37,17.69$ r & $\nabla$ \\
\hline *C ghg_diesel & 1 & $0.9393,0.9641,1.065,0.9407,1.041,0.8652,0$ & $\nabla$ \\
\hline X] ghg_elec & 1 & $1.068,1.018,0.9324,0.9882,0.8954,1.02,0.94$ & $\nabla$ \\
\hline * [ ghg_heat & 1 & $1.046,1.146,0.9954,0.9872,1.032,1.075,0.7 \vdots$ & $\nabla$ \\
\hline *【] ghg_coll & 1 & $1.067,1.224,0.8462,1.22,1.071,1.107,0.824 \epsilon$ & $\nabla$ \\
\hline $\mathbf{X} \square$ dist & 30 & $7.074,133.2,33.83,16.11,22.2,32.64,56.71, \varepsilon$ & $\nabla$ \\
\hline * [ ch4_pot & 450 & $447.6,435.3,420.7,454.9,469.1,448,472.8,4$ & $\nabla$ \\
\hline$x$ & 63 & $62.8,64.26,60.55,59.29,59.03,63.49,58.45, \epsilon$ & $\nabla$ \\
\hline$x \in$ elec_ad & 48.9 & $53.99,47.03,49.45,47.94,48.43,48.35,44.38$, & $\nabla$ \\
\hline$x$ elec_rec_ad & 39 & $40.59,37.6,37.13,34.32,41.39,38.1,37.97,3 \subseteq$ & $\nabla$ \\
\hline $\mathrm{N}[\mathrm{C}$ heat_rec_ad & 46 & $43.52,45.37,44.78,49.3,52.53,46.86,45,50.1$ & $\nabla$ \\
\hline * yield & 70 & $73.35,70.57,65.78,68.79,62.35,61.89,66.52$ & $\nabla$ \\
\hline * unburnt_ch4 & 2 & $1.953,1.846,2.386,2.076,1.909,1.802,2.239$ r & 目 \\
\hline NCW we_dig & 3 & $4.344,3.418,1.602,2.721,1.205,3.452,1.817$ r & $\nabla$ \\
\hline * cseq & 13 & $10.78,11.38,12.09,12.56,14.45,16.83,14.16$, & $\nabla$ \\
\hline * 2 nfert & 40 & $43.11,47.7,39.67,39.1,42.18,44.77,30.06,31$ & $\nabla$ \\
\hline * ghg_n & 1 & $0.9058,0.9438,1.105,0.9079,1.066,0.7955,0$ & $\nabla$ \\
\hline *⿰冫欠 n2o_uol & 1.4 & $1.737,3.01,1.159,0.6215,2.342,1.669,1.334$ & $\nabla$ \\
\hline NC veg_of_food & 76.1 & $75.62,73.15,70.24,77.08,79.92,75.7,80.66, \varepsilon$ & D \\
\hline & \multirow[t]{4}{*}{ Save 2} \\
\hline Name & \multicolumn{2}{|c|}{ parameter_1 } & \\
\hline Default value & \multicolumn{2}{|l|}{1} & \\
\hline SA values & \multicolumn{2}{|l|}{$1,3,7$} & \\
\hline
\end{tabular}

To run the calculations in "sensitivity analysis" mode, at least one parameter has to be selected and then the user should click on the "Run Sensitivity analysis" button.

\begin{tabular}{|c|c|c|c|}
\hline & & & 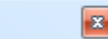 \\
\hline \multicolumn{4}{|c|}{ Search } \\
\hline Name & Default Value & SA Values & Selected \\
\hline *C plastic & 1.12 & $1.228,1.46,0.8386,1.454,1.236,1.291,0.795$ & $\nabla$ \\
\hline *⿻ wo & 67.1 & $60.27,74.15,67.67,64.16,65.68,67.5,70.11,7$ & $\nabla$ \\
\hline *⿻ h h & 19.21 & $19.14,19.63,18.39,17.97,17.89,19.37,17.69$, & $\nabla$ \\
\hline * & 1 & $0.9393,0.9641,1.065,0.9407,1.041,0.8652,0$ & $\nabla$ \\
\hline *【/ ghg_elec & 1 & $1.068,1.018,0.9324,0.9882,0.8954,1.02,0.94$ & $\nabla$ \\
\hline X] ghg_heat & 1 & $1.046,1.146,0.9954,0.9872,1.032,1.075,0.7:$ & $\nabla$ \\
\hline * & 1 & $1.067,1.224,0.8462,1.22,1.071,1.107,0.824 t$ & $\nabla$ \\
\hline *U dist & 30 & $7.074,133.2,33.83,16.11,22.2,32.64,56.71, \varepsilon$ & $\nabla$ \\
\hline * 4 ch4_pot & 450 & $447.6,435.3,420.7,454.9,469.1,448,472.8,4$ & $\nabla$ \\
\hline *Ech4_biogas & 63 & $62.8,64.26,60.55,59.29,59.03,63.49,58.45, \epsilon$ & $\nabla$ \\
\hline $\mathbf{x}[$ elec_ad & 48.9 & $53.99,47.03,49.45,47.94,48.43,48.35,44.38$ & $\nabla$ \\
\hline *C elec_rec_ad & 39 & $40.59,37.6,37.13,34.32,41.39,38.1,37.97,36$ & $\nabla$ \\
\hline W 2 heat_rec_ad & 46 & $43.52,45.37,44.78,49.3,52.53,46.86,45,50.1$ & $\nabla$ \\
\hline स yield & 70 & $73.35,70.57,65.78,68.79,62.35,61.89,66.52$ & $\nabla$ \\
\hline * unburnt_ch4 & 2 & $1.953,1.846,2.386,2.076,1.909,1.802,2.239$, & $\nabla$ \\
\hline W wc_dig & 3 & $4.344,3.418,1.602,2.721,1.205,3.452,1.817$ & $\nabla$ \\
\hline * cseq & 13 & $10.78,11.38,12.09,12.56,14.45,16.83,14.16$ & $\nabla$ \\
\hline X nfert & 40 & $43.11,47.7,39.67,39.1,42.18,44.77,30.06,31$ & $\nabla$ \\
\hline *C ghg_n & 1 & $0.9058,0.9438,1.105,0.9079,1.066,0.7955,0$ & $\nabla$ \\
\hline *C n2o_uol & 1.4 & $1.737,3.01,1.159,0.6215,2.342,1.669,1.334_{t}$ & $\nabla$ \\
\hline $\mathbf{X}$ veg_of_food & 76.1 & $75.62,73.15,70.24,77.08,79.92,75.7,80.66, \varepsilon$ & $\nabla$ \\
\hline \multicolumn{4}{|c|}{ Add new parameter } \\
\hline & & Stop Sensitivity Analysis & Select All \\
\hline
\end{tabular}




\subsection{Material generation}

The following figure is a screenshot showing how the waste generation was parameterised using four parameters: the content of plastic in the waste ("plastic"), the water content of the whole waste ("wc"), the lower heating value ("hv") and the methane potential ("ch4_pot"). It can be observed that to parameterize material generation, we use a different process than the classical one (presented in section Part II, Section 1.3). This process allows free definition of amounts of different properties. The screenshot presents the formulas used for the water content in the 12 material fractions. The pop-up window on the right side shows the table of parameters where all parameters are defined, together with their default value and the list of numbers to be tested. Here each parameter has a list of 1000 values randomly sampled in the distributions defined earlier. This lists of random values were obtained using a small excel macro.

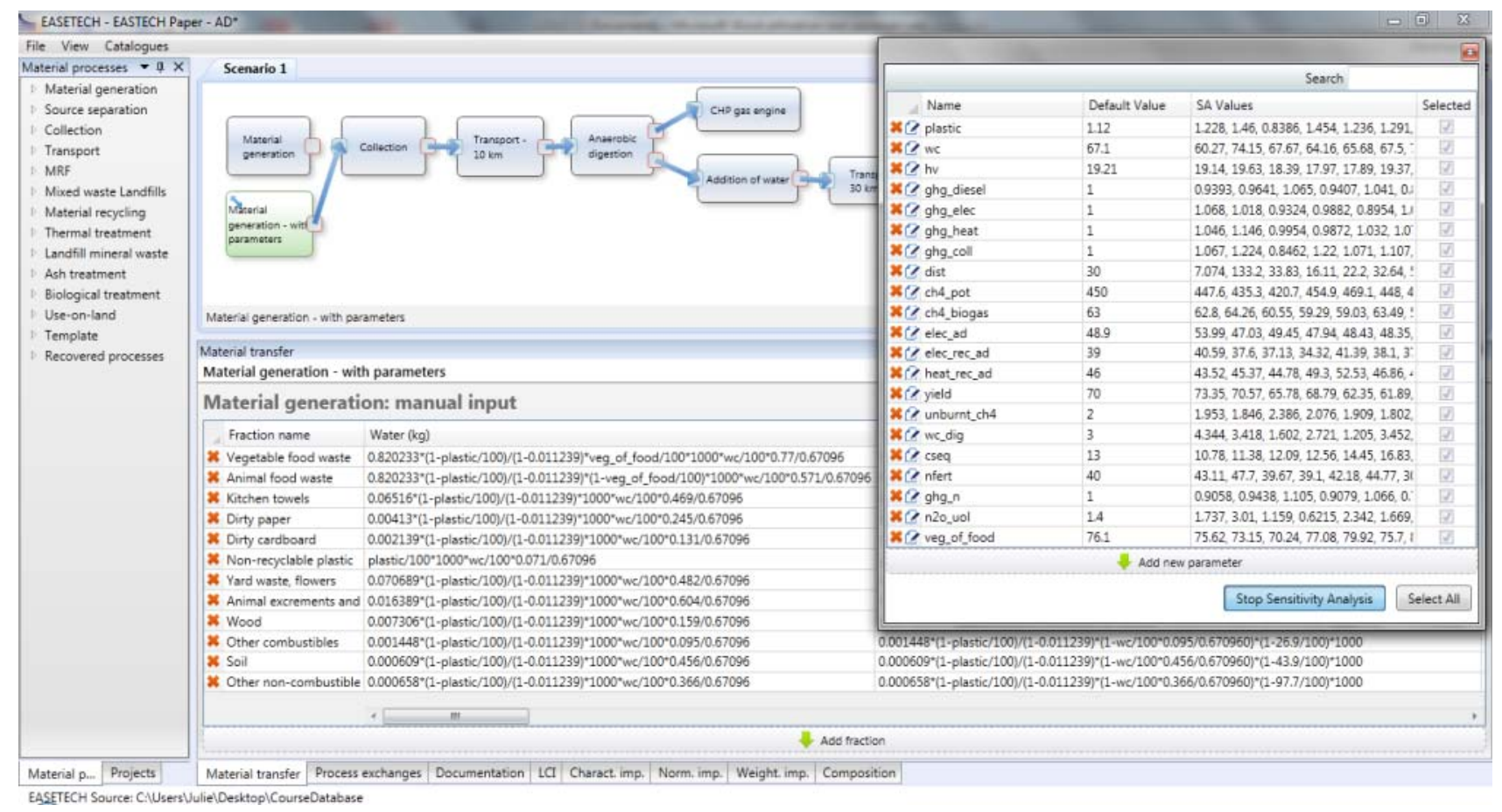

\subsection{Material composition calculation}

The output of this process can be computed and is presented in the next figure. It can be observed that each result field shows the 1000 values obtained as a result of the computation with 1000 values for each parameter. All table results can always be copied and pasted into Excel, which offers simple tools to convert a cell of 1000 values into 1000 cells that can be easily analysed. 


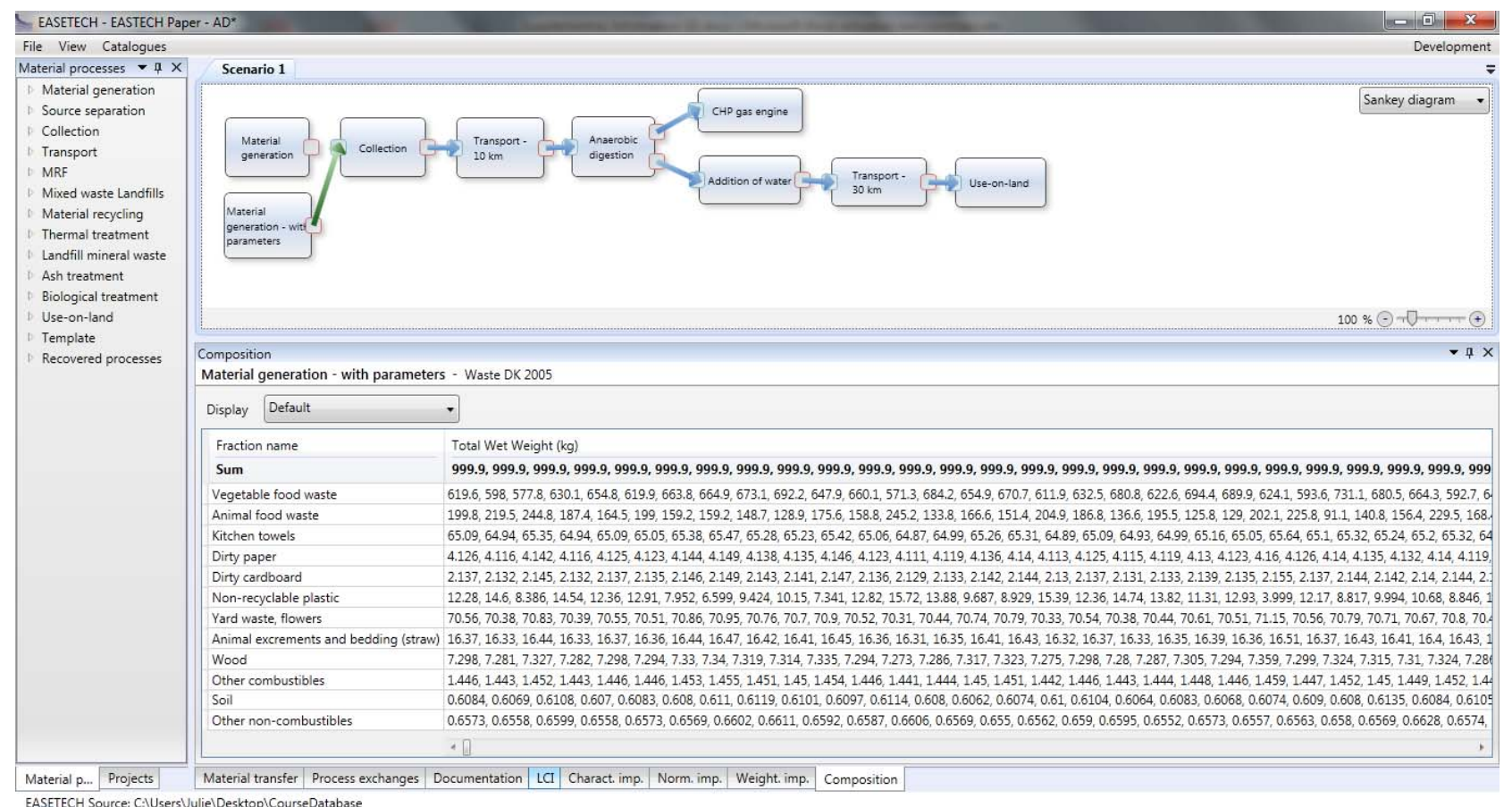

\subsection{LCl data in material process}

In the same way, data of the other processes have been parameterized. Below is presented the example for the "CHP gas engine" material process.

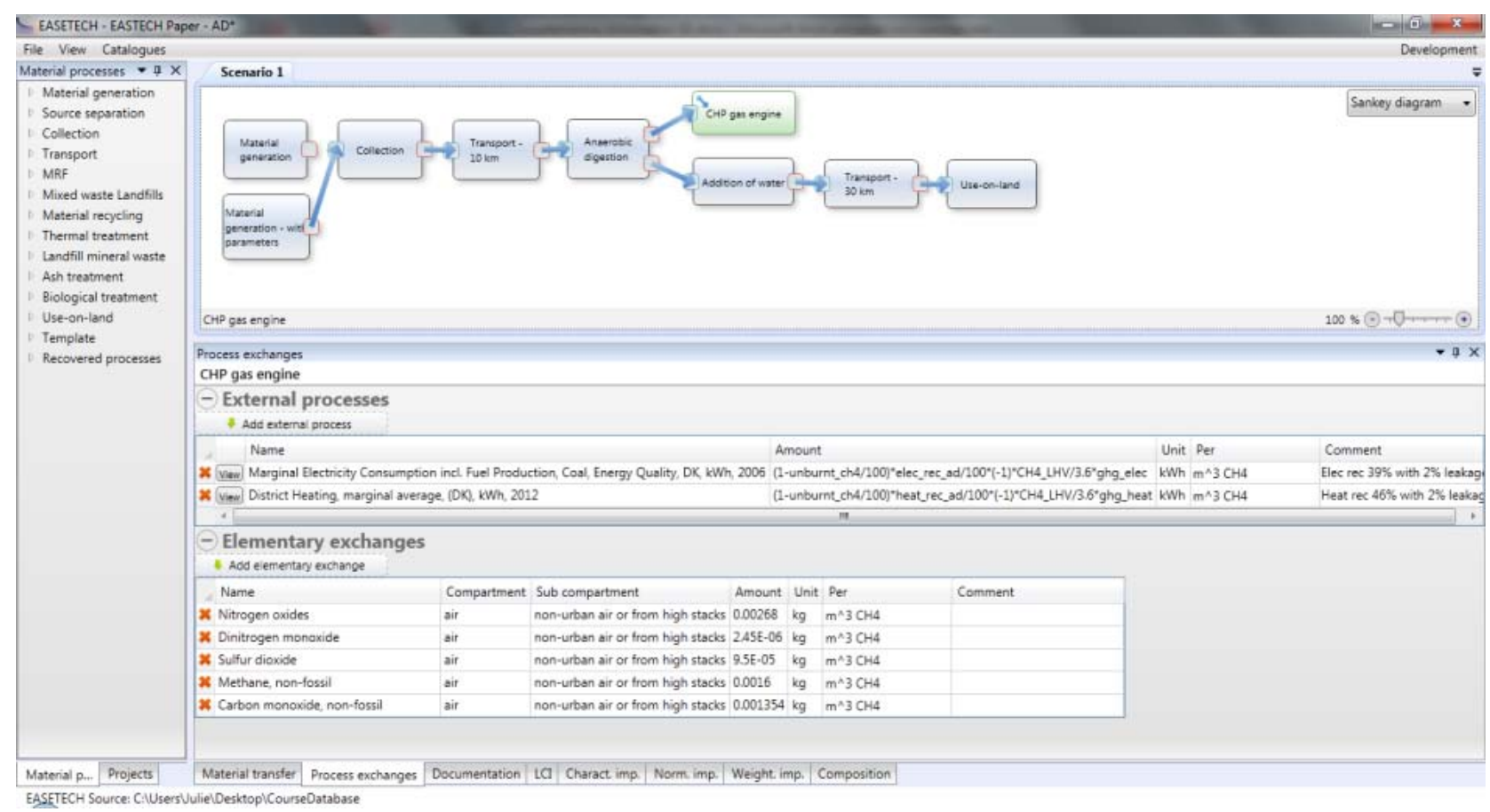

\subsection{Calculation of the characterised impact}




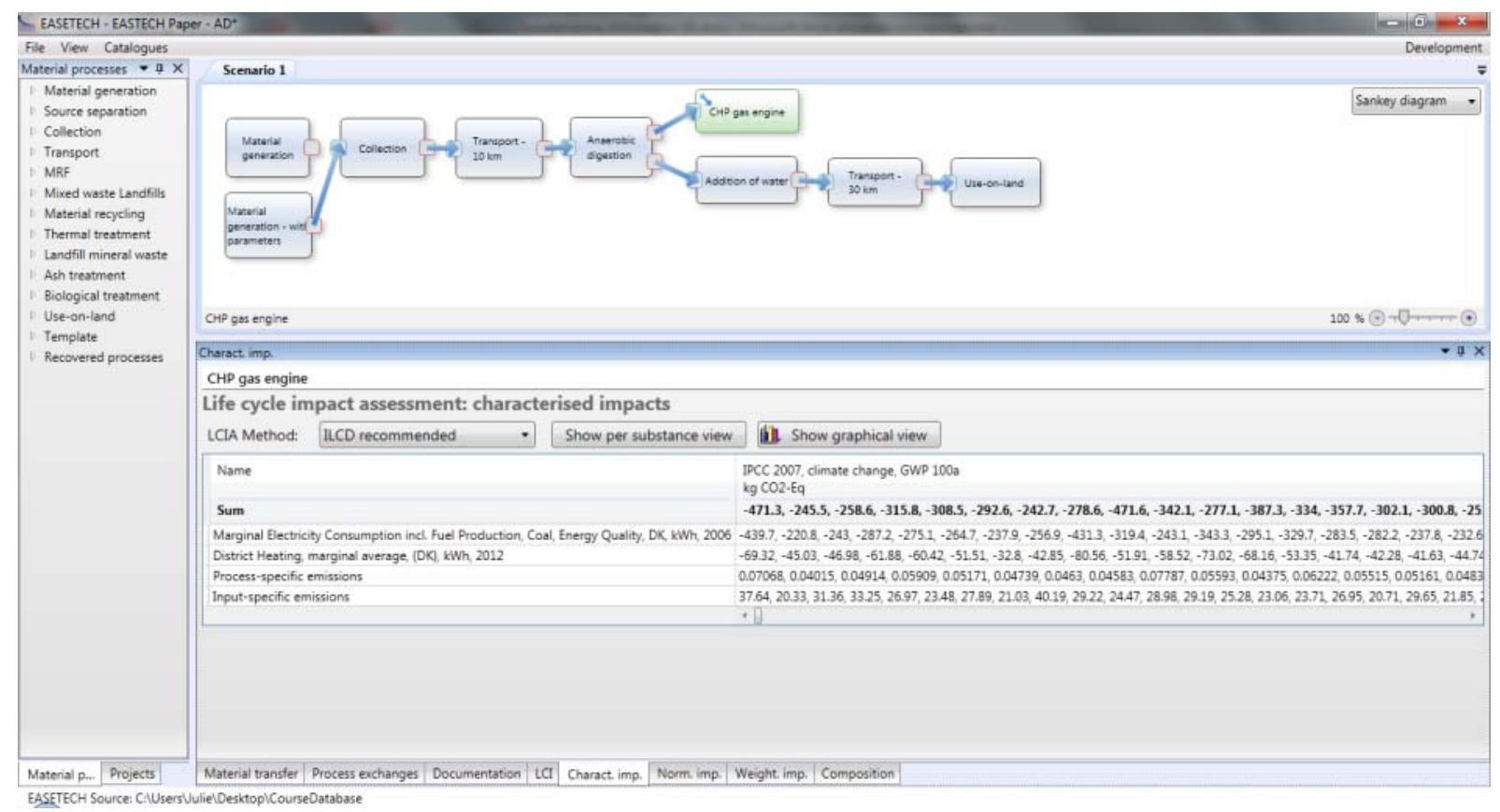

NB: the display of the results will be improved in the future, but it is still possible to make full use of the results by using excel tools.

\section{References}

Clavreul, J., Guyonnet, D., Christensen, T.H., 2012. Quantifying uncertainty in LCA-modelling of waste management systems. Waste Management 32, 2482-2495.

CML (2012). CML-IA Characterisation Factors. Excel spreadsheet [Online]

http://www.leidenuniv.nl/cml/ssp/databases/cmlia/cmlia.zip, Accessed 31 January 2013

Forster, P., Ramaswamy, V., Artaxo, P., Berntsen, T., Betts, R., Fahey, D.W., Haywood, J., Lean, J., Lowe, D.C., Myhre, G., Nganga, J., Prinn, R., Raga, G., Schulz, M., Van Dorland, R., 2007. Changes in atmospheric constituents and in radiative forcing. In: Solomon, S., Qin, D., Manning, M., Chen, Z., Marquis, M., Averyt, K.B., Tignor, M., Miller, H.L. (Eds.), Climate Change 2007: The Physical Science Basis. Contribution of Working Group I to the Fourth Assessment Report of the Intergovernmental Panel on Climate Change. Cambridge University Press, Cambridge, United Kingdom and New York, NY, USA.

Guinée, J.B., Gorrée, M., Heijungs, R., Huppes, G., Kleijn, R., Koning, A. de, Oers, L. van, Wegener Sleeswijk, A., Suh, S., Udo de Haes, H.A., Bruijn, H. de, Duin, R. van, Huijbregts, M.A.J., 2002. Handbook on life cycle assessment. Operational guide to the ISO standards. I: LCA in perspective. IIa: Guide. IIb: Operational annex. III: Scientific background. Kluwer Academic Publishers, ISBN 1-4020-0228-9, Dordrecht, $692 \mathrm{pp}$.

Huijbregts, M.a.J., Breedveld, L., Huppes, G., de Koning, A., van Oers, L., Suh, S. (2003) Normalisation figures for environmental life-cycle assessment. Journal of Cleaner Production 11, 737-748.

Humbert S., 2009. Geographically differentiated life-cycle impact assessment of human health. Ph.D. Dissertation, AAT 3402614, University of California, CA, USA.

Laurent, A., Olsen, S. I., Hauschild, M. Z., 2011a. Normalization in EDIP97 and EDIP2003: updated European inventory for 2004 and guidance towards a consistent use in practice. International Journal of Life Cycle Assessment 16, 401-409.

Laurent, A., Lautier, A., Rosenbaum, R.K., Olsen, S.I., Hauschild, M.Z., 2011b. Normalization references for Europe and North America for application with USEtox ${ }^{\mathrm{TM}}$ characterization factors. International Journal 
of Life Cycle Assessment 16:728-738.

Laurent, A., Olsen, S.I., Hauschild, M.Z., 2012. Limitations of carbon footprint as indicator of environmental sustainability. ES\&T 7:4100-4108.

Rosenbaum, R.K., Bachmann, T.M., Gold, L.S., Huijbregts, M.A.J., Jolliet, O., Juraske, R., Köhler, A., Larsen, H.F., MacLeod, M., Margni, M., McKone, T.E., Payet, J., Schuhmacher, M., van de Meent, D., Hauschild, M.Z., 2008. USEtox - The UNEP SETAC toxicity model: recommended characterisation factors for human toxicity and freshwater ecotoxicity in Life Cycle Impact Assessment. International Journal of Life Cycle Assessment 13, 532-546.

Sleeswijk, A.W., van Oers, L.F.C.M., Guinée, J.B., Struijs, J., Huijbregts, M.A.J., 2008. Normalisation in product life cycle assessment: An LCA of the global and European economic systems in the year 2000. Science of the Total environment 390: 227-240.

Van Zelm, R., Huijbregts, M.A.J., Den Hollander, H.A., Van Jaarsveld, H.A., Sauter, F.J., Struijs, J., Van Wijnen, H.J., Van de Meent, D. (2008). European characterization factors for human health damage of PM10 and ozone in life cycle impact assessment. Atmospheric Environment 42, 441-453.

Wenzel, H., Hauschild, M. \& Alting, L. (1997) Environmental Assessment of Products, Volume 1. Chapman \& Hall, London. 